Cover and Text Photographs. The aftermath of Hurricanes Katrina and Rita, 2005. Photographs by Emitt Witt, III and David Shaver, U.S. Geological Survey and Jianmin Wang, Missouri University of Science and Technology. 


\section{Environmental Chemical Data for Perishable Sediments and Soils collected in New Orleans, Louisiana, and along the Louisiana Delta following Hurricanes Katrina and Rita, 2005}

By Emitt C. Witt III, Honglan Shi, Krista A. Karstensen, Jianmin Wang, and Craig D. Adams

In cooperation with Missouri University of Science and Technology

Scientific Investigations Report 2008-5031 


\section{U.S. Department of the Interior DIRK KEMPTHORNE, Secretary}

\section{U.S. Geological Survey \\ Mark D. Myers, Director}

\section{U.S. Geological Survey, Reston, Virginia: 2008}

For product and ordering information:

World Wide Web: http://www.usgs.gov/pubprod

Telephone: 1-888-ASK-USGS

For more information on the USGS--the Federal source for science about the Earth, its natural and living resources, natural hazards, and the environment:

World Wide Web: http://www.usgs.gov

Telephone: 1-888-ASK-USGS

Any use of trade, product, or firm names is for descriptive purposes only and does not imply endorsement by the U.S. Government.

Although this report is in the public domain, permission must be secured from the individual copyright owners to reproduce any copyrighted materials contained within this report.

Suggested citation:

Witt, E.C., Shi, Honglan, Karstensen, K.A., Wang, Jianmin, and Adams, C.D., 2008, Environmental chemical data for perishable sediments and soils collected in New Orleans, Louisiana, and along the Louisiana Delta following Hurricanes Katrina and Rita, 2005: U.S. Geological Survey Scientific Investigations Report 2008-5031, 56 p. 


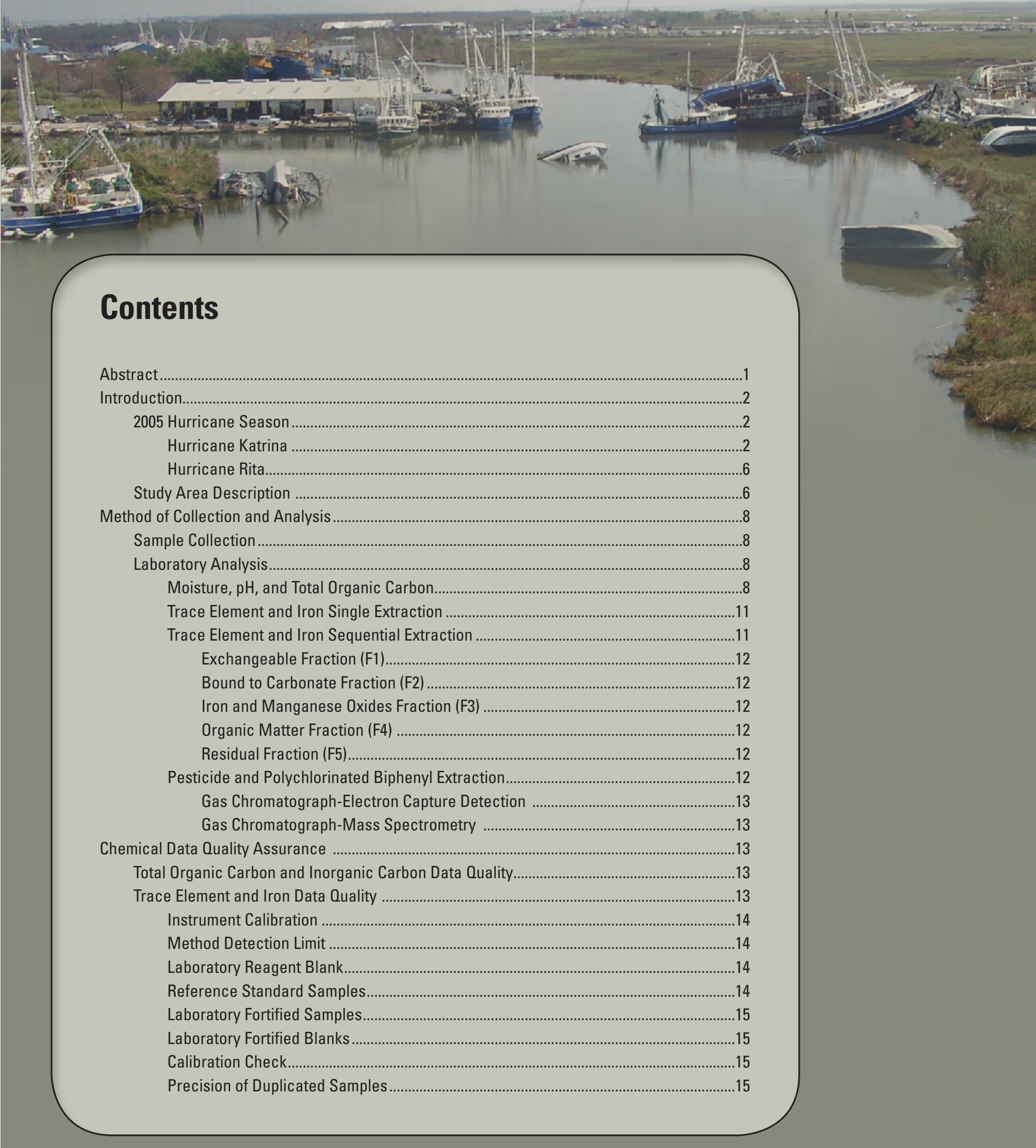


Pesticide and Polychlorinated Biphenyl Data Quality.............................................................16

Gas Chromatograph-Electron Capture Detection ...........................................................16

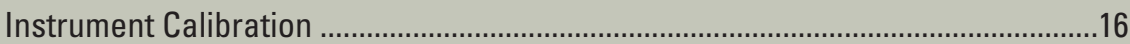

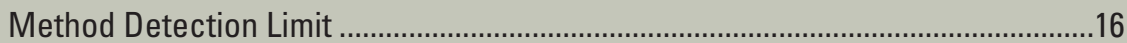

Laboratory Fortified Blank ......................................................................................16

Laboratory Fortified Sample...............................................................................16

Gas Chromatograph-Mass Spectrometry Method …………........................................19

Instrument Calibration ..........................................................................................

Method Detection Limit ......................................................................................19

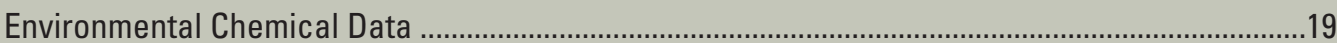

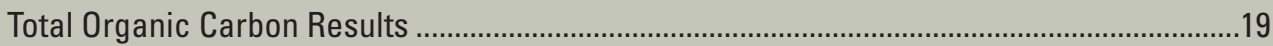

Trace Element and Iron Single Extraction Results ..............................................................20

Trace Element and Iron Sequential Extraction Results ...........................................................22

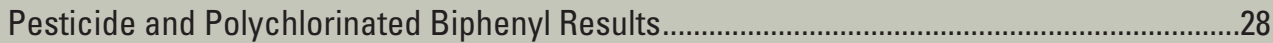

Pesticides in Sediment ................................................................................................28

Polychlorinated Biphenyl in Sediment ..........................................................................

Summary and Conclusion .........................................................................................................

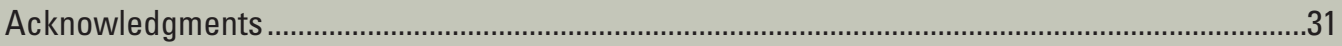

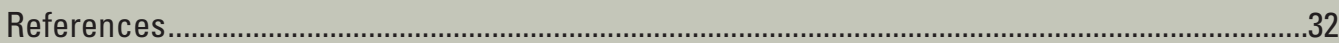

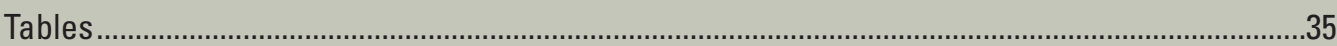

\section{Figures}

1. Map showing the National Hurricane Center storm track for Hurricanes Katrina and Rita, 2005

2-3. Photographs showing-

2. Destruction inflicted by Hurricane Katrina along the Louisiana Delta 4

3. The destructive force that moving debris had on homes and property following levee failure in New Orleans, Louisiana

4-5. Maps showing-

4. Generalized map of the study area

5. Locations of 157 sample sites in the study area .....................................................

6. Photographs showing soil and sediment collection areas ..........................................10

7. Boxplots showing the distribution and range of trace element data analyzed using the single extraction method

8. Map showing the Omernik Ecoregions and locations of National Geochemical Survey data

9. Graphs showing regression analysis of iron concentrations with vanadium, chromium, copper, cadmium, and arsenic

10. Map showing locations of samples analyzed using sequential extraction methods .....24

11. Boxplots showing the range of lead data measured from sequentially extracted samples of sediment from Hurricanes Katrina and Rita, 2005

12. Photographs showing potential causes of organic contamination in New Orleans and along the Louisiana Delta... 


\section{Tables}

1. Quantification ion and qualifier ion data for the Gas Chromatograph-Mass Spectrometry methods used for environmental samples .................................................13

2. Method detection limit for each element .....................................................................14

3. Results of laboratory reagent blank samples ................................................................ 14

4. Results of drinking water and waste water reference standard sample recovery ........15

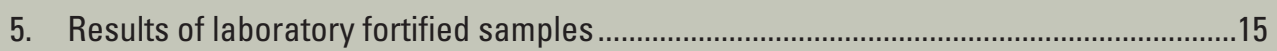

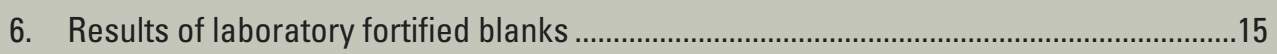

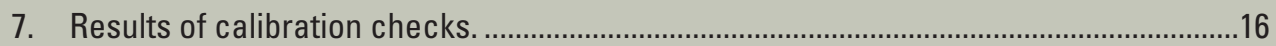

8. Results of single extraction duplicate samples used to measure the precision of analysis

9. Results of sequential extraction duplicate samples used to measure the precision of analysis.

10. Method detection limit of pesticides and arochlor by Gas ChromatographElectron Capture Detection.

11. Results of laboratory fortified blanks for pesticides, Arochlor, and surrogate compounds

12. Results of laboratory fortified sample recovery for pesticides, arochlor, and surrogate compounds...

13. Results of single extraction analysis for trace elements and iron from sediment and soil collected following Hurricanes Katrina and Rita, 2005.

14. Results of sequential extraction analysis for lead from sediment and soil collected following Hurricanes Katrina and Rita .

15. Results of sequential extraction analysis for vanadium from sediment and soil collected following Hurricanes Katrina and Rita .

16. Results of sequential extraction analysis for chromium from sediment and soil collected following Hurricanes Katrina and Rita .

17. Results of sequential extraction analysis for copper from sediment and soil collected following Hurricanes Katrina and Rita .

18. Results of sequential extraction analysis for arsenic from sediment and soil collected following Hurricanes Katrina and Rita.

19. Results of sequential extraction analysis for cadmium from sediment and soil following Hurricanes Katrina and Rita

20. Results of sequential extraction analysis for iron from sediment and soil collected following Hurricanes Katrina and Rita

21. Results of pesticides and polychlorinated biphenyl arochlors measured by Gas Chromatograph-Electron Capture Detection from sediment and soil collected following Hurricanes Katrina and Rita

22. Results of pesticide compounds measured by Gas Chromatograph-Mass Spectrometry from sediment and soil collected following Hurricanes Katrina and Rita. 


\section{Conversion Factors and Datums}

SI to Inch/Pound

\begin{tabular}{|c|c|c|}
\hline Multiply & By & To obtain \\
\hline \multicolumn{3}{|c|}{ Length } \\
\hline nanometer & $3.937 e-8$ & inch (in.) \\
\hline centimeter $(\mathrm{cm})$ & 0.3937 & inch (in.) \\
\hline millimeter (mm) & 0.03937 & inch (in.) \\
\hline meter $(\mathrm{m})$ & 3.281 & foot $(\mathrm{ft})$ \\
\hline kilometer $(\mathrm{km})$ & 0.6214 & mile (mi) \\
\hline kilometer $(\mathrm{km})$ & 0.5400 & mile, nautical (nmi) \\
\hline \multicolumn{3}{|c|}{ Area } \\
\hline square meter $\left(\mathrm{m}^{2}\right)$ & 0.0002471 & acre \\
\hline square kilometer $\left(\mathrm{km}^{2}\right)$ & 247.1 & acre \\
\hline square centimeter $\left(\mathrm{cm}^{2}\right)$ & 0.001076 & square foot $\left(\mathrm{ft}^{2}\right)$ \\
\hline square meter $\left(\mathrm{m}^{2}\right)$ & 10.76 & square foot $\left(\mathrm{ft}^{2}\right)$ \\
\hline square meter $\left(\mathrm{m}^{2}\right)$ & $3.861022 \mathrm{e}^{-7}$ & square mile $\left(\mathrm{mi}^{2}\right)$ \\
\hline square centimeter $\left(\mathrm{cm}^{2}\right)$ & 0.1550 & square inch $\left(\mathrm{ft}^{2}\right)$ \\
\hline square hectometer $\left(\mathrm{hm}^{2}\right)$ & 0.003861 & section (640 acres or 1 square mile) \\
\hline hectare (ha) & 0.003861 & square mile $\left(\mathrm{mi}^{2}\right)$ \\
\hline square kilometer $\left(\mathrm{km}^{2}\right)$ & 0.3861 & square mile $\left(\mathrm{mi}^{2}\right)$ \\
\hline \multicolumn{3}{|c|}{ Volume } \\
\hline cubic meter $\left(\mathrm{m}^{3}\right)$ & 0.0008107 & acre-foot (acre-ft) \\
\hline cubic meter $\left(\mathrm{m}^{3}\right)$ & 35.31 & cubic foot $\left(\mathrm{ft}^{3}\right)$ \\
\hline liter $(\mathrm{L})$ & 33.82 & ounce, fluid (fl. oz) \\
\hline liter $(\mathrm{L})$ & 0.2642 & gallon (gal) \\
\hline liter $(\mathrm{L})$ & 61.02 & cubic inch $\left(\mathrm{in}^{3}\right)$ \\
\hline microliter $(\mu \mathrm{L})$ & $0.0338 \times 10^{-3}$ & ounce, fluid \\
\hline milliliter (mL) & 0.06102 & cubic inch $\left(\right.$ in $\left.^{3}\right)$ \\
\hline milliliter (mL) & 0.0000353 & cubic foot $\left(\mathrm{ft}^{3}\right)$ \\
\hline \multicolumn{3}{|c|}{ Flow rate } \\
\hline liter per minute (L/min) & 0.0005886 & cubic foot per second $\left(\mathrm{ft}^{3} / \mathrm{s}\right)$ \\
\hline meter per hour $(\mathrm{m} / \mathrm{hr})$ & 3.281 & foot per hour $(\mathrm{ft} / \mathrm{hr})$ \\
\hline kilometer per hour $(\mathrm{km} / \mathrm{hr})$ & 0.6214 & mile per hour (mi/hr) \\
\hline \multicolumn{3}{|c|}{ Mass } \\
\hline $\operatorname{gram}(\mathrm{g})$ & 0.03527 & ounce, avoirdupois (oz) \\
\hline kilogram (kg) & 2.205 & pound avoirdupois (lb) \\
\hline milligram $(\mathrm{g})$ & $3.53 \times 10^{-5}$ & ounce \\
\hline \multicolumn{3}{|c|}{ Concentration } \\
\hline microgram per liter $(\mu \mathrm{g} / \mathrm{L})$ & 1 & part per billion (ppb) \\
\hline milligram per liter (mg/L) & 1 & part per million (ppm) \\
\hline milligram per kilogram $(\mathrm{mg} / \mathrm{kg})$ & 1 & part per million (ppm) \\
\hline
\end{tabular}


Temperature in degrees Celsius $\left({ }^{\circ} \mathrm{C}\right)$ may be converted to degrees Fahrenheit $\left({ }^{\circ} \mathrm{F}\right)$ as follows:

$$
{ }^{\circ} \mathrm{F}=\left(1.8 x^{\circ} \mathrm{C}\right)+32
$$

Temperature in degrees Fahrenheit $\left({ }^{\circ} \mathrm{F}\right)$ may be converted to degrees Celsius $\left({ }^{\circ} \mathrm{C}\right)$ as follows ${ }^{\circ} \mathrm{C}=\left({ }^{\circ} \mathrm{F}-32\right) / 1.8$

Vertical coordinate information is referenced to the North American Vertical Datum of 1988 (NAVD 88).

Horizontal coordinate information is referenced to the North American Datum of 1983 (NAD 83).

Altitude, as used in this report, refers to distance above the vertical datum.

Specific conductance is given in microsiemens per centimeter at 25 degrees Celsius $(\mu \mathrm{S} / \mathrm{cm}$ at $\left.25^{\circ} \mathrm{C}\right)$.

Concentrations of chemical constituents in water are given either in milligrams per liter (mg/L) or micrograms per liter $(\mu \mathrm{g} / \mathrm{L})$.

\section{Abbreviated Water-Quality Units}

$\begin{array}{ll}\mu \mathrm{g} / \mathrm{kg} & \text { microgram per kilogram } \\ \mu \mathrm{g} / \mathrm{L} & \text { microgram per liter } \\ \mathrm{mg} / \mathrm{kg} & \text { milligram per kilogram } \\ \mathrm{mg} / \mathrm{L} & \text { milligram per liter } \\ \mathrm{mL} / \mathrm{min} & \text { milliliter per minute } \\ \mathrm{M} & \text { molar }\end{array}$

\section{Abbreviations and Acronyms}

As

BTEX

$\mathrm{Cd}$

$\mathrm{Cr}$

$\mathrm{Cu}$

CVAPS

DRC

GC

GC-ECD

GC-MS arsenic

benzene, toluene, ethylene, and xylene

cadmium

chromium

copper

cold vapor atomic fluorescence spectroscopy

dynamic reaction cell

gas chromatograph

gas chromatograph-electron capture detection

gas chromatograph-mass spectrometry 


$\begin{array}{ll}\text { GFAA } & \text { graphite furnace atomic absorption } \\ \text { Hg } & \text { mercury } \\ \text { HHMSSL } & \text { human health medium-specific screening level } \\ \text { ICP-MS } & \text { inductively-coupled plasma-mass spectrometry } \\ \text { LFB } & \text { laboratory fortified blanks } \\ \text { LFS } & \text { laboratory fortified samples } \\ \text { LRB } & \text { laboratory reagent blank } \\ \text { MDL } & \text { method detection level } \\ \text { Hm } & \text { micrometer } \\ \text { Missouri S \& T } & \text { Missouri University of Science and Technology } \\ \text { NGS } & \text { National Geochemical Survey } \\ \text { Pb } & \text { lead } \\ \text { PCB } & \text { polychlorinated biphenyl } \\ \text { ppb } & \text { parts per billion } \\ \text { psi } & \text { pounds per square inch } \\ \text { RCF } & \text { relative centrifugal force } \\ \text { RPD } & \text { relative percent difference } \\ \text { rpm } & \text { revolutions per minute } \\ \text { SC } & \text { Sklar Primacs } \\ \text { TDI } & \text { tolerable daily intake } \\ \text { TOC } & \text { total organic carbon } \\ \text { USEPA } & \text { U.S. Environmental Protection Agency } \\ \text { USGS } & \text { U.S. Geological Survey } \\ \text { UTC } & \text { Universial Time Code } \\ \text { V } & \text { vanadium } \\ \text { WHO } & \text { World Health Origanization } \\ & \end{array}$




\title{
Environmental Chemical Data for Perishable Sediments and Soils collected in New Orleans, Louisiana, and along the Louisiana Delta following Hurricanes Katrina and Rita, 2005
}

\author{
By Emitt C. Witt III ${ }^{1}$, Honglan Shi ${ }^{2}$, Krista A. Karstensen ${ }^{1}$, Jianmin Wang ${ }^{2}$, and Craig D. Adams ${ }^{2}$
}

\begin{abstract}
In October 2005, nearly one month after Hurricanes Katrina and Rita, a team of scientists from the U.S. Geological Survey and the Missouri University of Science and Technology deployed to southern Louisiana to collect perishable environmental data resulting from the impacts of these storms. Perishable samples collected for this investigation are subject to destruction or ruin by removal, mixing, or natural decay; therefore, collection is time-critical following the depositional event.
\end{abstract}

A total of 238 samples of sediment, soil, and vegetation were collected to characterize chemical quality. For this analysis, 157 of the 238 samples were used to characterize trace element, iron, total organic carbon, pesticide, and polychlorinated biphenyl concentrations of deposited sediment and associated shallow soils. In decreasing order, the largest variability in trace element concentration was detected for lead, vanadium, chromium, copper, arsenic, cadmium, and mercury. Lead was determined to be the trace element of most concern because of the large concentrations present in the samples ranging from 4.50 to 551 milligrams per kilogram $(\mathrm{mg} / \mathrm{kg})$. Sequential extraction analysis of lead indicate that 39.1 percent of the total lead concentration in post-hurricane sediment is associ-

${ }^{1}$ U.S. Geological Survey.

${ }^{2}$ Missouri University of Science and Technology. ated with the iron-manganese oxide fraction. This fraction is considered extremely mobile under reducing environmental conditions, thereby making lead a potential health hazard. The presence of lead in post-hurricane sediments likely is from redistribution of pre-hurricane contaminated soils and sediments from Lake Pontchartrain and the flood control canals of New Orleans. Arsenic concentrations ranged from 0.84 to $49.1 \mathrm{mg} / \mathrm{kg}$. Although Arsenic concentrations generally were small and consistent with other research results, all samples exceeded the U.S. Environmental Protection Agency's Human Health Medium-Specific Screening Level of $0.39 \mathrm{mg} / \mathrm{kg}$. Mercury concentrations ranged from 0.02 to $1.30 \mathrm{mg} / \mathrm{kg}$. Comparing the mean mercury concentration present in post-hurricane samples with regional background data from the U.S. Geological Survey National Geochemical Dataset, indicates that mercury concentrations in post-hurricane sediment generally are larger. Sequential extraction analysis of 51 samples for arsenic indicate that 54.5 percent of the total arsenic concentration is contained in the extremely mobile iron-manganese oxide fraction. Pesticide and polychlorinated biphenyl Arochlor concentrations in post-hurricane samples were small. Prometon was the most frequently detected pesticide with concentrations ranging from 2.4 to 193 micrograms per kilogram $(\mu \mathrm{g} / \mathrm{kg})$. Methoxychlor was present in 22 samples with a concentration ranging from 3.5 to $3,510 \mu \mathrm{g} / \mathrm{kg}$. Although methoxychlor had the largest detected pesticide concentration, it was well below the U.S. Environmental Protection Agency's High-Priority Screening Level for residential soils. Arochlor congeners were not detected for any sample above the minimum detection level of $7.9 \mu \mathrm{g} / \mathrm{kg}$. 


\section{Introduction}

The 2005 storm season was the most devastating in Gulf Coast history. Hurricane Katrina came ashore on August 29, damaging the flood-control infrastructure of New Orleans and the Louisiana Delta with its storm surge and high winds. The resulting flood waters inundated more than 141,000,000 square meters $\left(\mathrm{m}^{2}\right)$ in New Orleans destroying homes, businesses, and supporting municipal infrastructure (Adams and others, 2007). Additionally, the flood waters brought nearly $708,000 \mathrm{~m}^{3}$ of sediment that was deposited in New Orleans. Less than one month later, Hurricane Rita passed through western Louisiana causing more flooding and sediment deposition to the already devastated area.

The origin of the sediment deposited in New Orleans primarily is from the channel systems that are designed to drain the city and Lake Pontchartrain. These sediments likely are to have accumulated large concentrations of trace elements and organic compounds from years of municipal and industrial drainage. The mixing of these sediments with debris from the hurricane-damaged infrastructure may be responsible for increases in trace element concentration.

A team of U.S. Geological Survey (USGS) and Missouri University of Science and Technology (Missouri S\&T) scientists deployed to the affected region from October 6 to 18,2005 , to collect perishable environmental and engineering data (Witt and others, 2006; Luna and others, 2006; Chen and others, 2006). The team was responsible for collecting many photographs and videos of the damage to infrastructure and flood control systems, as well as samples of the deposited sediments and associated soils. For the purpose of this report, sediment is defined as a solid material that has settled from a state of suspension in a liquid, and soil as the unconsolidated mineral or organic material on the surface of the earth that has been subjected to and shows effect of genetic and environmental factors of climate (including water and temperature effects) and macro- and microorganisms, conditioned by relief, acting on parent material during a specific time period (Neuendorf and others, 2005).

This report presents the chemical data and quality assurance information for 157 soil and sediment samples collected in New Orleans and the Louisiana Delta following the two storms. The physical devastation associated with the wrath of Hurricanes Katrina and Rita is not limited to scattered debris and structural damage; to the contrary, some of the most harmful effects of the storms lay beneath the surface. The collection, analytical methods, and results of this investigation serve to expose the potential problems and health risks associated with the post-storm sediment chemistry of New Orleans and the Louisiana Delta. Additionally, the results will serve as a planning tool for residents, developers, and debris removal teams as they prepare to make this region habitable once more.

\section{Hurricane Season}

The 2005 storm season was one of the worst and longest in recorded history. Thirty-one major storms occurred in the Atlantic-Caribbean-Gulf region during 2005; of those, 27 were given names by the National Hurricane Center validating the intensity and potentially catastrophic effects of these storms on land and sea. The official record of storms, by intensity, that occurred during the 2005 season included 1 subtropical depression, 1 subtropical storm, 2 tropical depressions, 12 tropical storms, and 15 hurricanes (U.S. National Oceanic and Atmosheric Administration, 2007). The storm season began with tropical storm Arlene on June 8 to 13, 2005, which made landfall on the Florida panhandle causing moderate damage. The season ended with tropical storm Zeta on December 30, 2005 to January 6, 2006. Tropical storm Zeta did not make landfall, but it was the second recorded storm to occur that late in the year and to continue to the next calendar year (Knabb and Brown, 2006). Hurricanes Katrina and Rita made landfall nearly one month apart during the peak of hurricane season within 161 kilometers $(\mathrm{km})$ of each other. The damage these two storms caused was unprecedented, and cleanup and rebuilding presently (2007) are still occurring.

\section{Hurricane Katrina}

Hurricane Katrina was the first storm to impact southern Louisiana. With sustained winds of $60 \mathrm{~km} /$ hour, Katrina initially was categorized as Tropical Depression 12 when spotted on August 23, 2005, over the Bahamas Islands (National Oceanic and Atmosheric Administration, 2005). By August 24,2005 , the storm had grown in intensity and was upgraded by the National Hurricane Center as Tropical Storm Katrina. The storm further intensified as it approached the Florida coast and was upgraded to Category I hurricane status. Katrina made landfall on the southern tip of Florida about $100 \mathrm{~km}$ north of Key West, with sustained winds of about 115 kilometers per hour $(\mathrm{km} / \mathrm{hr})$. The hurricane quickly moved to the Gulf of Mexico and gradually intensified over the next 5 days before making landfall at 7 a.m. Central Standard Time August 29, 2005, between Port Sulphur, Louisiana, and the Empire/ Buras, Louisiana, area (National Oceanic and Atmosheric Administration, 2005) (fig. 1). Initially, Katrina was reported to be a Category 4 storm when it made landfall, but a poststorm analysis by the National Hurricane Center indicates the storm actually was a Category 3 with sustained winds of 180 $\mathrm{km} / \mathrm{hr}$ (Knabb and others, 2006).

The impact of Hurricane Katrina on the Delta region was enormous. The levees that protected the narrow strip of land from floods failed after receiving an extensive pounding from waves and wind. Homes, vehicles, boats, businesses, schools, and cemeteries were destroyed and scattered around the Delta's limited landscape (figs. 2 and 3). The salt water inflow from the Gulf of Mexico killed many of the mature fruit orchards of the lower Delta. The torrential flow of water 


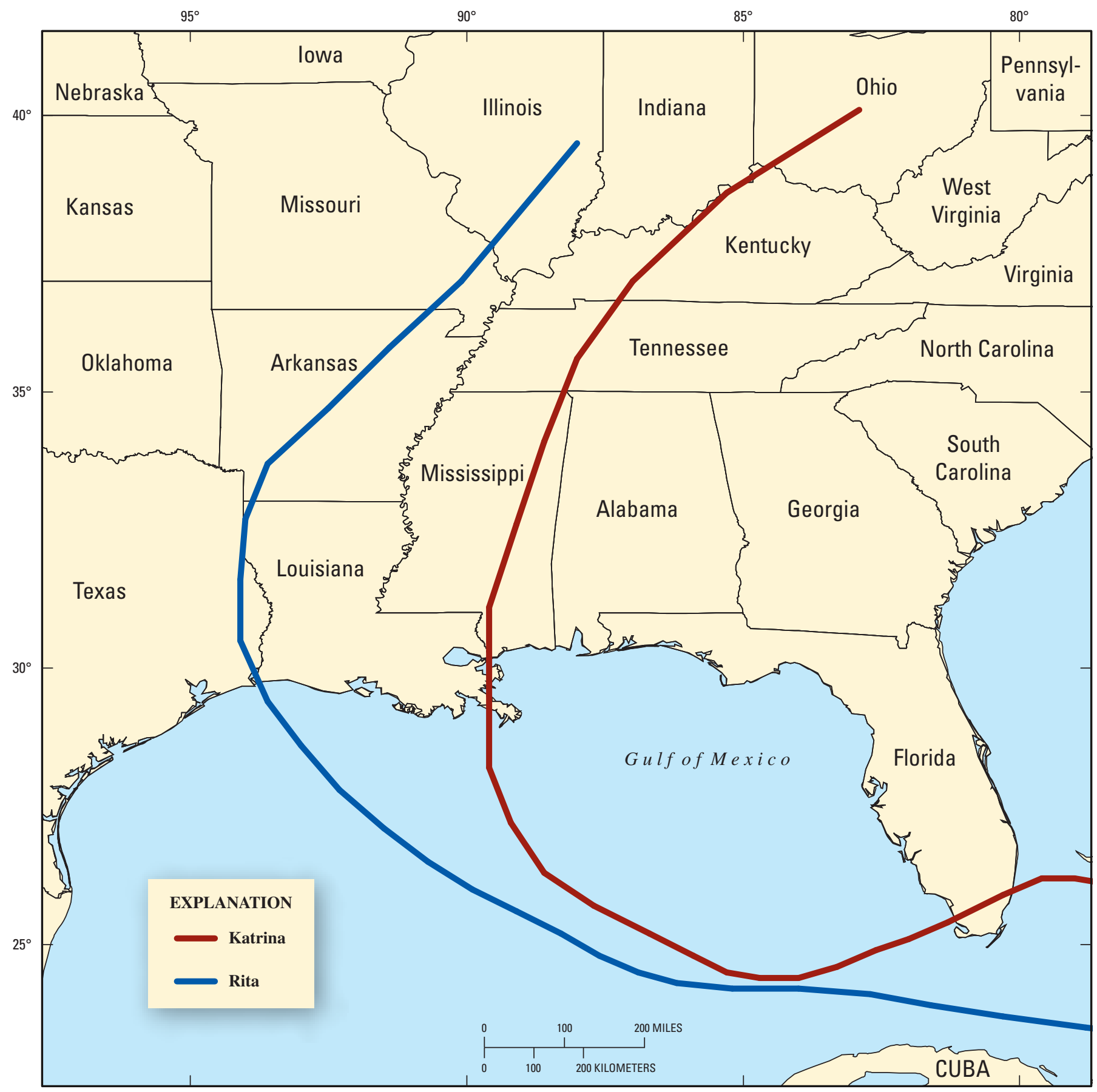

Base from Environmental Systems Research Institute digital data, 1983

Hurricane track data from the National Oceanic Atmospheric Administration National Hurricane Center, 2006 and the U.S. Census Bureau

Figure 1. National Hurricane Center storm track for Hurricanes Katrina and Rita, 2005.

dislodged many fuel storage tanks and ruptured those that did not become dislodged, causing the contents to be released throughout the Delta region. Large oil slicks were observed where water crested on the levees.

Hurricane Katrina made its second and final landfall a few hours later near the Louisiana/Mississippi border. The storm weakened slightly with sustained surface winds of 170 $\mathrm{km} / \mathrm{hr}$. As the center of the eye of the storm made its clos- est approach [20 miles (mi)] to the east of downtown New Orleans, it maintained Category 3 intensity (Knabb and others, 2006a). The strongest winds corresponding to this intensity likely were present only over water to the east of the eye of the hurricane (Knabb and others, 2006a); therefore, most of the city of New Orleans probably experienced sustained surface winds of Category 1 or 2 strength. The eye of the storm was east of New Orleans, and the storm surge associated with the 

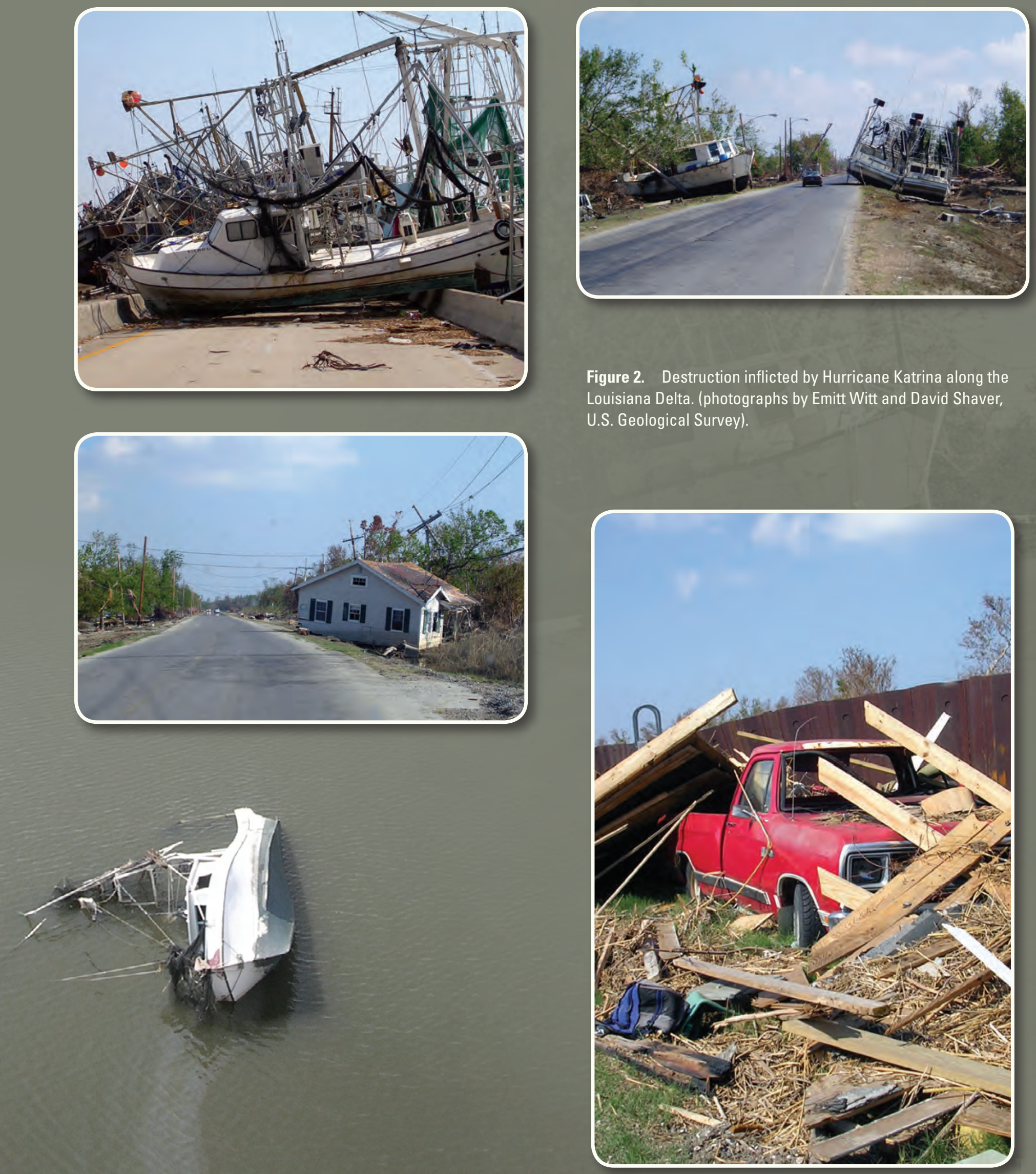

Figure 2. Destruction inflicted by Hurricane Katrina along the Louisiana Delta. (photographs by Emitt Witt and David Shaver, U.S. Geological Survey). 

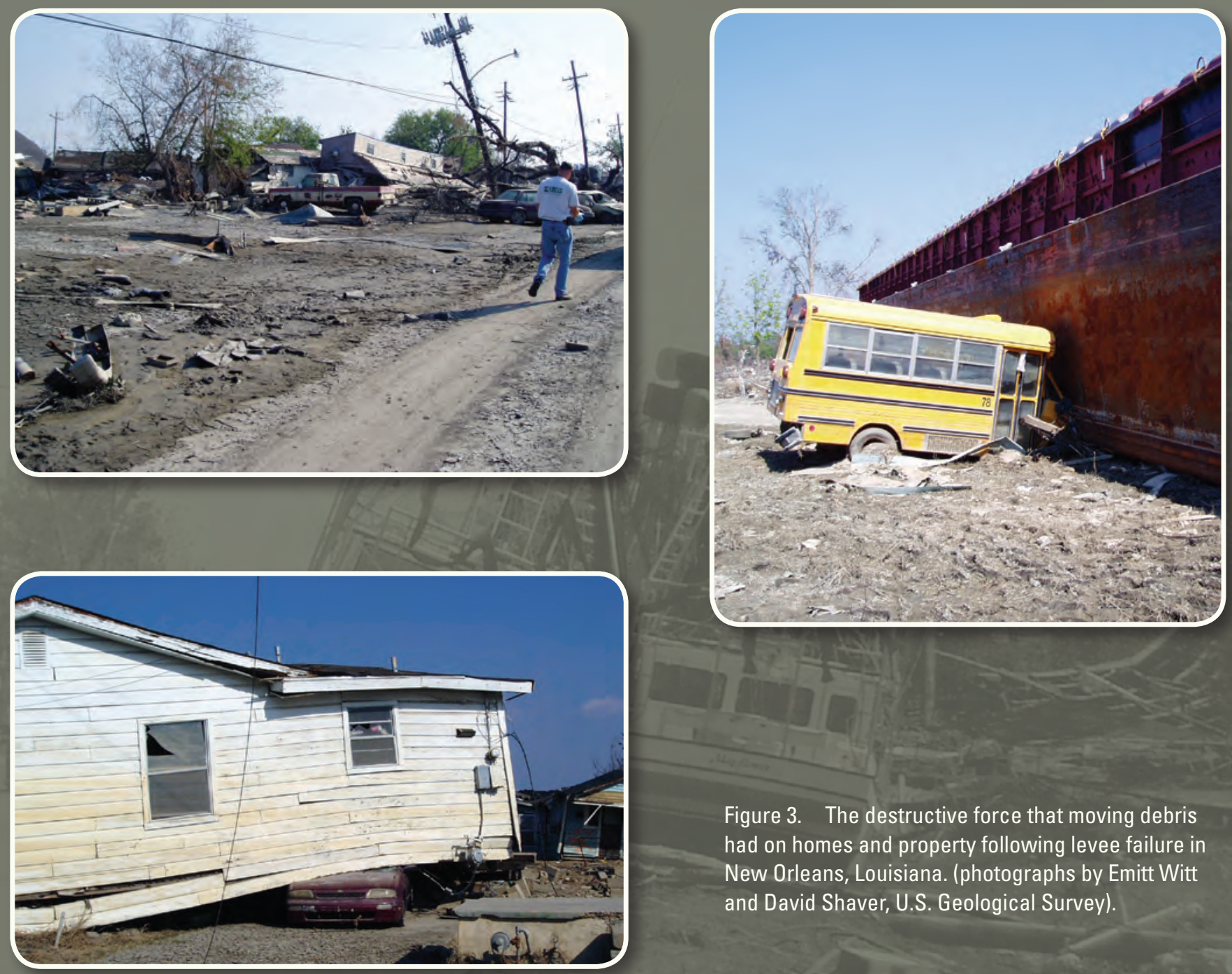

Figure 3. The destructive force that moving debris had on homes and property following levee failure in New Orleans, Louisiana. (photographs by Emitt Witt and David Shaver, U.S. Geological Survey).
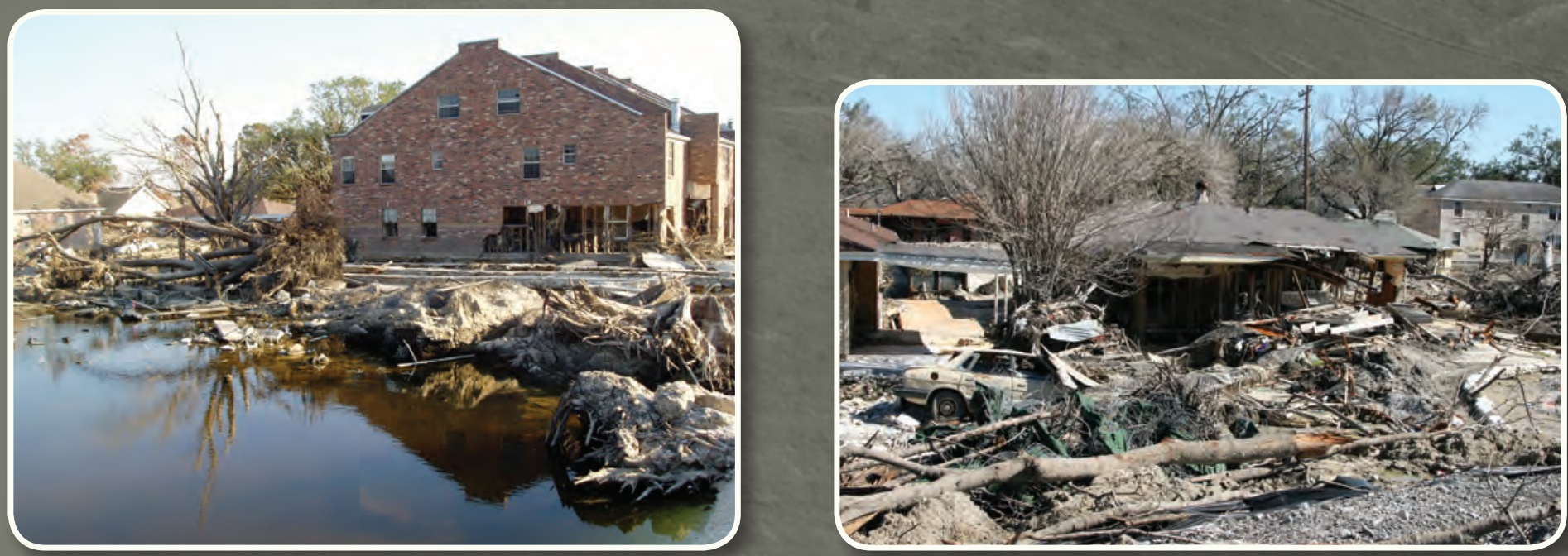
levee failures in the city was highest to the east of the path of Hurricane Katrina. Storm surge data indicate water levels of 5 to 6 meters (m) occurred in eastern New Orleans, St. Bernard Parish, and Plaquemines Parish; the surge was 3 to 4 $m$ in western New Orleans along the southern shores of Lake Pontchartrain (Knabb and others, 2006a). The highest surge associated with Hurricane Katrina was recorded in Mississippi (Charles Demas, U.S. Geological Survey Louisiana Water Science Center, written commun., 2007)

The substantial storm surge exceeded the limits of the New Orleans flood control system the day of landfall. Storm surge overtopped large sections of the levees east of New Orleans, in Orleans Parish and St. Bernard Parish. A substantial amount of water was pushed up the Intercoastal Waterway and into the Industrial Canal. Breaches occurred during the early morning of August 29, 2005, along the Industrial Canal east of downtown New Orleans, the London Avenue Canal north of downtown New Orleans, and the 17th Street Canal northwest of downtown. These breaches led to the flooding of about 80 percent of the City completely swallowing homes in some areas. At and near the breached levees, the damage to structures and personal property was enormous (fig. 3). The water that entered the City was heavily laden with sand and silt transported from the canals and Lake Pontchartrain. The water and sediment was further mixed with the debris created by the damaged flood-control system, and deposited throughout the affected area (fig. 3 ).

\section{Hurricane Rita}

Hurricane Rita began as a tropical depression on September 18, 2005, at about 1800 Universal Time Code (UTC) approximately $40 \mathrm{~km}$ east-southeast of the island of Mayaguana in the southeastern Bahamas (Knabb and others, 2006b). By September 20, tropical storm Rita became Hurricane Rita, attaining an intensity of Category 2. Hurricane Rita passed about $65 \mathrm{~km}$ south of Key West, Florida, and continued to gain strength as it moved through the Gulf of Mexico. The storm reached peak strength at Category 5 on September 22, then began to lose strength before reaching southwestern Louisiana just east of Sabine Pass on September 23 (fig. 1). Hurricane Rita weakened substantially to a Category 3 after making landfall. By 1200 UTC September 24, the storm was downgraded to a tropical storm soon after passing Beaumont, Texas.

Hurricane Rita devastated entire communities in coastal areas of southwestern Louisiana. Almost every structure in these areas was destroyed, and some were completely swept away. Several miles inland from the Gulf along Calcasieu Lake, numerous homes in the town of Grand Lake were damaged or destroyed. Many parts of the Lake Charles area suffered substantial flood damage, including the downtown area and some surrounding residential communities. Storm surge was a significant factor in property loss causing damage to homes and businesses in eastward, low-lying areas along the entire coast of Louisiana (Knabb and others, 2006b).
The USGS deployed 47 pressure transducers at 33 sites before the storm to monitor the timing, extent, and magnitude of the surge related to flooding. Based on storm surge data collected from McGee and others, 2006, the lasting impact on New Orleans, although not as severe as Hurricane Katrina, was the prolonging of flooding and sediment disposition.

\section{Study Area Description}

The study area includes the intersection of the southern shoreline of Lake Pontchartrain and extends southward to the 'bird foot' Delta that extends into the Gulf of Mexico (fig. 4). Samples collected in New Orleans represented the entire flood-impacted area, in addition to areas that received hurricane damage but no flood waters. Access to this area one month after the storm events was limited because of the large amount of debris scattered throughout the region. Most samples were collected in visibly impacted areas near homes, businesses, along road ways, or from the tops of and beneath automobiles. The sediment deposited in New Orleans after the storms could have come from a variety of sources including Lake Pontchartrain, the flood control canals, regional marshes, suspended soils that were in the city before the flooding, as well as other distributary channels in the region with Mississippi River drainage origins.

To mitigate flood hazards in a city whose average elevation is several feet below sea level, most of the stormwater runoff that accumulates in New Orleans is pumped to nearby Lake Pontchartrain. During normal conditions, stormwater is collected by an extensive system of canals and is discharged into the lake via drainage pumps and open surface drainage canals that redirect the runoff into the lake. The primary suspected source of pollution in Lake Pontchartrain is the pumped urban stormwater runoff that is discharged to the area (Carnelos and others, 2007). When Hurricanes Katrina and Rita struck New Orleans, the massive precipitation events overwhelmed the levees, canals, and drainage pumps, inundating the entire city. The floodwaters of Lake Pontchartrain redistributed many of the pollutants including pathogens, nutrients, and solids that had been pumped into the lake from previous precipitation events.

From a climatological perspective, the amount of rainfall and runoff this area receives has a substantial affect on the chemistry of the dispositioned sediments; thus, storm-water drainage is likely to contain a wide variety of urban contaminants. New Orleans is known for its large lead concentration in soils. Before Hurricanes Katrina and Rita, a program was underway to mitigate whole-body contact by children with New Orleans soils (Mielke and others, 2007). The background presented herein will facilitate analysis of these data by USGS and other research institutions in the future. 


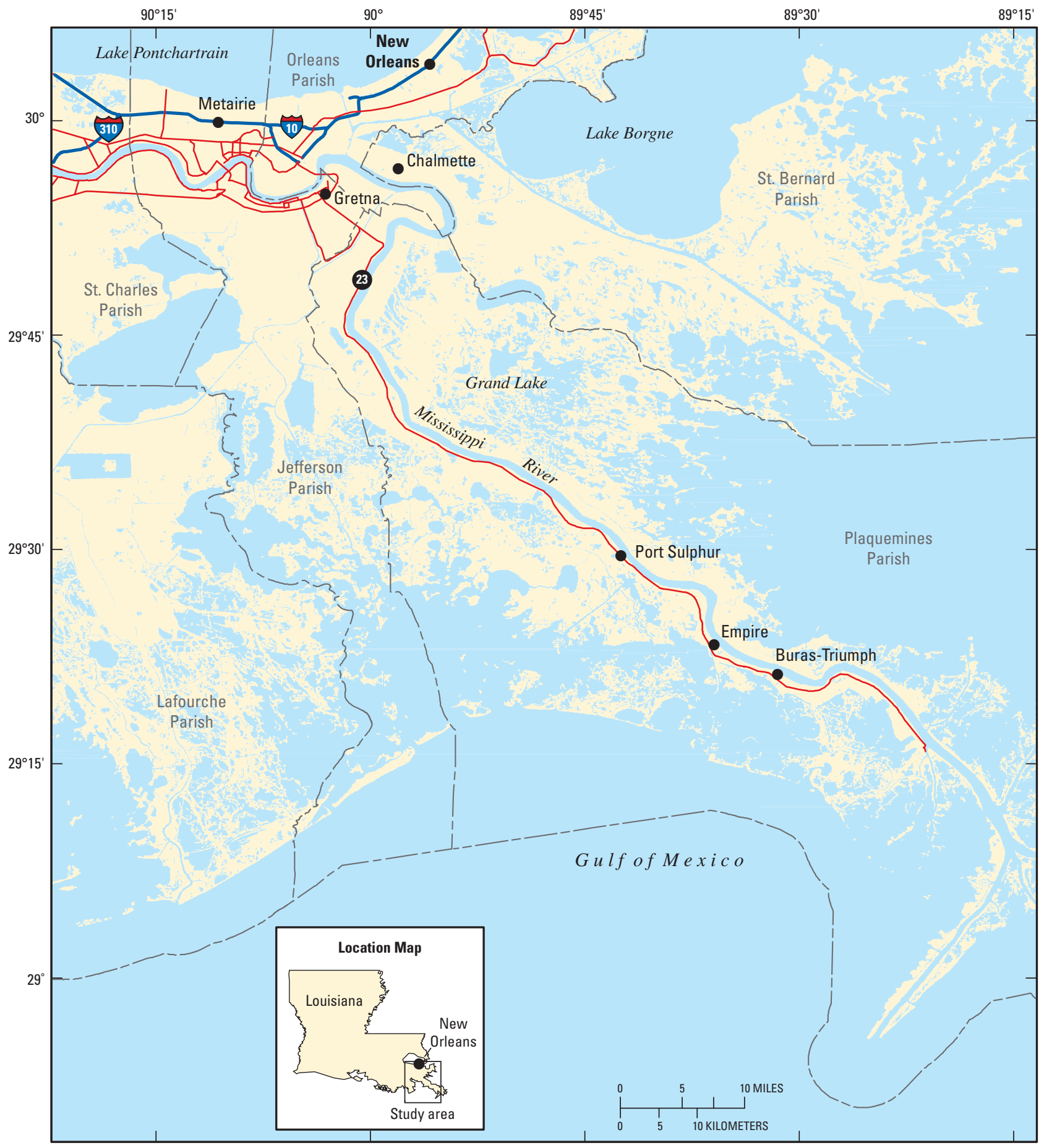

Base from the Louisiana Oil Spill Coordinator's Office, 2000

Horizontal coordinate information referenced to the

North American Datum of 1983 (NAD 83)

Figure 4. Generalized map of the study area. 


\section{Method of Collection and Analysis}

\section{Sample Collection}

From October 6 to 18, 2005, 238 sediment, soil, and other samples were collected in New Orleans and along Highway 23 on the Louisiana Delta (fig. 5). The Missouri S\&T Environmental Research Laboratory analyzed 46 of 203 soil and sediment samples for a preliminary investigation; those were not reanalyzed for this study because too little sample material remained (Adams and others, 2007). Thirty-five samples that were not used in this analysis include reference duplicates, oil-stained vegetation, soil samples from known oil spillage sites (targeted sampling that does not represent the region), and road surfaces. This analysis included 157 samples that were considered to be an unbiased representation of perishable sediments and soils from the hurricane affected region.

Sample locations were selected to provide a cross section of residential, business, and industrial (refinery) areas. Sites included the 17th-Street Levee breach, at the Industrial Levee breach, neighborhoods of the Brookmoor District, and near refineries in eastern New Orleans along the Mississippi River. Samples were collected along Highway 23 south of New Orleans including Empire (near the location where the eye of Hurricane Katrina passed through on August 29, 2005) as well as sites a few miles beyond Venice, near the Gulf fishing fleet marina. Given the logistical difficulties with moving around the impacted area, a pre-planned sampling strategy could not be employed. Samples were collected where access was available and when permissions were obtained. In most cases, the team moved freely between the damaged regions, with little control by the municipal authorities, land and business owners, or the National Guard. Given the complexity of the sampling effort so soon after the event, this analysis makes the assumption that these data are distributed randomly for comparative purposes.

Two procedures were used for sample collection- $\mathrm{a}$ coring procedure and a surface 'grab' collection procedure. In the coring procedure, a 2-centimeter [( $\mathrm{cm})(0.787$-inch (in.)] diameter hand-held corer was used to collect a soil sample up to $4 \mathrm{in}$. deep. The corer is made of stainless steel and has a plastic container to hold the sample. In some cases where deposited sediments were thicker, a deeper (up to 8 in.) core sample was collected. Where using a coring tool was impractical, such as collecting samples from the tops of and beneath automobiles, sidewalks, and inside and outside structures, a simple 'grab' method was used. Grab samples were collected with either a wooden tongue depressor or a small garden shovel, then were placed in 60-milliliter $(\mathrm{mL})$ amber glass vials with Teflon-lined caps. To prevent cross-contamination of samples during sample collection, all personnel wore disposable latex gloves. The instruments used for sample collection were cleaned between sample sites to the best standard possible with the limited amount of rinse water available under the complexity of the situation. It was assumed that this method would not substantially affect the chemistry of the samples because the reporting levels were substantially above the parts per billion range. The samples were labeled and the vials immediately double-bagged into plastic zip-lock bags and placed in the dark in a cooler. No preservatives were added to samples. Samples were kept as close to 4 degrees Celsius $\left({ }^{\circ} \mathrm{C}\right)$ as possible and in the dark until analysis could be performed at the Missouri S\&T Environmental Research Center Laboratory. Photographs of typical sample collection sites are shown in figure 6 .

\section{Laboratory Analysis}

Samples were analyzed beginning in October 2006 at the Missouri S\&T, Environmental Research Center Laboratory for moisture, $\mathrm{pH}$, single- and sequentially-digested concentrations (hereinafter referred to as "extraction") of the trace elements $\mathrm{V}, \mathrm{Cr}, \mathrm{Cu}, \mathrm{Cd}, \mathrm{Pb}, \mathrm{As}$, and $\mathrm{Hg}$, the major metallic element iron, pesticides, and polychlorinated biphenyls (PCBs).

Analysis for total organic carbon was done at the University of Minnesota Soil Testing and Research Analytical Laboratory.

The chemicals and supplies used for analysis include certified grade magnesium chloride, sodium acetate, hydroxylamine hydrochloride, ammonium acetate, and anhydrous sodium sulfate; all were purchased from Fisher Scientific . Trace element grade nitric acid, hydrochloric acid, and hydrogen peroxide also were Fisher Scientific products. High performance liquid chromatography grade acetic acid, pesticide grade hexane, and acetone also were purchased from Fisher Scientific. The trace element standard solutions were purchased from Perken Elmer. Certified reference standard samples of drinking water and waste water were purchased from High Purity Standards.

\section{Moisture, pH, and Total Organic Carbon}

Moisture content was measured by weighing 1.00 gram (g) of soil sample into a pre-dried aluminum weighing dish. The sample was dried at $105^{\circ} \mathrm{C}$ in an oven until constant weight was achieved. The difference of the wet weight and the dry weight of each sample is calculated as follows:

$$
\begin{aligned}
& \% \text { Moisture }=100 \times \text { (weight of wet sample-weight } \\
& \text { of dry sample)/weight of wet sample) }
\end{aligned}
$$

A part of each sample was measured for $\mathrm{pH}$ by mixing $1.00 \mathrm{~g}$ of wet sample and $2.00 \mathrm{~mL}$ of de-ionized water in a test tube. The mixture was agitated to complete mixing, then centrifuged at 2,000 relative centrifugal force (RCF) for 5 minutes to precipitate the soil. The $\mathrm{pH}$ of the supernate was measured with a standard $\mathrm{pH}$ electrode and meter.

Total organic carbon (TOC) analysis for samples was performed by Soil Testing and Research Analytical Lab at University of Minnesota, 1902 Dudley Avenue, St. Paul, Minesota. Total organic carbon was measured using a destructive quantitative technique involving dry combustion at high 


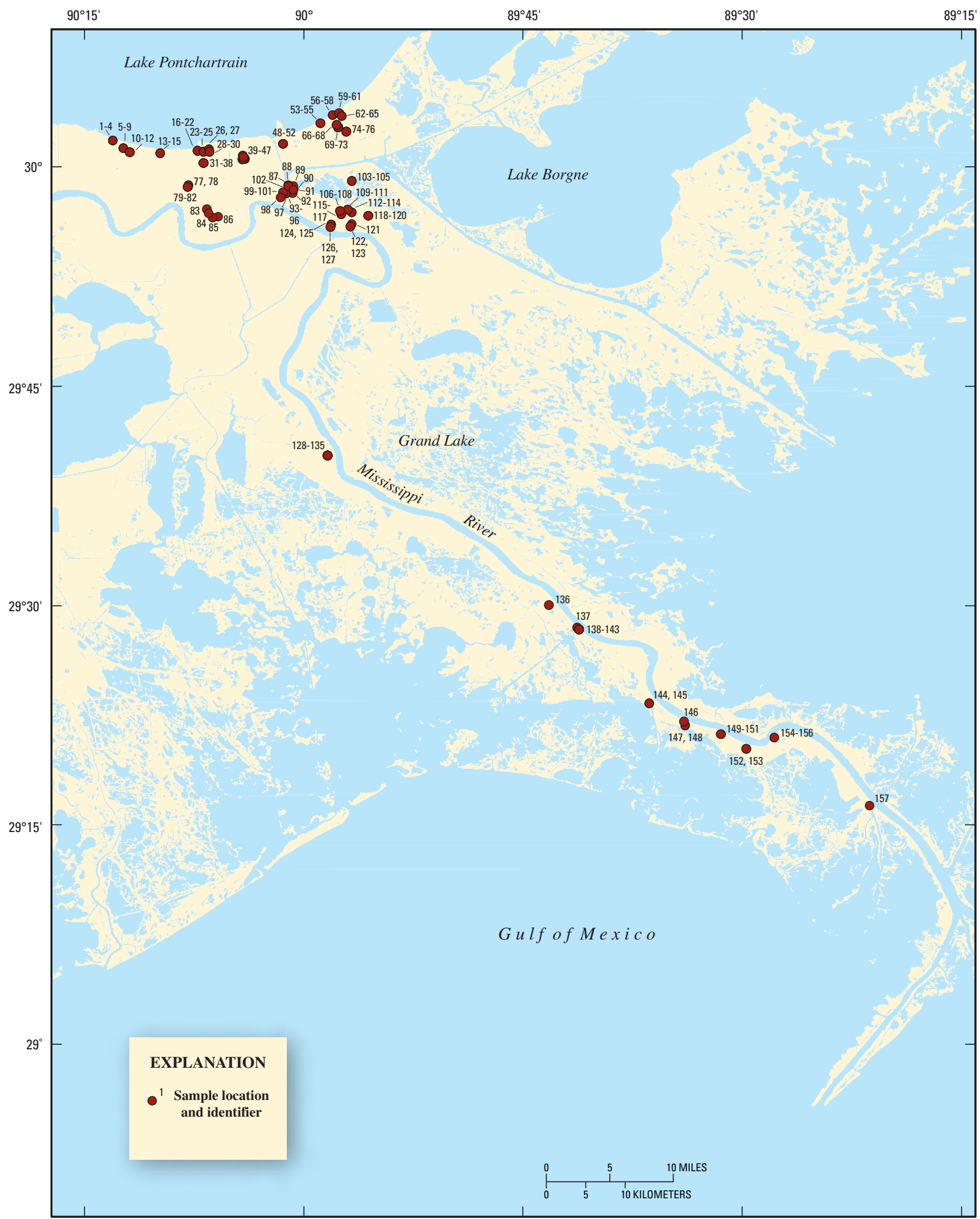

Base from the Louisiana Oil Spill Coordinator's Office, 2000

Horizontal coordinate information referenced to the

North American Datum of 1983 (NAD 83)

Figure 5. Locations of 157 sample sites in the study area. 

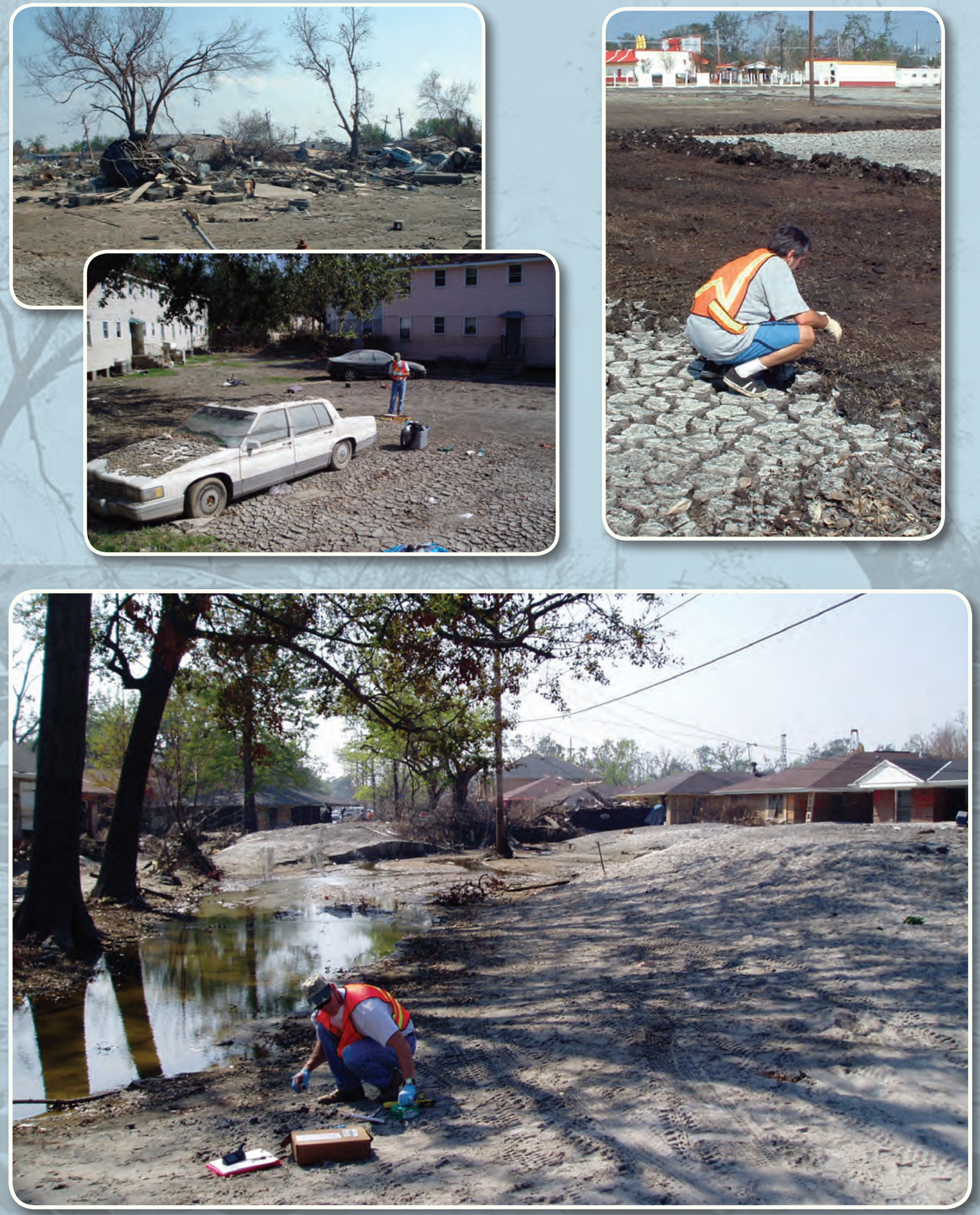

Figure 6. Soil and sediment collection areas (photographs by Emitt Witt and David Shaver, U.S. Geological Survey and Jianmin Wang, Missouri University of Science and Technology). 
temperatures followed by measurement of the evolved carbon dioxide $\left(\mathrm{CO}_{2}\right)$ (Tiessen and Moir, 1993). Before analysis, $\mathrm{pH}$ was measured to screen samples for the presence of calcium carbonate. If $\mathrm{pH}$ was greater than 7.8 , then calcium carbonates are present. This suggests that part of the sample contains inorganic carbon that must be considered during quantification (McLean, 1982). As a quality assurance measure and to account for the presence of carbonates, a $\mathrm{pH}$ of 7.4 was used as a conservative threshold indicator that the sample must be conditioned to remove carbonates (U.S. Enivironmental Protection Agency, 2002b).

A Sklar Primacs (SC) carbon analyzer was used to measure total carbon following the total combustion of 200 to 300 miligram $(\mathrm{mg})$ of sample in an oxygen rich atmosphere of a $1,050{ }^{\circ} \mathrm{C}$ furnace. The carbon-dioxide produced by the combustion is swept by an oxygen stream through a moisture trap, and then to the infrared detector that measures the amount of carbon dioxide produced. For samples with $\mathrm{pH}$ greater than 7.4 , inorganic carbon is determined by adding 20 percent phosphoric acid to the sample, heating to $90{ }^{\circ} \mathrm{C}$ and then bubbling with oxygen to sweep the carbon dioxide produced to an infrared detector for quantification. For samples that contain carbonates, the organic carbon is calculated by subtracting the measured inorganic carbon from the measured total carbon.

\section{Trace Element and Iron Single Extraction}

Samples were prepared for analysis using a microwave assisted acid-digestion following U.S. Environmental Protection Agency (USEPA) Method 3051A (1998). A Perkin Elmer Multiwave 3000 microwave digestion system was used to implement this procedure. Approximately $0.5 \mathrm{~g}$ of wet sample was added to a pre-acid cleaned microwave digestion vessel (for heavy duty 8-position rotor), then $9 \mathrm{~mL}$ trace element grade nitric acid $\left(\mathrm{HNO}_{3}\right)$ and $3.00 \mathrm{~mL}$ of trace element grade hydrochloric acid $(\mathrm{HCl})$ were added to the sample.

At the completion of the digestion process, the sample was transferred into a pre-acid cleaned $50 \mathrm{~mL}$ polypropylene centrifuge tube and diluted to $50.0 \mathrm{~mL}$ with de-ionized water. Appropriate dilutions were made for trace element analysis by Inductively Coupled Plasma-Mass Spectrometry (ICP-MS). All trace elements except mercury were analyzed according to USEPA Method 200.8 (U.S. Enivironmental Protection Agency, 1994). Arsenic, Cd, Cr, Cu, Pb, and V were analyzed using a Perkin Elmer Elan DRC-e ICP-MS. A Cyclonic spray chamber with Meinhard nebulizer and nickel cones was used and the samples were delivered at 1 milliliter per minute $(\mathrm{mL} / \mathrm{min})$ by a peristaltic pump. The radiated power was 1,500 watts. Argon flow rates for the plasma and auxiliary gas were 15.0 and 1.20 liters per minute $(\mathrm{L} / \mathrm{min})$ respectively. Quantitation was performed with an internal standard method. A multi-element internal standard mixture was used and was added continuously online. Arsenic as arsenate (AsO) was detected by Dynamic Reaction Cell (DRC) mode to eliminate the chloride interference from the $\mathrm{HCl}$ addition during acid digestion. The DRC reaction cell gas was oxygen.
Mercury concentrations in the digested samples were measured using USEPA Method 1631, revision E (U.S. Enivironmental Protection Agency, 2002a). A Tekran® Series 2600 Ultra-trace Mercury Analysis System (Tekran Inc., Toronto, Canada) was used to analyze the samples. The equipment uses a dual stage gold pre-concentration for mercury followed by Cold Vapor Atomic Fluorescence Spectroscopy (CVAFS) detection. The microwave acid-digested sample solutions were digested with 0.5 percent bromine chloride $(\mathrm{BrCl})$ for 12 hours before analysis, which ensured that bromine chloride had enough time to oxidize all forms of mercury in the sample to $\mathrm{Hg}^{2+}$. The bromine chloride stock solution was prepared by dissolving $5.50 \mathrm{~g}$ potassium bromide and $7.50 \mathrm{~g}$ potassium bromate in $100 \mathrm{~mL}$ de-ionized water, and then slowly adding $400 \mathrm{~mL}$ of trace element grade hydrochloric acid under a fume hood. Both potassium bromide and potassium bromate were heated at $180{ }^{\circ} \mathrm{C}$ in a mercury-free oven for a period of 12 hours before bromine chloride stock solution preparation to negate any background mercury. After oxidation with bromine chloride and just prior to analysis, the samples were reduced sequentially with hydroxylamine hydrochloride $\left(\mathrm{NH}_{2} \mathrm{OH} \cdot \mathrm{HCl}\right)$ to destroy the free halogens present. $\mathrm{NH}_{2} \mathrm{OH} \cdot \mathrm{HCl}$ was prepared by weighing $75.0 \mathrm{~g} \mathrm{NH} \mathrm{N}_{2} \mathrm{OH} \cdot \mathrm{HCl}$ and dissolving it into $250 \mathrm{~mL}$ de-ionized water. The solution was purified using a 3 percent stannous chloride $\left(\mathrm{SnCl}_{2}\right)$ reducing solution and purged with ultra high purity argon for at least 2 hours to convert all the $\mathrm{Hg}^{2+}$ to volatile elemental $\mathrm{Hg}(0)$. This was separated from the solution over a phase separator by mercury free ultra high purity argon carrier gas. The $\mathrm{Hg}(0)$ was then trapped on a gold coated sand trap, desorbed thermally, and moved through a cell of the CVAFS for detection.

Iron was measured by flame atomic absorption spectrometry using USEPA Method 7000A (1992; superceded by USEPA Method 7000B, 2007). The digested solutions were diluted 5 to 20 times with de-ionized water, then directly aspirated into an air-acetylene oxidizing flame of a Perkin Elmer model 3110 flame atomic absorption spectrometer. A single element hollow cathode iron lamp was used as a light source. Absorbance was determined at 248.3 nanometers (nm) with the slit set at 0.20 nanometer $(\mathrm{nm})$. The iron concentration was obtained with an external calibration method within the linear calibration range [0.1 milligram per liter $(\mathrm{mg} / \mathrm{L})-20 \mathrm{mg} / \mathrm{L}]$.

\section{Trace Element and Iron Sequential Extraction}

Sequential extraction of trace elements $\mathrm{V}, \mathrm{Cd}, \mathrm{Cr}, \mathrm{Cu}$, $\mathrm{Pb}$, and $\mathrm{As}$ was done to evaluate the speciation of particulate-bound constituents. This analysis method is more time consuming and costly to conduct than the single extraction approach, but provides detailed information about the origin, mode of occurrence, biological and physiochemical availability, mobilization, and transport of trace elements in the environment. Mercury was not analyzed in the sequential extraction fraction because of the low levels of mercury observed in the single extraction analysis. 
The sequential extraction procedure was modified from Tessier and others (1979) to include five measurable fractions: exchangeable, bound to carbonates, bound to Fe-Mn oxides, bound to organic matter, and residual. These five fractions were measured from a series of extractions from a single $0.50 \mathrm{~g}$ aliquot of sample. The extraction process for each fraction is described in the following sections.

\section{Exchangeable Fraction (F1)}

This fraction involves the trace elements complexed to clays, hydrated oxides, and humics. This fraction was extracted at room temperature for 1 hour with $5.00 \mathrm{~mL}$ of 1 molar (M) magnesium chloride ( $\mathrm{pH}$ 7.0) under agitation on a shaker at low speed. The sample was centrifuged at 7,000 $\mathrm{g}$ for 40 minutes. The supernatant was transferred to a pre-acid cleaned sampler tube and analyzed for trace elements and iron. The residue was washed with $4 \mathrm{~mL}$ of de-ionized water, and separated from the wash by centrifuging for 40 minutes at $7,000 \mathrm{~g}$. The washed residue is used for the next extraction procedure.

\section{Bound to Carbonate Fraction (F2)}

This fraction involves metals complexed with carbonate. The fraction was prepared using the residual from the F1 extraction, and adding $5.00 \mathrm{~mL}$ of a buffered $1 \mathrm{M}$ sodium acetate solution ( $\mathrm{pH}$ 5.0). The mixture was agitated for 5 hours at room temperature, separated from the residue, and analyzed for trace elements and iron. The remaining residue was washed and used for the next extraction procedure.

\section{Iron and Manganese Oxides Fraction (F3)}

The F3 fraction accounts for trace elements associated with iron and manganese oxides. Residue from the F2 is mixed with $10 \mathrm{~mL}$ of $0.04 \mathrm{M} \mathrm{NH} \mathrm{H}_{2} \mathrm{OH} \cdot \mathrm{HCl}$ in 25 percent acetic acid (HOAc) and agitated for 6 hours at $96^{\circ} \mathrm{C}$. The mixture was centrifuged and the supernatant is analyzed for trace elements and iron. The residue is washed with de-ionized water, centrifuged, and used for the next extraction procedure.

\section{Organic Matter Fraction (F4)}

This fraction accounts for trace elements and iron associated with organic matter in the sample. The constituents are released from organic matter through oxidation. In this procedure, the $\mathrm{F} 3$ residue was mixed with $1.50 \mathrm{~mL}$ of $0.02 \mathrm{M}$ $\mathrm{HNO}_{3}$ and $2.5 \mathrm{~mL}$ of 30 percent hydrogen peroxide $\left(\mathrm{H}_{2} \mathrm{O}_{2}\right)$ and agitated for 2 hours at $85+/-2{ }^{\circ} \mathrm{C}$. Then $1.50 \mathrm{~mL}$ more of 30 percent $\mathrm{H}_{2} \mathrm{O}_{2}$ is added and agitated for 3 more hours at $85+/-2{ }^{\circ} \mathrm{C}$. After the mixture has cooled to room temperature, $2.50 \mathrm{~mL}$ of $3.20 \mathrm{M}$ ammonium acetate $\left(\mathrm{NH}_{4} \mathrm{OAc}\right)$ in 20 percent $\mathrm{HNO}_{3}$ and $2.00 \mathrm{~mL}$ de-ionized water was added and allowed to continue digestion for another 30 minutes. As with the previous fraction, the supernatant is analyzed for trace elements and iron, and the residue is washed with de-ionized water, centrifuged, and used in the next extraction procedure.

\section{Residual Fraction (F5)}

The remaining residue solid should contain mainly primary and secondary minerals that may hold trace metal elements within their crystal structure. These metal elements are not expected to be released in solution during a reasonable time span under the conditions normally encountered in nature (Tessier and others, 1979); therefore, a strong acid digestion as described in Method 3051A (U.S. Enivironmental Protection Agency, 1998) was used on the F4 fraction to extract the remaining trace elements.

An ICP-MS was used to measure all trace elements within all fractions with the exception of vanadium and chromium. The ICP-MS detection conditions were the same as those of the single extraction samples. Vanadium and chromium in the F3 (iron and manganese oxides fraction) were detected using graphite furnace atomic absorption (GFAA) spectrometry because matrix interference was encountered using the ICP-MS method. A Perkin Elmer Analyst 600 GFAA was used. The samples were diluted with 1 percent $\mathrm{HNO}_{3}$ before analysis. A cleaning reagent ( 0.2 percent Triton$\mathrm{X}$ and 1 percent nitric acid in de-ionized water) was used to flush the inlet between each sample; the matrix modifier used was $0.015 \mathrm{mg}$ of $\mathrm{Mg}\left(\mathrm{NO}_{3}\right)_{2}$. Vandium and chromium were analyzed at $318.4 \mathrm{~nm}$ and $357.9 \mathrm{~nm}$, respectively, with vanadium and chromium Hollow Cathode Lamps as light sources. The instrument was optimized and calibrated by following the manufacturer's instructions.

\section{Pesticide and Polychlorinated Biphenyl Extraction}

Pesticide and PCB were extracted simultaneously from soil samples by ultrasonic extraction using the modified USEPA Method 3550C (U.S. Enivironmental Protection Agency, 2000). Eight $\mathrm{g}$ of sample was added to a $40-\mathrm{mL}$ glass vial, then $6 \mathrm{~g}$ of pre-heated anhydrous sodium sulfate was added to the vial. After mixing, 15 microliters $(\mu \mathrm{L})$ pentachloronitrobenzene (PCNB, 5 parts per million ( $\mathrm{ppm}$ ) in acetone) of surrogate was added. Before extraction, $17 \mathrm{~mL}$ of acetone/hexane (1:1) mixture was added. The sample was well mixed on a vortex mixer, then placed in an ultrasonic water bath and extracted for 20 minutes. The sample was centrifuged for 10 minutes at 1,000 revolutions per minute (rpm) with a clinical centrifuge and the supernatant was transferred into a graduated conical centrifuge tube. The residue was extracted for a second time with $13 \mathrm{~mL}$ of hexane/acetone mixture using the same procedure as the first extraction. Following the second extraction, the extractant was evaporated by a Turbo Vap LV Evaporator to $3.00 \mathrm{~mL}$ to increase the concentration. The final extract was dried with anhydrous sodium sulfate $\left(\mathrm{Na}_{2} \mathrm{SO}_{4}\right)$ and centrifuged to remove any particles before instrument analysis. The extracted sample was stored in an amber vial at $4^{\circ} \mathrm{C}$ before analysis.

For this study, 20 samples per batch run were extracted; each batch run contained a laboratory reagent blank, a fortified reagent blank (reagent spike), a laboratory fortified sample 
(sample spike), and a sample duplicate. An ultrasonic water bath instead of an ultrasonic probe was used to improve the efficiency of processing large sample batches. This extraction method was verified by performing a series of fortified reagent blank extractions and fortified sample extractions before sample extraction. The results of this verification are presented in the "Quality Assurance" section of this report.

\section{Gas Chromatograph-Electron Capture Detection}

Gas Chromatograph Electron Capture Detection (GCECD) analysis was done using USEPA Method 8082 (U.S. Enivironmental Protection Agency, 1996). One mL of extracted sample was transferred into a gas chromatograph auto-sampler vial, then $5 \mu \mathrm{L}$ of 2,4,5,6-tetrachloro-m-xylene (TCX, 5.00 $(\mathrm{mg} / \mathrm{L})$ in acetone), the internal standard, was added to make a final concentration of 25.0 micrograms per liter $(\mu \mathrm{g} / \mathrm{L})$. An Agilent model 6890 Gas Chromatograph (GC) with a microelectron capture detector and a liquid auto-sampler was used for the analysis; two $\mu \mathrm{L}$ of sample was injected into the $\mathrm{GC}$ using the splitless mode. An Agilent HP-5 column [30.0 m x 0.32 millimeter (mm), 0.25-micrometer ( $\mu \mathrm{m})$ film thickness] was used for separation. The carrier gas used was high purity nitrogen at 16.0 pounds per square inch (psi) constant column head pressure. The inlet and detector temperatures were controlled at $225^{\circ} \mathrm{C}$ and $300{ }^{\circ} \mathrm{C}$, respectively. The oven gradient temperatures were set at $100{ }^{\circ} \mathrm{C}$ for 2 minutes, then increased to $160{ }^{\circ} \mathrm{C}$ for 15 degrees Celsius per minute $\left({ }^{\circ} \mathrm{C} /\right.$ minutes $)$, followed by $5{ }^{\circ} \mathrm{C} /$ minute to $270{ }^{\circ} \mathrm{C}$ and held for 2 minutes. All data were recorded and processed using Chemstation software.

\section{Gas Chromatograph-Mass Spectrometry}

Gas Chromatograph-Mass Spectrometry (GC-MS) analysis was done using USEPA Method 508 (U.S. Environmental Protection Agency, 1995). For this analysis, $0.5 \mathrm{~mL}$ of extracted sample was transferred into a GC auto-sampler vial, then $25 \mu \mathrm{L}$ of $\mathrm{d}_{10}$-phenanthrene (10 mg/L in isooctane) internal standard was added to the vial to make a final concentration of $500 \mu \mathrm{g} / \mathrm{L}$. An Agilent 6890 gas chromatograph with a $5973 \mathrm{~N}$ mass spectral detector equipped with a liquid auto-sampler was used for this analysis. Mass separation was done using a Hewelwtt-Packard-5 ms column (30 m x 250 $\mu \mathrm{m}, 0.25-\mu \mathrm{m}$ film thickness); two $\mu \mathrm{L}$ sample was injected into the instrument using splitless mode. The carrier gas used was high purity helium at a constant flow rate of $1 \mathrm{~mL} / \mathrm{min}$. The sample inlet, mass spectral quad detector, and source temperature was $280^{\circ} \mathrm{C}, 150^{\circ} \mathrm{C}$, and $230^{\circ} \mathrm{C}$, respectively. The oven temperature was programmed as: Initial temperature $100{ }^{\circ} \mathrm{C}$, then rammed at $40{ }^{\circ} \mathrm{C} / \mathrm{min}$ to $170{ }^{\circ} \mathrm{C}$ followed by $3{ }^{\circ} \mathrm{C} / \mathrm{min}$ to $185^{\circ} \mathrm{C}$, then at $10{ }^{\circ} \mathrm{C} / \mathrm{min}$ to $220{ }^{\circ} \mathrm{C}$, and finally $60{ }^{\circ} \mathrm{C} / \mathrm{min}$ to $280{ }^{\circ} \mathrm{C}$ and held for 6.75 minutes. The total run time was 18 minutes. Selected ion monitoring mode was used for quantification of the pesticides atrazine, simazine, heptachlor, methoxychlor, and prometon. The quantification ions and the qualifier ions for each pesticide detection are listed in table 1. All data were recorded and processed using Hewelett-Packard Chemstation software.

Table 1. Quantification ion and qualifier ion data for the Gas Chromatograph-Mass Spectrometry methods used for environmental samples.

[MW, molecular weight; --, no data]

\begin{tabular}{lcccc}
\hline \multicolumn{1}{c}{ Pesticide } & MW & $\begin{array}{c}\text { Quantification } \\
\text { ion mass }\end{array}$ & $\begin{array}{c}\text { Qualifier } \\
\text { ion 1 }\end{array}$ & $\begin{array}{c}\text { Qualifier } \\
\text { ion 2 }\end{array}$ \\
\hline Atrazine & 216 & 200 & 215 & 173 \\
Simazine & 202 & 201 & 186 & 173 \\
Heptachlor & 373 & 272 & 237 & -- \\
Methoxychlor & 346 & 227 & 152 & 169 \\
Prometon & 225 & 210 & 225 & 183 \\
Phenanthrene-d & & & \\
$\quad$ (Internal Standard) & 188 & 188 & 160 & -- \\
\hline
\end{tabular}

\section{Chemical Data Quality Assurance}

This section will provide the user of these data with the assurance that they meet defined standards of quality with a stated level of confidence (U.S. Environmental Protection Agency, 1998, 2002a; Taylor, 1987). Because these analyses were done by a research laboratory and not a production laboratory where rigorous quality assurance plans exist, it is necessary to publish the laboratory quality assurance procedures and results for this study.

\section{Total Organic Carbon and Inorganic Carbon Data Quality}

The quality assurance procedures used for TOC analysis are consistent with those present in the analysis method (U.S. Environmental Protection Agency, 2002b) and the instrument's operation manual. The Sklar Primacs carbon analyzer was calibrated before analysis using increasing weights of calcium carbonate (10 to $100 \mathrm{mg}$ ) to establish a calibration curve. A duplicate sample was run with each group of 10 unknowns to establish analytical precision. Results of these duplicates indicate that the precision of analysis is excellent for the TOC and inorganic carbon results. Calibration checks and standard soil check samples were run before and after each group of 10 unknowns. Five reference standard samples ranging from 0.46 to 12.0 percent carbon were measured as part of the analytical precision checks. All 31 analyses of these five standards were within acceptable limits of +/- 20 percent.

\section{Trace Element and Iron Data Quality}

U.S. Environmental Protection Agency Methods 3051A and 200.8 in this study were used to analyze 157 samples. The 
following sections describe the instrument calibration, method detection limits, control samples, and other validations for these environmental data.

\section{Instrument Calibration}

For all of the detection methods and instruments used in this study, the instrument responses were calibrated with standard solutions using a range of concentrations. The estimated instrument detection limits were calculated at 3 to 5 times of signal/noise ratio. The linear ranges of the calibration were determined and used for the quantitative analysis of the samples.

Initial calibration was performed with the element concentrations of $0.02,0.1,1,10,100,500$, and 1,000 $\mu \mathrm{g} / \mathrm{L}$. All element calibration curves were linear up to $1 \mathrm{mg} / \mathrm{L}$ with ICPMS detection methods. This linearity was consistent with the observed range of concentrations in the environmental samples.

\section{Method Detection Limit}

The Method Detection Limit (MDL) is based on the ability of a method to determine an analyte in a sample matrix regardless of its source of origin (Taylor, 1987). The quantitative MDL for this study was determined by fortifying reagent blanks with 2 to 5 times the concentration of the estimated instrument detection limit. This represents the lower limit of analyte detection with 99 percent confidence (table 2). Seven replicates were analyzed and results were used to calculate the MDL using the equation:

$$
\mathrm{MDL}=\mathrm{SD} \times \mathrm{t}
$$

where:

SD is the standard deviation of the replicated
analysis, and
$\mathrm{t}$ is the student's t value for a 99 percent
confidence level and a standard deviation
estimate with $\mathrm{n}-1$ degrees of freedom $(\mathrm{t}=$
3.14 for 7 replicates $)$.

Table 2. Method detection limit for each element.

[MDL, method detection limit; mg/kg, milligram/kilogram]

\begin{tabular}{lcc}
\hline & \multicolumn{2}{c}{ MDL in dry soil (mg/kg) } \\
\cline { 2 - 3 } \multicolumn{1}{c}{ Element } & Single extraction & Sequential extraction \\
\hline Vanadium & 0.14 & 1.00 \\
Chromium & 0.59 & 1.00 \\
Copper & 0.36 & 0.40 \\
Cadmium & 0.06 & 0.01 \\
Lead & 0.07 & 0.10 \\
Arsenic & 0.12 & 0.10 \\
Mercury & 0.02 & None \\
Iron & 15.0 & 15.0 \\
\hline
\end{tabular}

\section{Laboratory Reagent Blank}

The purpose of a Laboratory Reagent Blank (LRB) is to define error from sources external to the environmental sample. These sources of error or contamination potentially can be introduced from the laboratory environment, the reagents used in the analysis, the analytical instruments, and the analyst. At least one LRB was prepared and measured for each batch run of up to 20 samples. Laboratory Reagent Blanks were prepared and measured using the same procedure as for the environmental samples. The nine LRBs and results for each trace element measured by USEPA Methods 3051A and 200.8 are listed in table 3. Theoretically, these LRBs should have no detectable concentrations of elements. Vanadium was detected eight times above the MDL of 0.14 milligram per kilogram $(\mathrm{mg} / \mathrm{kg})$, but more than one order of magnitude lower than the typical environmental sample concentration. In some LRBs, mercury had detectable concentrations above the MDL. Generally, results indicated that contamination is not being introduced into the samples from external sources that would appreciably compromise the results of the environmental samples. No correction for blank concentrations was employed in the final environmental sample results.

Table 3. Results of laboratory reagent blank samples.

[All concentrations in units of milligrams per kilogram; LRB, laboratory reagent blank; $\mathrm{ND}$, no detection]

\begin{tabular}{|c|c|c|c|c|c|c|c|}
\hline LRB & Vanadium & Chromium & Copper & Cadmium & Lead & Arsenic & Mercury \\
\hline 1 & 0.23 & ND & ND & ND & ND & ND & ND \\
\hline 2 & 0.33 & ND & ND & ND & ND & ND & ND \\
\hline 3 & 1.05 & ND & ND & ND & ND & ND & ND \\
\hline 4 & 0.83 & ND & ND & ND & ND & ND & ND \\
\hline 5 & ND & ND & ND & ND & ND & ND & ND \\
\hline 6 & 0.68 & ND & ND & ND & ND & ND & 0.02 \\
\hline 7 & 0.52 & ND & ND & ND & ND & ND & 0.03 \\
\hline 8 & 0.41 & ND & ND & ND & ND & ND & 0.02 \\
\hline Replicate & 0.44 & ND & ND & ND & ND & ND & 0.03 \\
\hline
\end{tabular}

\section{Reference Standard Samples}

Reference standards are used to test the recovery of analytes by the analytical instrumentation. For the ICP-MS analysis, two standards were used to check the method performance. Reference standard 1 was certified drinking water (Cat \# CRM-RMDW-A ), and reference standard 2 was certified wastewater (Cat\# CWW-TM-C ). The method validation and quality assurance were performed by spiking these standards into the environmental samples before digestion, followed by analysis using USEPA Method 200.8 for each batch run (U.S. Environmental Protection Agency, 1994). Although certified soil samples would have been the better reference standard to use, using certified water reference standards is an acceptable substitute for this method performance validation and allowed us to consider matrix interference in the recovery results. Results of reference standard recoveries are presented in table 4. 
Table 4. Results of drinking water and waste water reference standard sample recovery.

[ $\mu \mathrm{g} / \mathrm{L}$, microgram per liter; mg/L, milligram per liter]

\begin{tabular}{|c|c|c|c|c|c|c|}
\hline \multirow[b]{2}{*}{ Element } & \multirow[b]{2}{*}{$\begin{array}{c}\text { Certified } \\
\text { concentration }\end{array}$} & \multicolumn{2}{|c|}{ Reference standard $1(\mu \mathrm{g} / \mathrm{L})$} & \multirow[b]{2}{*}{$\begin{array}{c}\text { Certified } \\
\text { concentration }\end{array}$} & \multicolumn{2}{|c|}{ Reference standard 2 (mg/L) } \\
\hline & & $\begin{array}{c}\text { Detected } \\
\text { concentration }\end{array}$ & Percent recovery & & $\begin{array}{c}\text { Detected } \\
\text { concentration }\end{array}$ & Percent recovery \\
\hline Vanadium & 35.0 & 41.6 & 119 & 50.0 & 47.1 & 94.3 \\
\hline Chromium & 20.0 & 20.6 & 103 & 50.0 & 47.0 & 93.9 \\
\hline Copper & 20.0 & 21.7 & 108 & 50.0 & 54.6 & 109 \\
\hline Cadmium & 10.0 & 11.2 & 112 & 15.0 & 15.9 & 106 \\
\hline Lead & 20.0 & 20.1 & 101 & 50.0 & 48.0 & 96.0 \\
\hline Arsenic & 55.0 & 57.5 & 105 & 15.0 & 16.0 & 107 \\
\hline
\end{tabular}

\section{Laboratory Fortified Samples}

Laboratory fortified samples (LFS), also called sample spikes, are used to test or validate the recovery of analytes from spiked samples. When the appropriate sample reference is absent, the LFS is done to validate the method performance and to confirm that the sample matrix is not interfering with analyte detection. A LFS was performed with each batch run of up to 20 samples. A known amount of the standard was added to the sample and mixed well, and the extraction and analysis were performed using the same procedures as for the environmental samples. The percent recovery of the LFS was calculated by the equation listed below; and the results are presented in table 5. Generally, recovery of the known analyte quantity was good for all elements except cadmium. It is not known why cadmium recovery was a problem, but seems to be related to the sample matrix because the fortified blank recoveries were excellent for all trace elements (table 5).

$$
\% \text { Recovery }=100 \times\left(\mathrm{C}_{\mathrm{fs}}-\mathrm{C}_{\mathrm{s}}\right) / \mathrm{C}_{\text {add }}
$$

where:

$\mathrm{C}_{\mathrm{fs}} \quad$ is the detected fortified sample concentration,

$\mathrm{C}_{\mathrm{s}}$ is the detected sample concentration, and

$\mathrm{C}_{\text {add }}$ is the concentration of standard added.

Table 5. Results of laboratory fortified samples.

[All results represent percent recovery; LFS, laboratory fortified sample; SPK, spike; --, no data]

\begin{tabular}{cccccccc}
\hline LFS-SPK Vanadium Chromium & Copper & Cadmium & Lead & \multicolumn{2}{c}{ Arsenic } & Mercury \\
\hline 8 & -- & -- & -- & -- & -- & -- & 99.3 \\
19 & 105 & 101 & 86.5 & 69.1 & 105 & 112 & 92.8 \\
29 & 82.3 & 94.9 & 85.3 & 83 & 77.7 & 94.8 & 102 \\
46 & 120 & 93.6 & 80.6 & 82 & 93.3 & 84.2 & 119 \\
99 & 87.5 & 93.1 & 81.9 & 84.9 & 126 & 111 & 100 \\
116 & 114 & 103 & 103 & 93.2 & 103 & 108 & 89.4 \\
121 & 109 & 103 & 97.6 & 66.7 & 97.9 & 100 & 97.3 \\
\hline
\end{tabular}

\section{Laboratory Fortified Blanks}

Laboratory Fortified Blanks (LFB) were used to test the recovery of each trace analyte in the absence of matrix interference. Three LFBs were analyzed using the same methods for the environmental samples. Each blank was spiked with a known amount of the standard and analyzed. The percent recovery was calculated using the formula below, and the results are given in table 6. Overall, the percent recovery for all of the elements was within 80 to120 percent. The lower mercury recovery may be because of the volatile nature of this trace element and possible loss during analysis.

$$
\begin{gathered}
\% \text { Recovery }=100 \times \text { Concentration detected } \\
/ \text { Concentration added }
\end{gathered}
$$

Table 6. Results of laboratory fortified blanks.

[All results represent percent recovery;LFB, laboratory fortified blank; SPK, spike]

\begin{tabular}{cccccccc}
\hline LFB-SPK Vanadium & Chromium & Copper & Cadmium & Lead & \multicolumn{2}{c}{ Arsenic } & Mercury \\
\hline 1 & 115 & 118 & 118 & 117 & 121 & 121 & 97.8 \\
2 & 115 & 107 & 113 & 108 & 111 & 109 & 82.3 \\
3 & 102 & 94.1 & 101 & 101 & 101 & 97.8 & 90.9 \\
\hline
\end{tabular}

\section{Calibration Check}

To monitor the instrument performance, standard solutions were measured during batch runs. At least one standard solution was measured for every 10 to 15 samples to ensure the instrument is calibrated and working properly; calibration checks during sample analysis are shown in table 7.

\section{Precision of Duplicated Samples}

One or more duplicate samples were analyzed for each batch of up to 20 samples. Duplicates were measured for single and sequential extraction methods (tables 8 and 9). 
The precision of the duplication is expressed as the relative percent difference (RPD) and is calculated using the equation below. Based on USEPA guidance for sampling and analysis of sediments, the quality control criterion for analysis precision should be no greater than 30 to 50 percent RPD (U.S.

Environmental Protection Agency, 2002a). Considering this criterion, the precision of analysis for post-hurricane samples is excellent.

$$
\mathrm{RPD}=100 \times\left(\mathrm{C}_{\mathrm{h}}-\mathrm{C}_{1}\right) / \mathrm{C}_{\mathrm{av}}
$$

where

$$
\begin{gathered}
\mathrm{C}_{\mathrm{h}} \quad \text { is detected high concentration of duplicated } \\
\text { sample, } \\
\mathrm{C}_{1} \quad \text { is detected low concentration of duplicated } \\
\mathrm{C}_{\mathrm{av}} \quad \text { is the average of the } \mathrm{C}_{\mathrm{h}} \text { and } \mathrm{C}_{1}
\end{gathered}
$$

Table 7. Results of calibration checks.

[All results represent percent recovery]

\begin{tabular}{cccccccc}
\hline $\begin{array}{c}\text { Calibration } \\
\text { check }\end{array}$ & \multicolumn{1}{c}{ Vanadium Chromium } & Copper & Cadmium & Lead & Arsenic & Mercury \\
\hline 1 & 97.8 & 97.2 & 97.3 & 93.5 & 95.8 & 92.9 & 95.5 \\
2 & 96.1 & 96.1 & 96.5 & 90.5 & 94.6 & 95.2 & 98.6 \\
3 & 96.2 & 95.8 & 98.1 & 88.3 & 95.6 & 96.8 & 104 \\
4 & 96.3 & 96.8 & 96.9 & 94.3 & 96 & 95.8 & 101 \\
5 & 91 & 90.5 & 89 & 92 & 91 & 117 & 101 \\
6 & 98.9 & 99.5 & 99.9 & 97.2 & 99.5 & 104 & 103 \\
7 & 96.2 & 101 & 111 & 95.3 & 99.9 & 98.8 & 91 \\
8 & 107 & 96.1 & 104 & 103 & 106 & 102 & 92.1 \\
9 & 106 & 105 & 103 & 107 & 105 & 122 & 95.6 \\
\hline
\end{tabular}

Table 8. Results of single extraction duplicate samples used to measure the precision of analysis.

[All results represent percent difference; D, duplicate; --, no data]

\begin{tabular}{cccccccccc}
\hline $\begin{array}{c}\text { Sample } \\
\text { number } \\
\text { pairs }\end{array}$ & Vanadium Chromium & Copper Cadmium & Lead & Arsenic & Mercury & Iron \\
\hline 8/8-D & 12.8 & 12.3 & 0.80 & 3.80 & 5.20 & 12 & 8.60 & 10.9 \\
19/19-D & 2.80 & 6.60 & 4.20 & 10.0 & 5.00 & 9.10 & 4.20 & 4.40 \\
29/29-D & 14.7 & 12.1 & 4.40 & 1.30 & 5.30 & 9.10 & -- & 5.50 \\
$46 / 46-D$ & 3.10 & 8.20 & 5.40 & 16.8 & 0.60 & 57.2 & 0.00 & 17.6 \\
66/66-D & 3.60 & 4.80 & 2.30 & 1.30 & 1.40 & 6.60 & 4.40 & 1.90 \\
99/99-D & 7.40 & 0.70 & 4.50 & 9.00 & 0.90 & 8.30 & 8.00 & 5.60 \\
116/116-D & 12.4 & 2.90 & 12.6 & 35.9 & 4.10 & 16.1 & 19.2 & 4.90 \\
121/121-D & 2.70 & 5.30 & 50.8 & 8.40 & 6.90 & 9.10 & 10.7 & 4.00 \\
\hline
\end{tabular}

\section{Pesticide and Polychlorinated Biphenyl Data Quality}

\section{Gas Chromatograph-Electron Capture Detection}

The pesticides and the arochlors were detected simultaneously by Gas Chromatograph-Electron Capture Detection (GC-ECD). Upon review of the chromatograms, atrazine, simazine, heptachlor, methoxychlor, surrogate pentachloronitrobenzene, and internal standard 2,4,5,6-tetrachloro-m-xylene were well separated with the two Aroclor standards 1016 and 1260.

\section{Instrument Calibration}

Initial calibration was performed with seven points standards at the concentration ranges of $0.05 \mathrm{ppm}$ to $10 \mathrm{ppm}$ of atrazine, simazine, Arochlor 1016 and 1260; 1.00 parts per billion (ppb) to $2 \mathrm{ppb}$ heptachlor, $2.00 \mathrm{ppb}$ to $400 \mathrm{ppb}$ methoxthychlor. The linear ranges of atrazine, simazine, and the Aroclors were up to 3 ppm whereas heptachlor and methoxchlor calibration curve were linear for all of seven concentrations used for calibration. The correlation coefficient for each pesticide and the two Arochlor endmember congeners was 0.99 , indicating that excellent instrument calibration was achieved.

\section{Method Detection Limit}

The MDL were determined by fortifying low concentration standards into the reagent blank. The same method of calculating MDLs for the trace elements was used for pesticides and the polychlorinated biphenyl Arochlor congeners. The MDLs for pesticides and Arochlor congeners are listed in table 10 .

\section{Laboratory Fortified Blank}

Laboratory Fortified Blanks (LFB) were used to test the recovery of each compound in the absence of matrix interference; results are shown in table 11. Recovery of spiked pesticide compound concentrations was good for all pesticides with the exception of simazine. Aroclor congener 1016, 1260 and surrogate penta chloronitrobenzene (PCHB) had acceptable recoveries. Recovery for surrogate compounds are considered acceptable when they range between 70 to 130 percent (U.S. Environmental Protection Agency, 1995).

\section{Laboratory Fortified Sample}

Laboratory Fortified Samples (LFS) are used to test the effects of the sample matrix on the recovery of spiked sample media. Results indicate that the recovery of spiked concentrations of pesticides and PCB Arochlors generally were good (table 12). Two samples could not be quantified because the background concentration was too large. 


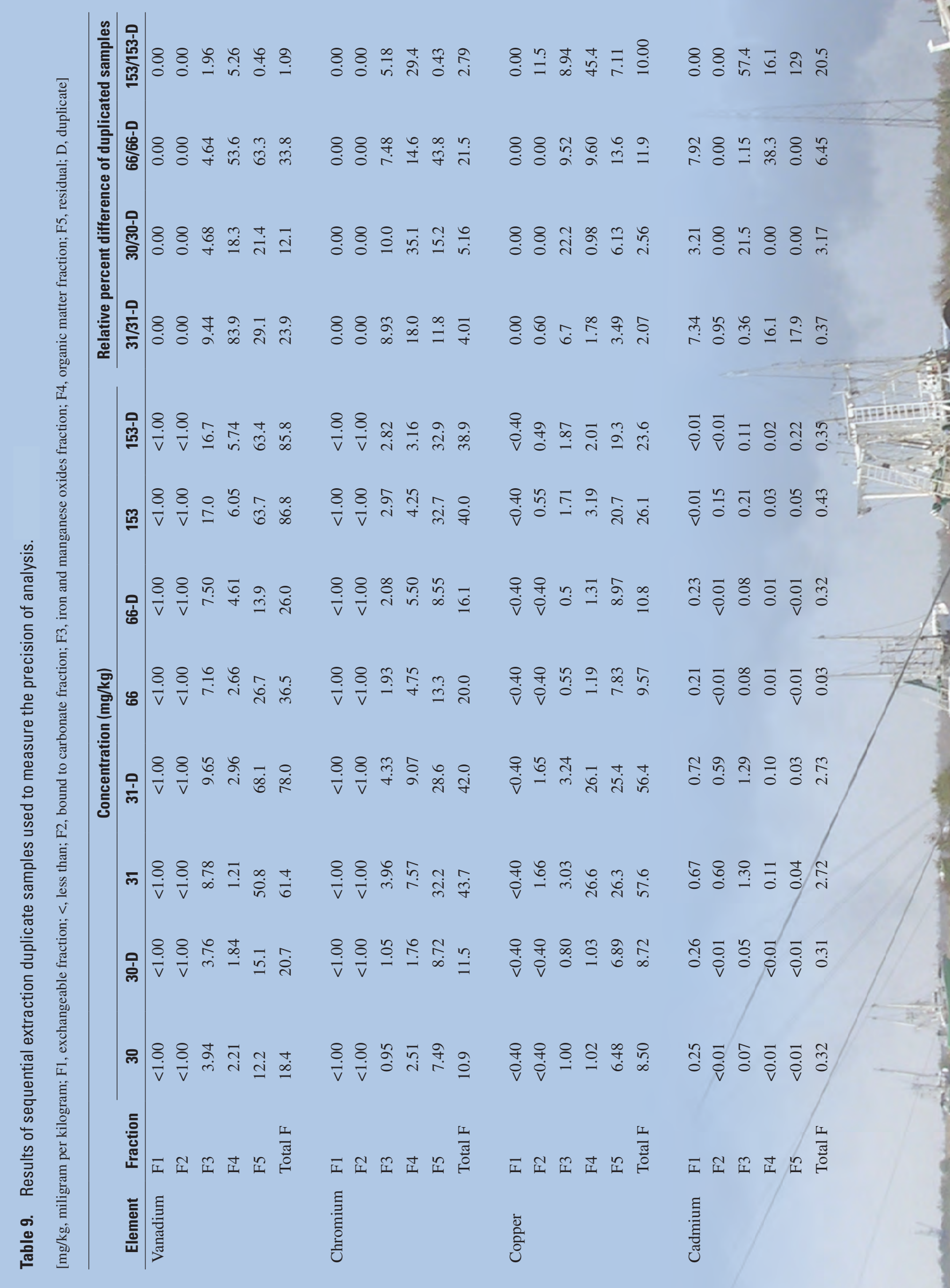




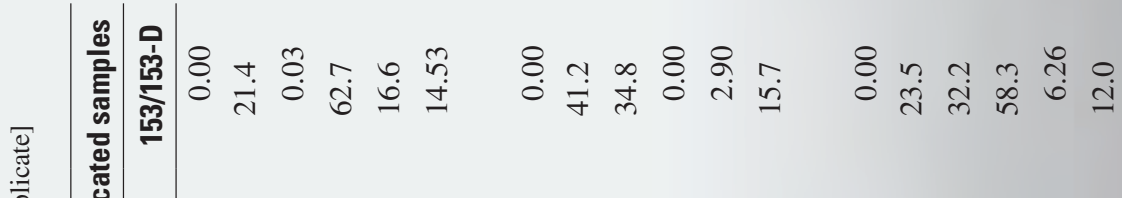

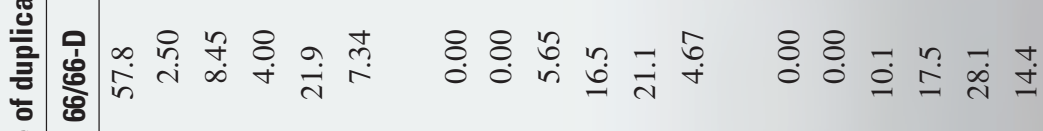

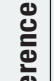

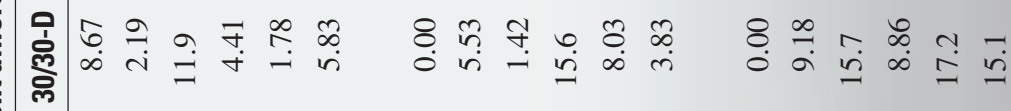

总

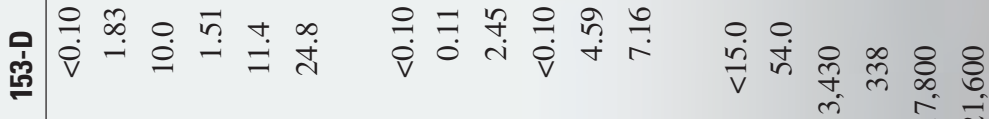

m

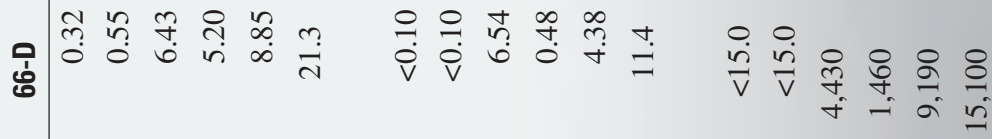

产

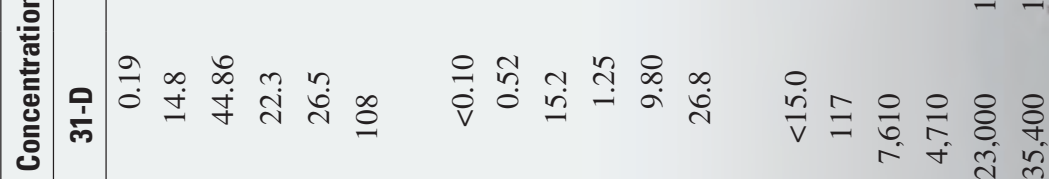

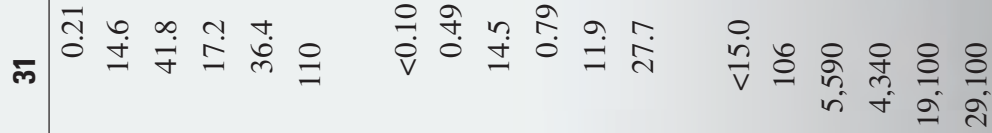

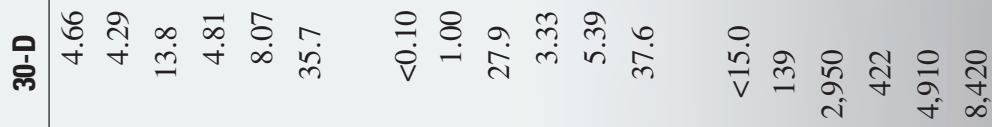

$x+1+1$

i.

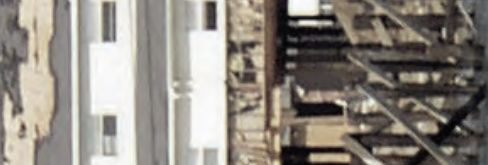

I 11 in $=25:$
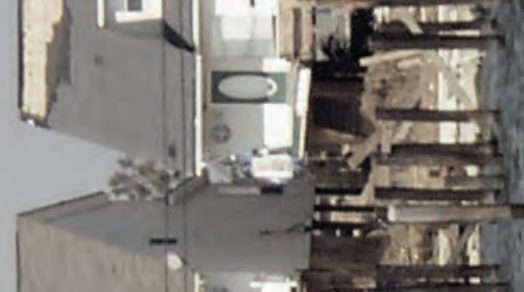

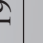


Table 10. Method detection limit of pesticides and arochlor by Gas Chromatograph-Electron Capture Detection.

[MDL, method detection limit; $\mu \mathrm{g} / \mathrm{kg}$, microgram per kilogram]

\begin{tabular}{lc}
\hline \multicolumn{1}{c}{ Compound } & MDL $(\boldsymbol{\mu g} / \mathbf{k g}$ dry soil) \\
\hline Simazine & 11.8 \\
Atrazine & 9.40 \\
Heptachlor & 0.40 \\
Methoxychlor & 0.40 \\
Arochlor 1016 & 7.90 \\
Arochlor 1221 & 7.90 \\
Arochlor 1232 & 7.90 \\
Arochlor 1242 & 7.90 \\
Arochlor 1248 & 7.90 \\
Arochlor 1254 & 7.90 \\
Arochlor 1260 & 3.60 \\
\hline
\end{tabular}

Table 11. Results of laboratory fortified blanks for pesticides, Arochlor, and surrogate compounds.

[All results represent percent recovery; LFB, lab fortified blank; RSPK, reagent spike; PCNB, penta chloronitrobenzene; --, no data]

\begin{tabular}{cccccccc}
\hline LFB- & & & \multicolumn{4}{c}{ Meth- } & Arochlor Arochlor Surrogate \\
RSPK & Simazine & Atrazine & Heptachlor oxychlor & $\mathbf{1 0 1 6}$ & $\mathbf{1 2 6 0}$ & PCNB \\
\hline 1 & 87.2 & 108 & 118 & 104 & -- & -- & -- \\
2 & 83.8 & 96.3 & 118 & 109 & 86.4 & 99 & 80.4 \\
3 & 79.9 & 85.2 & 111 & 97.1 & 104 & 98.9 & 91.0 \\
4 & 84.8 & 106 & 85.0 & -- & 92.2 & 99.1 & 91.4 \\
\hline
\end{tabular}

\section{Gas Chromatograph-Mass Spectrometry Method}

Instrument Calibration

Some samples were analyzed by Gas ChromatographMass Spectrometry Method (GC-MS). For example, samples with high background concentrations precluded the use of GCECD detection. GC-MS also was used to confirm pesticides concentrations detected by the GC-ECD analysis.
A 10-points initial calibration was performed for the pesticides prometon, simazine, atrazine, heptachlor, and methoxychlor at concentrations ranging from 2.00 to 1,000 $\mathrm{ug} / \mathrm{L}$. All of the pesticides calibrations were linear within these calibration ranges. Methoxychlor calibration was specifically linear within the concentration range of $10.0 \mathrm{ug} / \mathrm{L}$ to 1,000 ug/L. A correlation coefficient of calibration better than 0.99 was determined for all pesticide compounds measured.

\section{Method Detection Limit}

The MDLs were determined by fortifying low concentration standards into seven replicates of reagent blank. The MDLs of the pesticides calculated for prometon, simazine, atrazine heptachlor, and methoxychlor are $0.67,0.44,0.27$, 0.44 , and 3.47 microgram per kilogram $(\mu \mathrm{g} / \mathrm{kg})$, respectively.

\section{Environmental Chemical Data}

The chemical constituents selected for this analysis were thought to be the constituents most likely to be bonded with sediments following the mixing of sediment and water with the diverse hurricane debris consisting of automobiles, boats, household wastes, building materials, industrial equipment, and assorted chemicals. This reporting is limited to the presentation of the distribution of data within the dataset. No analysis has been conducted to relate the concentrations data with the areas where the samples were collected, however, with respect to organic carbon results, a description of the general locations of the sample results is given to facilitate the understanding of the likelihood of their occurrence. It is solely up to the reader to make that assessment based on the sampling locations presented in figure 5 and the concentration data contained in table13, at the back of this report.

\section{Total Organic Carbon Results}

The 2005 storm season transported massive amounts of organic carbon to New Orleans and the Delta by inundating the surrounding areas with floodwaters and debris. The source

Table 12. Results of laboratory fortified sample recovery for pesticides, arochlor, and surrogate compounds.

[All results represent percent recovery; LFS, lab fortified sample; SPK, spike; PCNB, penta chloronitrobenzene; --, no data]

\begin{tabular}{cccccccc}
\hline LFS-SPK & Simazine & Atrazine & Heptachlor & Methoxychlor & Arochlor 1016 & Arochlor 1260 & $\begin{array}{c}\text { Surrogate } \\
\text { PCNB }\end{array}$ \\
\hline 12 & 94.7 & 98.1 & 115.2 & -- & 95.2 & 97.0 & 86.7 \\
20 & 110 & 116 & 100 & -- & 94.7 & 95.3 & 87.5 \\
46 & 93.8 & 90.3 & 87.6 & 97 & 92.2 & 101 & -- \\
85 & 101 & 101 & 79.3 & -- & 94.2 & 99.6 & 100 \\
125 & -- & 78.8 & 121 & 84.5 & 85.7 & 103 & 87.1 \\
137 & 87.4 & 88.9 & 122 & 112 & 97.0 & 103 & 82.9 \\
\hline
\end{tabular}


of most of the carbon came from the upper layer of soils within the marshes, swamps, surface/subsurface hydrologic features surrounding the area, and transported anthropogenic debris.

This study indicated that the TOC generally is larger in the northern sample points of the study area. One of the dominating trace element adsorbing surfaces in this part of the study area is the organic matter. Since most of the northern section of the study area is made up of silt, clay, peat, and organic matter, trace elements are adsorbed easily. Osgood and Zieman (1993) and Osgood and others (1995) determined that sandy marsh sediments associated with marshes in Virginia had lower organic content than siltier sites nearby. Additionally, as the silt-clay content (percent of dry weight) of a soil increases so does the TOC (percent of dry weight) (National Oceanic and Atmosheric Administration, 2004). This helps to explain why the TOC values in the northern section of the study area are larger than the values in the southern areas where the soil becomes sandier and grain size becomes coarser.

There were 150 samples processed for percent TOC; seven samples did not have enough sediment remaining to be processed (table 13). Values ranged from 0.01 to 17.9 percent in dry soil. A regression analysis was conducted between TOC and $\mathrm{V}, \mathrm{Cr}, \mathrm{Cu}, \mathrm{Cd}, \mathrm{Pb}, \mathrm{As}, \mathrm{Hg}$, and $\mathrm{Fe}$; however, no correlation was observed. Graphical results of the regression analysis are not presented in this report

\section{Trace Element and Iron Single Extraction Results}

The sample results for total digested trace element analysis for $\mathrm{V}, \mathrm{Cd}, \mathrm{Cr}, \mathrm{Cu}, \mathrm{Pb}, \mathrm{As}$, and $\mathrm{Hg}$, along with summary statistics, are listed in table 13 , and the distribution of these results, sorted by element, are shown in figure 7. The largest range in constituent concentration variability in decreasing order, was observed for $\mathrm{Pb}, \mathrm{V}, \mathrm{Cr}, \mathrm{Cu}, \mathrm{As}, \mathrm{Cd}$, and $\mathrm{Hg}$. A single sample had a copper concentration of 960 $\mathrm{mg} / \mathrm{kg}$, and represented the largest concentration of all the analyzed trace elements. Also, this concentration represented a significant outlier in the copper dataset and did not relate to the other trace element concentrations determined for the same sample.

Generally, lead concentration was observed to be consistently larger than the detection level for all samples, and ranged from 4.50 to $551 \mathrm{mg} / \mathrm{kg}$. The large range and large overall concentrations for lead in sediments is consistent with pre-hurricane lead studies of residential soils in New Orleans (Mielke and others, 2007, 2000, 1997, 1999, and 2006). This finding suggests that debris from the hurricane may not have increased lead concentration, but the hurricane itself was responsible for redistributing already contaminated sediments and soils throughout New Orleans and the Delta. It should be noted that the USEPA has established a $400 \mathrm{ppm}$ by weight lead standard for bare residential soils in child playground areas and an average concentration of 1,200 ppm in non-playground areas (U.S. Environmental Protection Agency, 2006a). Results of this analysis identified only two samples with concentrations exceeding the lower standard; nevertheless, the USEPA standard suggests that a lead hazard may occur from the creation of dust during the sediment removal process in New Orleans. Sediment removal is not a concern in the Delta region where the landscape primarily is rural and storm-related sediment deposition was minimal.

Vanadium concentrations in samples represented the most normal distribution of all constituents measured, ranging from 5.7 to $92.1 \mathrm{mg} / \mathrm{kg}$. There were no extreme outlier concentrations of vanadium for any sample, which is consistent with

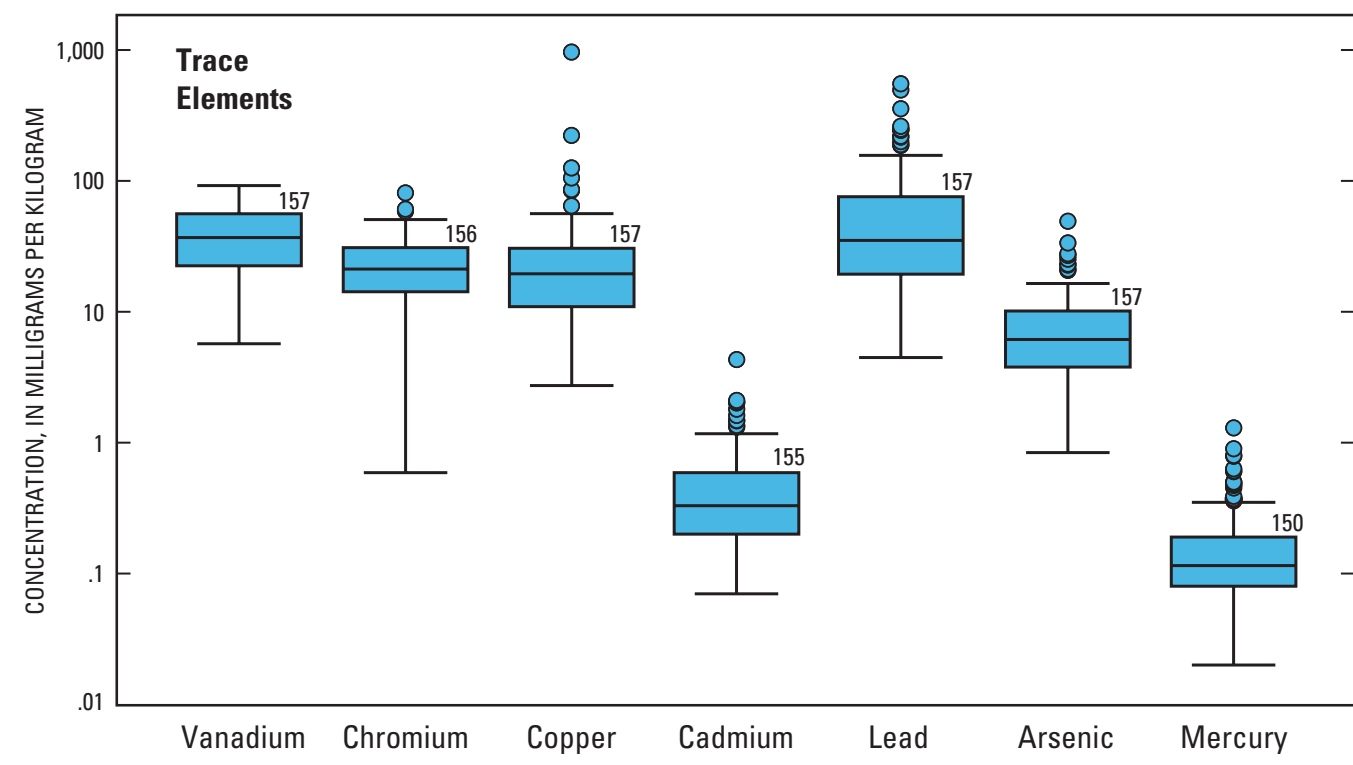

EXPLANATION

Percentile-Percentage of analyses equal to or less than indicated value

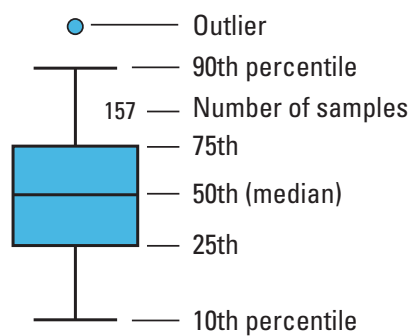

Figure 7. Boxplots showing the distribution and range of trace element data analyzed using the single extraction method. 
pre-hurricane studies of fresh Mississippi River delta alluvium and New Orleans alluvial soils (Mielke and others, 2000). Vanadium is associated with automotive waste, machinery, and some industrial processes linked to the southern Louisiana region. Overall, the concentration levels observed from these samples do not indicate a substantial hurricane affected contamination problem.

Chromium and copper tend to have similar variable relations with the exception of the number of outliers (fig. 7). Chromium ranged from 0.59 to $81.1 \mathrm{mg} / \mathrm{kg}$ and its data distribution only possessed two extreme outliers (fig. 7), but are within the range of concentrations (non-detect to $205 \mathrm{mg}$ / $\mathrm{kg}$ for urban New Orleans; 0.30 to 3.00 for fresh Mississippi alluvium) of pre-hurricane samples collected and analyzed by Mielke and others (2000). Chromium has been determined to be a dominant trace element in New Orleans soils and is associated with lead and copper (Mielke and others, 2000). The relation among the post-hurricane samples of this study does not appear to be that clear.

The use of arsenic in household chemicals, industrial processes, and agricultural chemicals is becoming more limited; however, historical use of this trace element in treated wood products and some pesticides was expected to resurface in sediment scoured from Lake Pontchartrain, the urban soil environment, and the industrial canals. The variability of arsenic between sample sites is small, and the median concentration is substantially below the median concentrations for vanadium, lead, chromium, and copper (table13, fig. 7). Furthermore, arsenic concentration in samples is relatively small, ranging from 0.84 to $49.1 \mathrm{mg} / \mathrm{kg}$. These results compare well to a study by Cobb and others (2006), where concentrations in 43 samples collected in three longitudinal transects within the center of New Orleans following Hurricanes Katrina and Rita ranged from 0.23 to $28.0 \mathrm{mg} / \mathrm{kg}$. The USEPA Region 6 has established two screening levels for arsenic detected in soil; a cancer Human Health MediumSpecific Screening Level (HHMSSL) of $0.39 \mathrm{mg} / \mathrm{kg}$ and a non-cancer HHMSSL of $22 \mathrm{mg} / \mathrm{kg}$. These screening levels are chemical concentrations that correspond to fixed levels of risk in soils, air, and water. The cancer HHMSSL represents a one in one million $\left[10^{-6}\right]$ chance of contracting cancer at the established technical concentration; the non-cancer HHMSSL represents the concentration level at which other health risks may occur that are not related to cancer (U.S. Environmental Protection Agency, 2006a). U.S. Environmental Protection Agency notes that these are not considered regulatory 'action' or 'cleanup' levels, but can be used as a technical tool in evaluating potential risk to human health. All samples in this study had arsenic concentrations above the cancer HHMSSL and seven samples had concentrations above the non-cancer HHMSSL.

Cadmium concentration in samples ranged from 0.07 to $4.30 \mathrm{mg} / \mathrm{kg}$, with a median concentration of $0.33 \mathrm{mg} / \mathrm{kg}$ (table 13, fig. 7). The presence of cadmium in the environment is linked to the deposition of cadmium-laden dust from industrial processes. Hurricanes Katrina and Rita probably did not increase the concentration levels in New Orleans soil and sediment, but contributed to its distribution throughout the city. An analysis of pre-hurricane Mississippi alluvium and New Orleans soils presents an interesting comparison with these data. Mielke and others (2000) obtained more than 90 samples of Mississippi alluvium and about 4,000 samples of New Orleans soil. The range of their data for the Mississippi alluvium and New Orleans soil was 0.40 to $1.50 \mathrm{mg} / \mathrm{kg}$ and non-detection to $87.0 \mathrm{mg} / \mathrm{kg}$, respectively. Mielke's data are consistent with the post-hurricane concentrations present in this study, and indicates that sediments deposited in New Orleans and along the Louisiana Delta are consistent with Mississippi alluvium for the region.

Mercury concentration in samples ranged from 0.02 to $1.30 \mathrm{mg} / \mathrm{kg}$, with a median concentration of $0.11 \mathrm{mg} / \mathrm{kg}$ (table 13, fig. 7). Background mercury concentration for soil and sediments in southern Louisiana apparently is nonexistent; however, within the lower Mississippi Valley north of New Orleans and the Delta, mercury concentration in natural soils and sediment averages about $0.04 \mathrm{mg} / \mathrm{kg}$ (U.S. Geological Survey, 2004). This was determined from 460 samples collected by the USGS National Geochemical Survey (NGS) in the Level III Omernik Ecoregion 73 (Omernik, 1995). Ecoregion 73 extends from southern Missouri's Mississippi embayment region through southern Louisiana's 'bird foot' Delta (fig. 8). A majority of the samples collected for this study had mercury concentrations exceeding the NGS average concentration. Statistical comparison of the population of post-hurricane data with Ecoregion 73 data indicates that the post-hurricane data are significantly larger than pre-hurricane data for Ecoregion 73. A similar comparison was made for Ecoregions 75 and 34 (fig. 8). These areas bracket the lower Mississippi Alluvial Plain and represent the Gulf of Mexico coastal environment along Texas to the west and Florida to the east of Louisiana. Statistical comparison of these NGS data with post hurricane data indicates that the population of post hurricane data is significantly larger than NGS data in Ecoregions 75 and 34.

Mercury has known health risks when present in its methylated form. The elemental form is not widely present in the environment, and rarely is considered toxic until it makes the transition to methyl mercury. The USEPA Region 6 has a HHMSSL for total mercury of $23.0 \mathrm{mg} / \mathrm{kg}$ dry; all of the samples have mercury levels below this screening level.

Elemental iron concentrations were determined to enable geochemical research comparisons for future studies. Because iron analysis was an afterthought in this study, one sample lacked adequate material for analysis. Iron concentrations in samples ranged from 1,530 to $56,200 \mathrm{mg} / \mathrm{kg}$, with a median and mean concentration of 13,700 and $15,100 \mathrm{mg} /$ $\mathrm{kg}$, respectively (table 13). Elemental iron is quite abundant in soils with a global average of $26,000 \mathrm{mg} / \mathrm{kg}$ (Sposito, 1989). The USEPA Region 6 has established a HHMSSL of $55,000 \mathrm{mg} / \mathrm{kg}$ for iron (U.S. Environmental Protection 


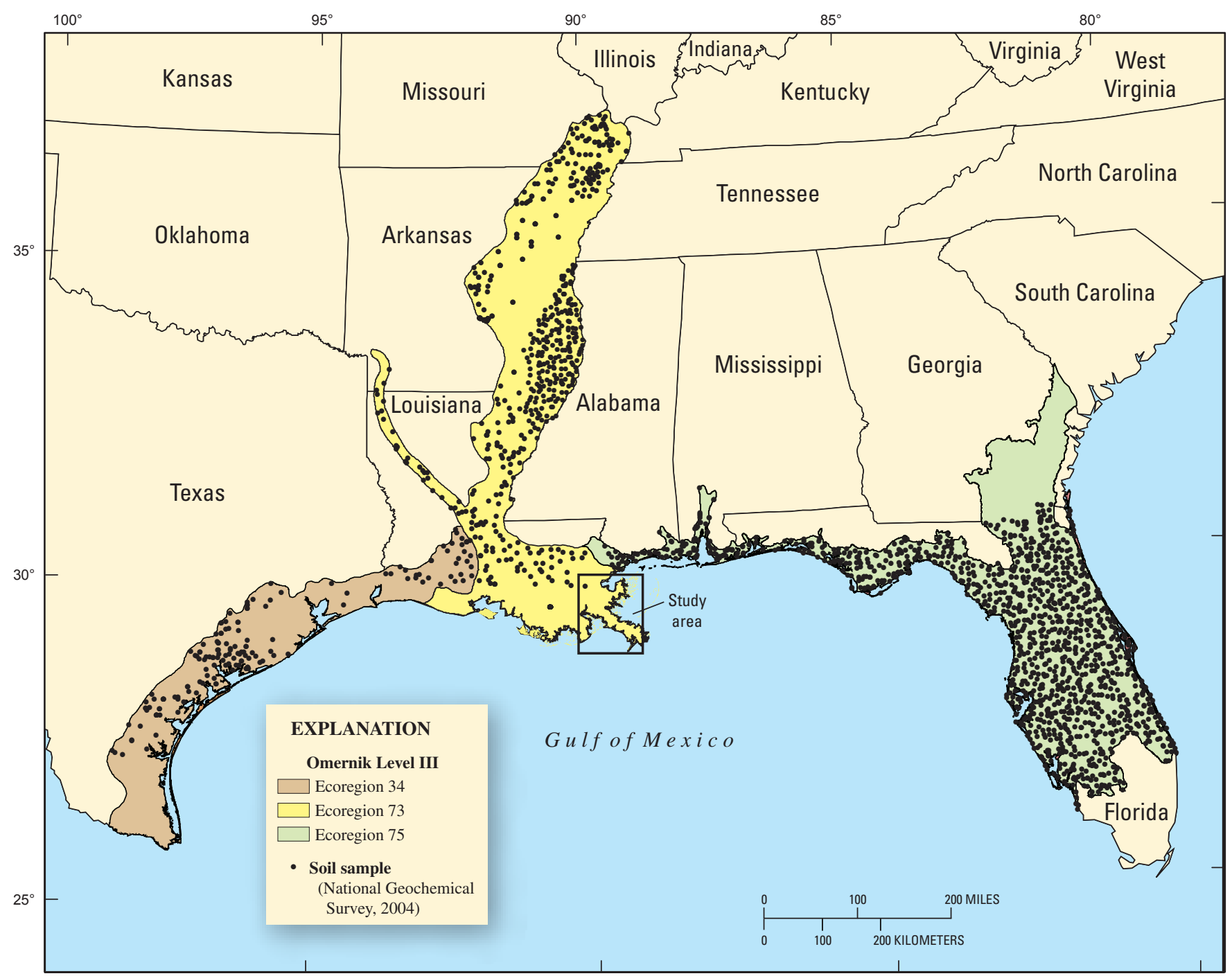

Base from Environmental Systems Research Institute digital data, 1983

Figure 8. The Omernik Ecoregions and locations of National Geochemical Survey data.

Agency, 2006). The HHMSSL for iron was exceeded in one sample.

The correlation between the total iron concentration and concentrations of other trace elements was analyzed. The correlation analysis results, shown in figure 9, illustrate that $\mathrm{V}, \mathrm{Cr}, \mathrm{Cu}, \mathrm{Cd}$, and As are strongly correlated to the total iron concentration, whereas lead and mercury are not.

The significance of this analysis relates to the researched role that the oxides of major elements play in soil surface adsorption. For example, iron, aluminum, and manganese oxides are sinks for many trace elements, including cations and oxyanions (Basta and others, 2005). Additionally, iron oxide commonly is used as a sorbent for arsenic removal from drinking water, and also is used to adsorb cations such as lead, copper, zinc, and cobalt.

The experiment data in this study are consistent with the previous findings with one exception; lead and mercury results vary because of the impact of other factors such as soil organic matter, which has a strong binding strength with most heavy metals.

\section{Trace Element and Iron Sequential Extraction Results}

Sequential extraction was completed on 6 of 7 trace elements and iron to determine the binding properties of each element with its host matrix and the partitioning among the various forms in which each element might exist. A susbset of 51 samples was selected from the 157 samples that were analyzed by single extraction methods (fig. 10). A comparison of the single extraction data with the sum of the sequentially extracted parts is shown in boxplot format for each element (fig. 11). Sequential extraction is a procedure by which progressively stronger digestion is used to facilitate an understanding of the relative mobility of an element contained in sediments and soils. Therefore, those elements that are 

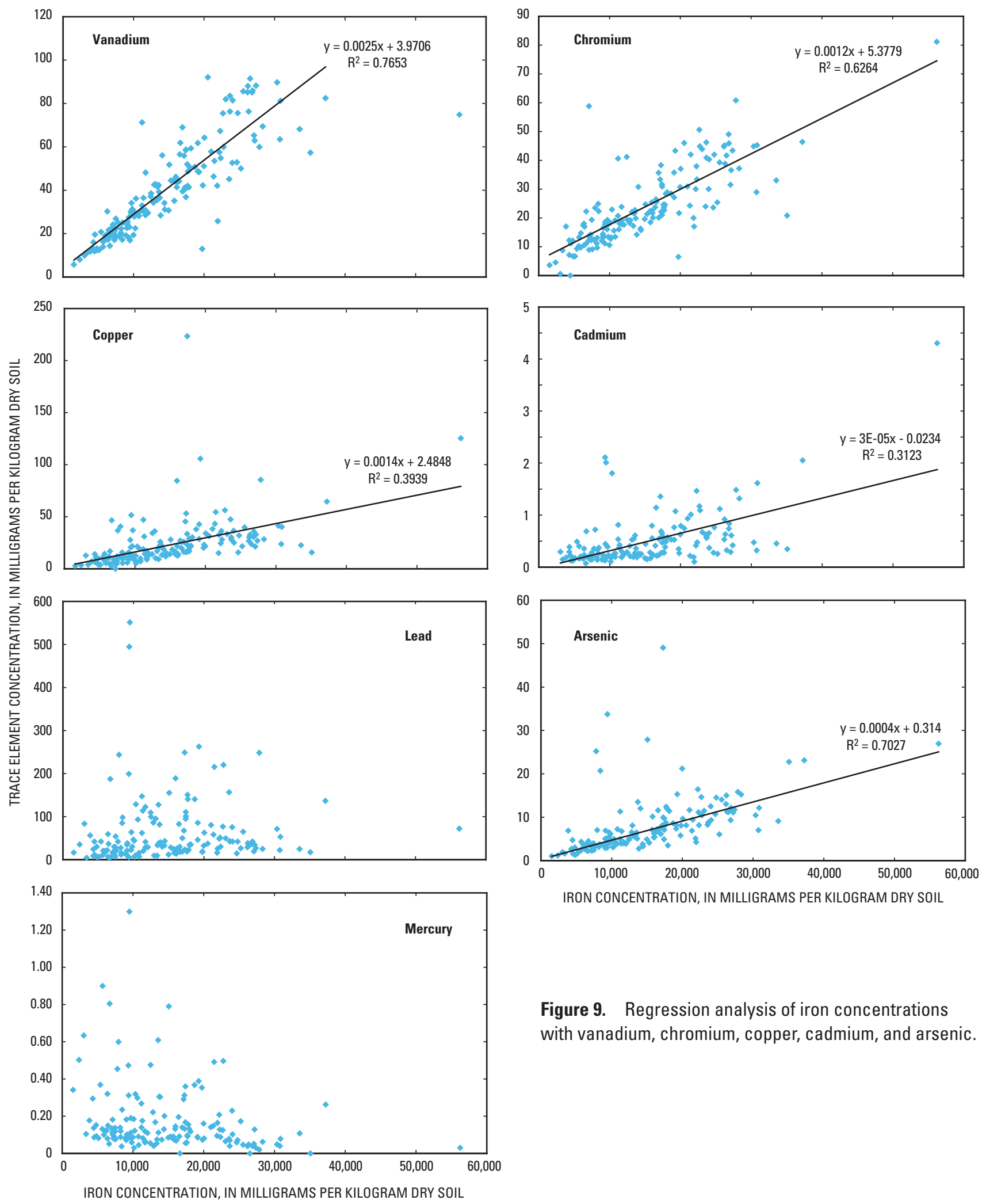

Figure 9. Regression analysis of iron concentrations with vanadium, chromium, copper, cadmium, and arsenic. 


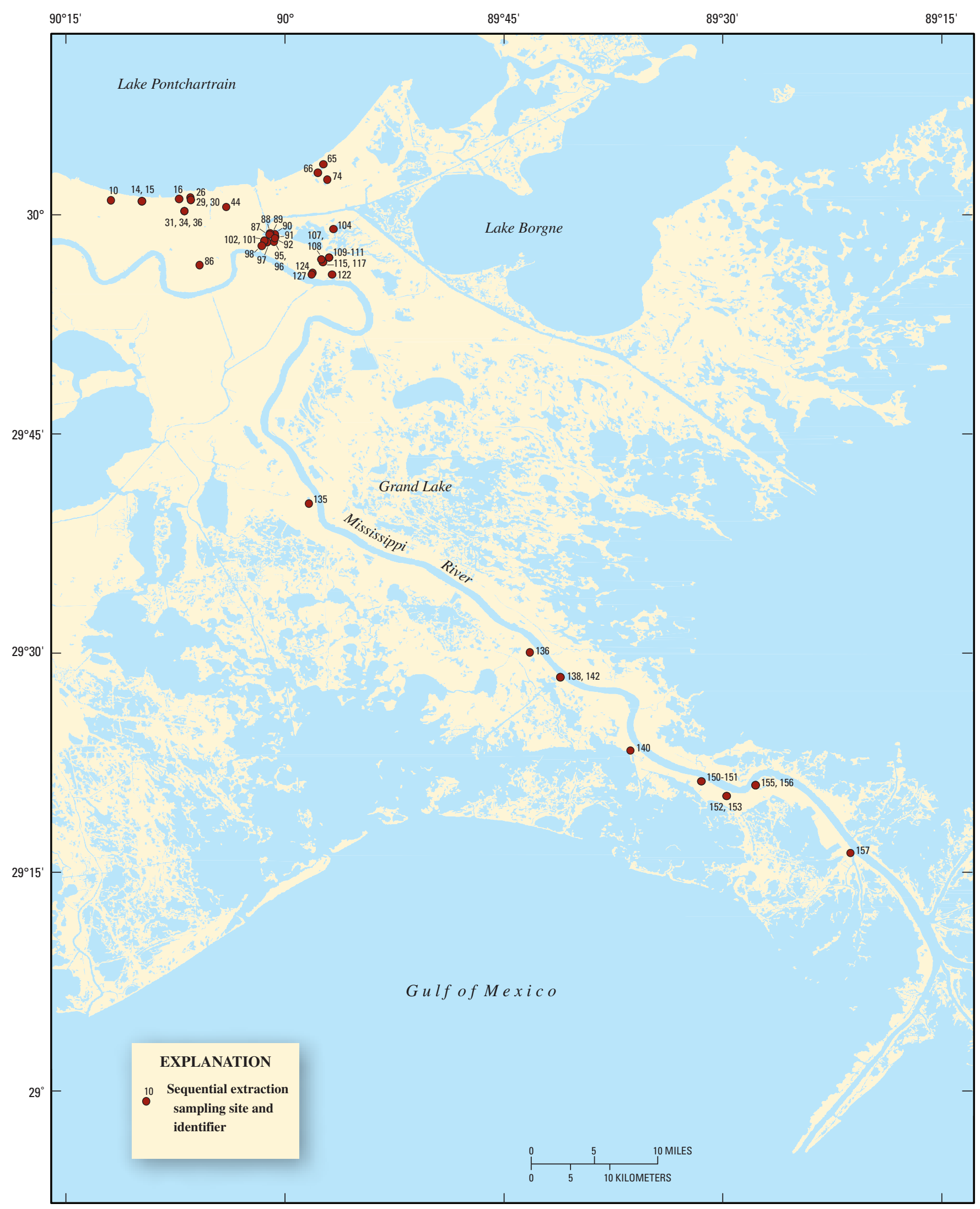

Base from the Louisiana Oil Spill Coordinator's Office, 2000

Horizontal coordinate information referenced to the

North American Datum of 1983 (NAD 83)

Figure 10. Locations of samples analyzed using sequential extraction methods. 

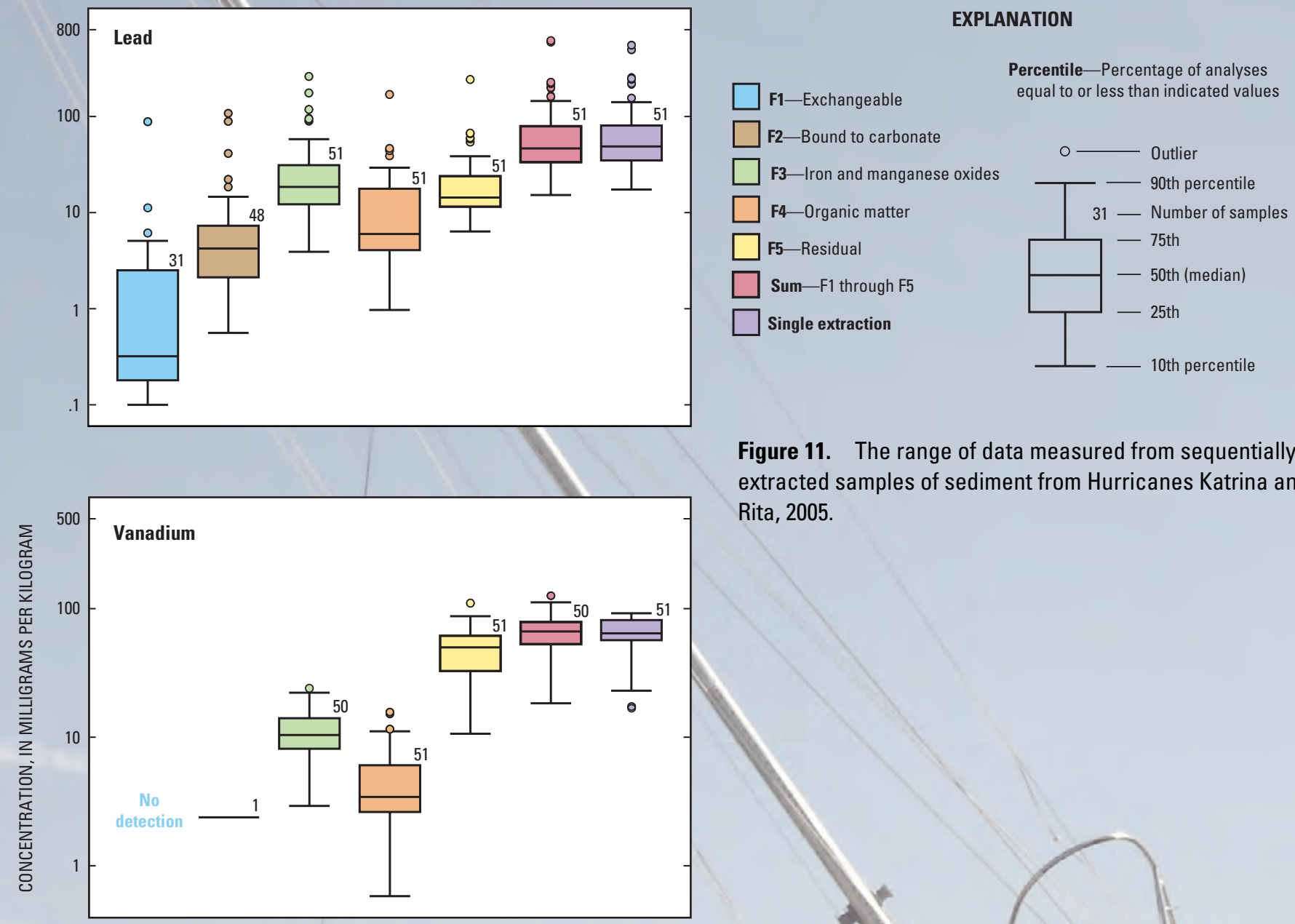

Figure 11. The range of data measured from sequentially extracted samples of sediment from Hurricanes Katrina and Rita, 2005.

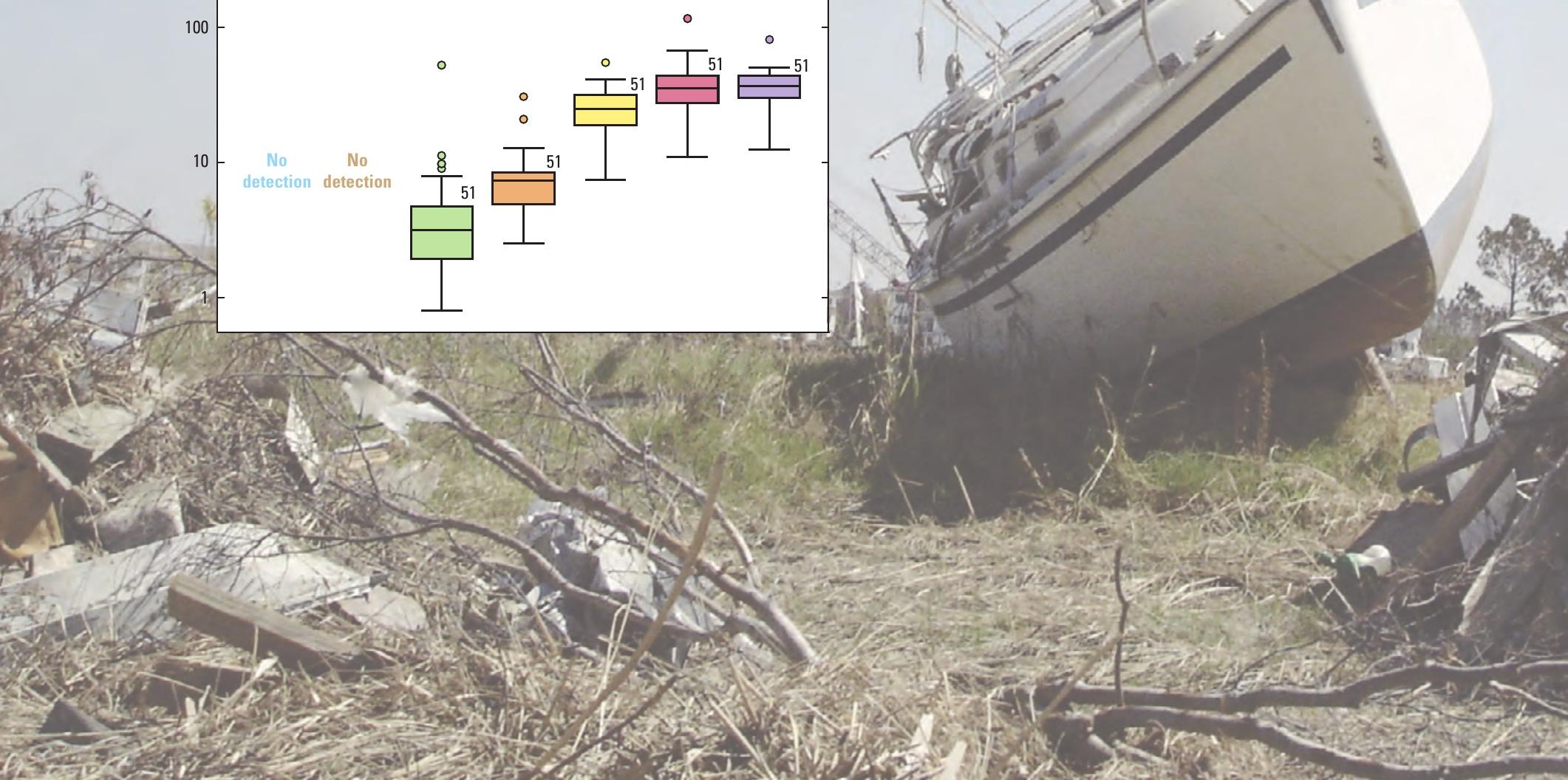



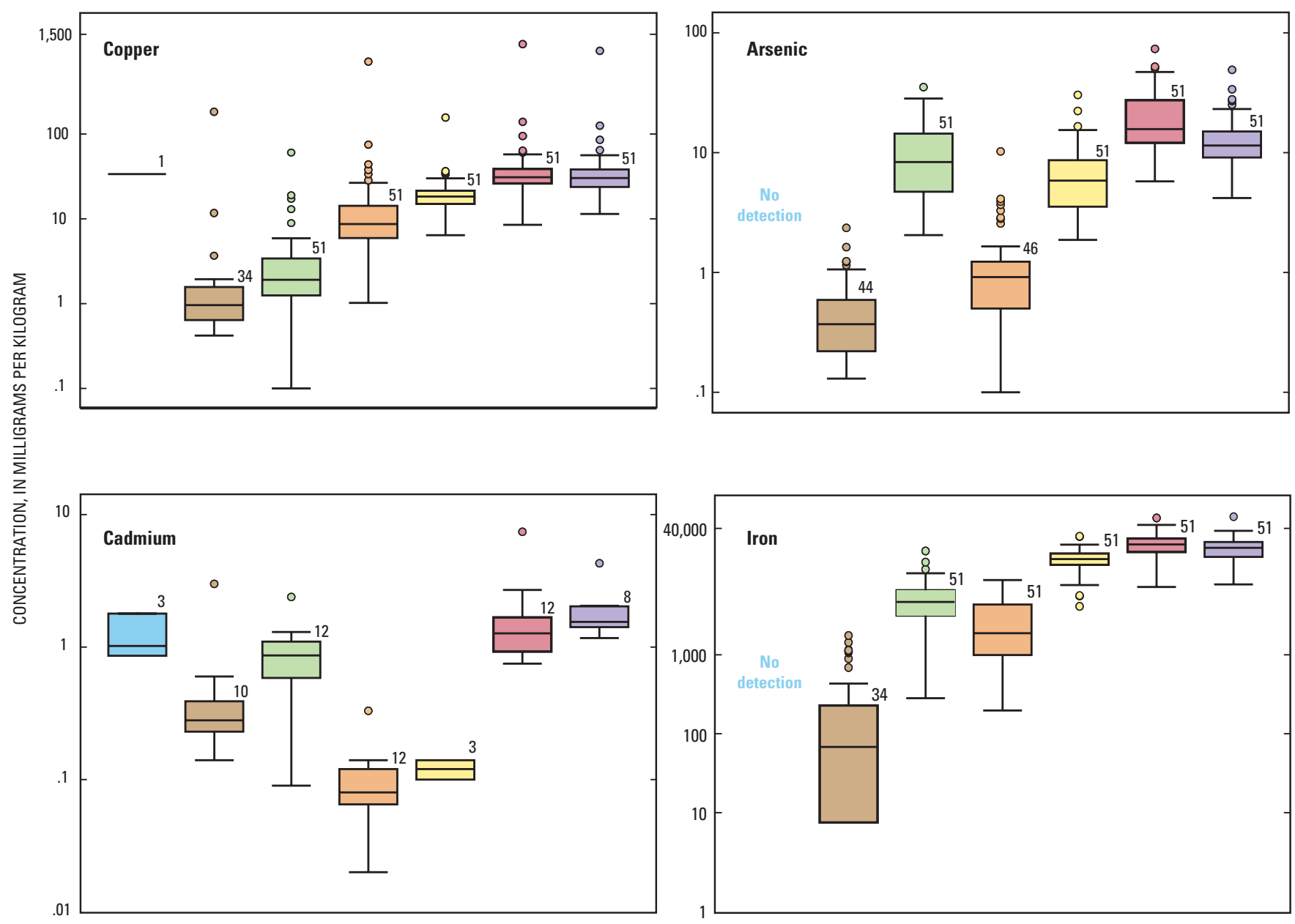

Figure 11. The range of data measured from sequentially extracted samples of sediment from Hurricanes Katrina and Rita, 2005.-Continued

released in the F1 fraction are likely to occur rather rapidly in the environment through small changes in the ionic composition of natural waters. Contrastingly, the elements present in the F5 fractions are more likely to be tightly linked to the crystalline structure of the sediments. These elements are less likely to affect water chemistry or issue other environmental concerns during normal environmental conditions.

Lead concentrations were present in each fraction of the sequential extraction method (table 14, at the back of this report; fig. 11). The F1 fraction concentration ranged from 0.10 to $88.4 \mathrm{mg} / \mathrm{kg}$, and was detected in 31 of 51 samples analyzed. This large concentration range, which accounts for 5 percent of the total mean concentration for the sequential analysis, indicates there is a small mobile phase in the sample that can move from its matrix with changes in $\mathrm{pH}$, association with acid rain, and mixture with estuary and/or seawater. Lead is present in large concentrations in the soils of New Orleans and probably becomes mobile routinely during rainfall events that drain to the canals and Lake Pontchartrain; therefore, the $\mathrm{Pb}$ detected in the $\mathrm{F} 1$ fraction could be the redistribution of extremely mobile lead that accumulated in the sediments of
Lake Pontchartrain, the city of New Orleans, and the canal for many decades from surface-water drainage. Lead in the F2 fraction, ranging from 0.56 to $108 \mathrm{mg} / \mathrm{kg}$, was present in 48 of 51 samples. This fraction indicates that some lead is tied to carbonates in the sediment and can be easily mobilized with changes in $\mathrm{pH}$. Lead primarily is associated with iron-manganese oxides that are represented by the F3 fraction. All 51 samples had lead in the F3 fraction; the concentration ranged from 3.90 to $260 \mathrm{mg} / \mathrm{kg}$, with an average of $32.7 \mathrm{mg} / \mathrm{kg}$. This fraction represented 39.1 percent of the mean concentration of lead in samples, which is consistent with studies of marine sediments in other regions of the world (Choi and others, 2006). Whereas lead is more stable in the iron-manganese oxides, it can be mobilized with $\mathrm{pH}$ changes and more reductive conditions-environments that are likely to be present in canals, Lake Pontchartrain sediments, and land fills. The F4 fraction contained lead concentrations ranging from 0.97 to $169 \mathrm{mg} / \mathrm{kg}$ indicating that this element is substantially tied to organics in the sediments. During oxidizing conditions in natural waters, organic matter can be degraded, which can lead to a release of soluble trace elements (Tessier and others, 
1979). The residual, or F5 fraction, ranged in lead concentration from 6.36 to $242 \mathrm{mg} / \mathrm{kg}$ and represented 30.1 percent of the mean concentration of lead in the sequential analysis. Lead contained within the F5 fraction is not likely to be released into solution under normal environmental conditions because of its association with the crystalline structure of the sediment and soil matrix.

Vanadium was detected in 4 of 5 sequential extraction fractions (table 15, at the back of this report; fig. 11). Vanadium was not detected in the F1 fractions, and only one concentration measuring $2.38 \mathrm{mg} / \mathrm{kg}$ was detected in the F2 fraction. In the F3 fraction 50 of 51 samples contained vanadium concentrations ranging from 2.92 to $24.0 \mathrm{mg} / \mathrm{kg}$. Generally, about 17 percent of the vanadium in samples was determined to be associated with the iron-manganese oxides. Even though substantially smaller in overall concentrations, vanadium was detected in all 51 samples of the F4 fraction, indicating that organic matter may be contributing to sequestering this trace element. The concentrations in the $\mathrm{F} 4$ fraction ranged from 0.58 to $15.7 \mathrm{mg} / \mathrm{kg}$. These data indicate that about 7.2 percent of the average vanadium concentration detected in all samples is associated with organic matter. The largest concentrations were observed in the F5 fraction where the concentration ranged from 10.6 to $110 \mathrm{mg} / \mathrm{kg}$. These results suggest that 75.2 percent of vanadium in samples is associated with the crystalline non-mobile phase of the sediments. This is not surprising as vanadium can exist in five oxidation states ranging from -1 to +5 , and is typically associated with iron. Vanadium toxicity generally is low; however, the toxicity increases as the valence increases (Barceloux, 1999). This element is not particularly significant to this study, but can be an indicator of air pollution as it most commonly is present in industrial dust emissions. It is possible that decades of industry in the southern Louisiana region contributed to a substantial increase in this constituent. Because the pentavalent form $\left(\mathrm{V}_{2} \mathrm{O}_{5}\right)$ is the most toxic, there is concern that large concentrations of vanadium in dust during sediment removal from New Orleans could cause potential health issues (Sjoberg, 1950).

Sequential extraction of chromium indicates no readily available concentrations in the F1 and F2 fractions (table 16, at the back of this report; fig. 11). This finding is consistent with the F1 and F2 extraction for six marine sediment samples in Hong Kong (Choi and others, 2006). The F3 fraction ranged from 0.80 to $52.4 \mathrm{mg} / \mathrm{kg}$ and accounted only for 12.5 percent of chromium in all samples. Most of the chromium tended to be tightly bound and rather insoluble as evidenced by the F4 and F5 fractions. The F4 and F5 fractions concentrations ranged from 2.51 to $30.6 \mathrm{mg} / \mathrm{kg}$ and 7.49 to $54.7 \mathrm{mg} / \mathrm{kg}$, respectively. In these samples, 20 percent of the chromium is associated with organic matter and 67 percent is associated with the mineral content. Because iron concentrations were quite large in all samples, it is possible that insoluble secondary oxidation minerals were formed in these sediments. Iron augmentation of contaminated soils and sediments has been shown to be a feasible remediation practice (Kumpiene and others, 2006). The mechanism for secondary mineral forma- tion with zero-valent iron is described in Sastre and others (2004). This iron-trace element relation could have a substantial affect on the mobility of arsenic, vanadium, and cadmium, but has been shown to have little effect on reducing the mobility of copper (Kumpiene and others, 2006).

Copper was detected in all sequential extraction fractions; however, only one sample had a concentration of 33.7 $\mathrm{mg} / \mathrm{kg}$ in the F1 fraction (table 17, at the back of this report; fig. 11). It is not clear why this single sample is different from the others, but it does suggest that the copper present in these samples can not be easily mobilized in natural waters. In the F2 fraction, 34 samples had concentrations ranging from 0.42 to $183 \mathrm{mg} / \mathrm{kg}$. Generally, 11.6 percent of copper exists in a readily available form bound to carbonates in the sediment. All 51 samples had $\mathrm{Cu}$ concentrations bound to iron-manganese oxides in the $\mathrm{F} 3$ fraction. This fraction ranged from 0.10 to $60.5 \mathrm{mg} / \mathrm{kg}$ and accounted for only 7.5 percent of the total average concentration. The F4 fraction measured substantially larger than the F3 fraction and ranged from 1.02 to $716 \mathrm{mg} / \mathrm{kg}$. The F4 fraction represented 45.8 percent of the average copper concentration, indicating that most of the copper in samples from southern Louisiana is associated with organic matter, a finding that is consistent with Pardo and others (1990). Stumm and Morgan (1981) proposed that copper easily can form complexes with organic compounds that make them rather stable in the aquatic environments. The F5 fraction ranged from 6.41 to $156 \mathrm{mg} / \mathrm{kg}$. Generally, 37.8 percent of the copper in all 51 samples is associated with the crystalline matrix of the sediment samples.

Arsenic concentrations were limited to fractions F2-F5 (table 18, at the back of this report; fig. 11). In the F2 fraction, 44 of 51 samples had concentrations ranging from 0.30 to 2.35 $\mathrm{mg} / \mathrm{kg}$. This fraction accounted for 2.6 percent of the average concentration in all samples, and demonstrates a stronger affinity for arsenic to bind with the iron-manganese oxides of the F3 fraction and form insoluble secondary oxidation minerals with iron of the F5 fraction. The F3 fraction had a concentration range from 2.05 to $39.7 \mathrm{mg} / \mathrm{kg}$, and represented 51 samples. This fraction accounted for 54.5 percent of the average concentration of all samples, indicating arsenic can be mobilized should anoxic conditions exist. In open oxidative conditions however, such as the case in the New Orleans environment following Hurricanes Katrina and Rita, arsenic would likely remain tied to the iron-manganese oxides. If arsenic were to be transported to other environments, such as the bottom of Lake Pontchartrain or the drainage canals, the environmental conditions could become reductive enough to mobilize a substantial part of this fraction with time. The F4 fraction concentration ranged from 0.10 to $10.2 \mathrm{mg} / \mathrm{kg}$, and represented 46 of 51 samples. Whereas the potential for arsenic to be bound to organic matter exists, the F4 fraction suggests that this will occur only about 6.9 percent of the time. All 51 samples had concentrations ranging from 1.87 to 30.3 $\mathrm{mg} / \mathrm{kg}$ in the $\mathrm{F} 5$ fraction, representing 37.2 percent of this trace element in the sediment samples. 
Sequential extraction analysis of cadmium proved to be problematic. The distribution of cadmium data among the five fractions and the inconsistent number of samples where concentrations were observed are shown in figure 16. The largest concentration $(2.39 \mathrm{mg} / \mathrm{kg})$ was detected in the $\mathrm{F} 3$ fraction (table 19, at the back of this report). The F3 and F4 fraction had concentrations in 12 samples, whereas, the F1, F2, and F5 fractions had concentrations in 3, 10, and 3 samples, respectively. Whereas the presence of cadmium in post-Katrina samples was somewhat sporadic and small within the five fractions, these results seem to be consistent with those results observed by Choi and others (2006) for six marine sediments in Hong Kong. If the cadmium concentrations are truly representative of the post-Hurricane sediments, then there is little concern for mobility during any possible environmental change or handling process.

Analysis of iron was a decision made by the team following the trace element sequential analysis. Because of this, only limited quantities of sample remained for analysis; nevertheless, enough material remained to perform analysis on all 51 samples. Sequential extraction of these samples yielded expected and interesting results (fig. 11). None of the 51 samples had concentrations above the MDL of $15.0 \mathrm{mg} / \mathrm{kg}$ in the F1 fraction. In the F2 fraction, 34 samples had concentrations above the MDL, ranging from 17.0 to $1,750 \mathrm{mg} / \mathrm{kg}$ (table 20 , at the back of this report; fig. 11). This indicates that about 0.9 percent of the total iron concentration in samples is associated with carbonates. The F3 fraction contained about 21 percent of the iron concentration, indicating that a substantial part of the iron is in the form of oxides. The F3 concentrations ranged from 282 to $20,596 \mathrm{mg} / \mathrm{kg}$. All 51 samples had measurable concentrations of iron in the F4 fraction, ranging from 197 to $8,858 \mathrm{mg} / \mathrm{kg}$. Iron complexed with organic matter accounted for 10.1 percent of the total detected in these samples. The residual F5 fraction contained about 67.1 percent of the total iron concentration. This indicates that iron is contained within various inorganic crystalline states that are not likely to become soluble under normal environmental conditions.

\section{Pesticide and Polychlorinated Biphenyl Results}

The destruction caused by both hurricanes included the dispersion of organic chemicals throughout New Orleans and the Delta. The field teams observed many oil slicks that deposited at high water mark areas, fallen power lines, and broken transformers. The organic chemical contents from local businesses and homes strewn about the landscape also were apparent (fig. 12). Analysis of the environmental samples was targeted towards the organic compounds thought to be available to sediments in the affected region. In a preliminary study of these environmental sediment samples, 46 samples were analyzed for 18 pesticide compounds and benzene, toluene, ethylene, and xylene (BTEX). Results indicated that small concentrations of pesticides were observed in the sediments, with the dominant pesticide being methoxychlor. Of the BTEX compounds, benzene was observed 78 percent of the time at concentrations near the method detection limit of $10.0 \mu \mathrm{g} / \mathrm{kg}$ (Adams and others, 2007). Using the results of this preliminary investigation, the remaining samples were subjected to a more refined analysis to include the pesticides prometon, simazine, atrazine, heptachlor, and methoxychlor. In addition, the polychlorinated biphenyl (PCB) arochlors, 1016, 1221, $1232,1242,1248,1254$, and 1260 were measured.

\section{Pesticides in Sediment}

Five pesticide compounds including prometon, simazine, atrazine, heptachlor, and methoxychlor were measured in 157 environmental sediment samples (tables 21 and 22, at the back of this report). Only four of these compounds had detectable concentrations using the GC-ECD analysis method. Of these four compounds, atrazine had a single measurable concentrations of $547 \mu \mathrm{g} / \mathrm{kg}$; methoxychlor had three measurable concentrations ranging from 37.5 to $49.3 \mu \mathrm{g} / \mathrm{kg}$; and heptachlor had five measurable concentrations ranging from 2.42 to $17.4 \mu \mathrm{g} / \mathrm{kg}$ (table 21). Prometon could not be measured using GC-ECD because of a lack of electron affinity group of the chemical. The GC-MS method was applied to 42 of 157 samples to confirm and refine the results from the GC-ECD analysis. Results of this analysis indicates that 26 samples contained measurable prometon concentrations ranging from 2.4 to $193 \mu \mathrm{g} / \mathrm{kg} ; 22$ samples contained measurable methoxychlor concentrations ranging from 3.50 to $3,510 \mu \mathrm{g} / \mathrm{kg} ; 20$ samples contained measurable atrazine concentrations ranging from 4.4 to $187 \mu \mathrm{g} / \mathrm{kg} ; 7$ samples contained measurable simazine concentrations ranging from 4.80 to $82.4 \mu \mathrm{g} / \mathrm{kg}$; and 7 samples contained measurable heptachlor concentration ranging from 2.90 to $33.3 \mu \mathrm{g} / \mathrm{kg}$ (table 22 ).

Methoxychlor was reported in an earlier investigation to be the pesticide of concern (Adams and others, 2007). Methoxychlor is a diphenylalkane insecticide used to control flies, mosquitoes, cockroaches, and chiggers and is used on food crops, farm animals, pets, and in home gardens (Agency for Toxic Substance and Disease Registry, 1995). This insecticide has not been proven to cause cancer, but it can enter the body through direct contact with the skin. Methoxychlor may be related to developmental and reproductive effects, so its presence in flood-water sediments should be a concern to repopulating residents and recovery workers (Agency for Toxic Substance and Disease Registry, 1995). Common pathways for contact include handling contaminated food, water, and soil. Using methoxychlor as insect control along the southern coast may be largely responsible for the wide distribution of this compound in samples.

Methoxychlor is persistent in soils; it degrades slowly in aerobic conditions and more quickly in anaerobic environments. The World Health Organization (WHO) tolerable daily intake (TDI) guideline for methoxychlor in soils is 5.00 $\mu \mathrm{g} / \mathrm{kg}$ body weight/day (World Health Organization, 1996). To achieve this level, one would need to consume approximate $100 \mathrm{~g}$ of sediment contaminated at the highest concentra- 

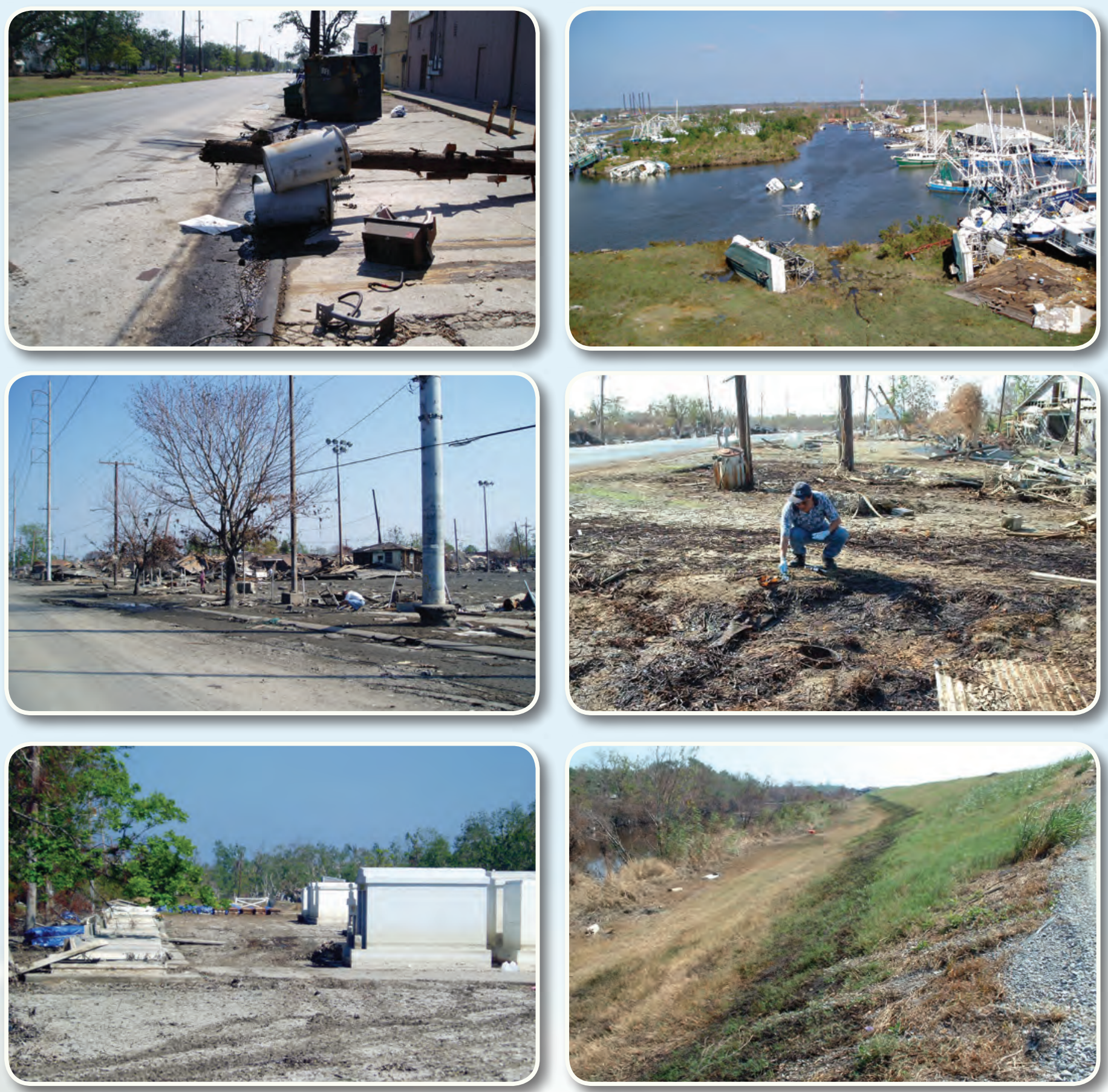

Figure 12. Potential causes of organic contamination in New Orleans and along the Louisiana Delta (photographs taken by Emitt Witt and David Shaver, U.S. Geological Survey and Jianmin Wang, Missouri University of Science and Technology).

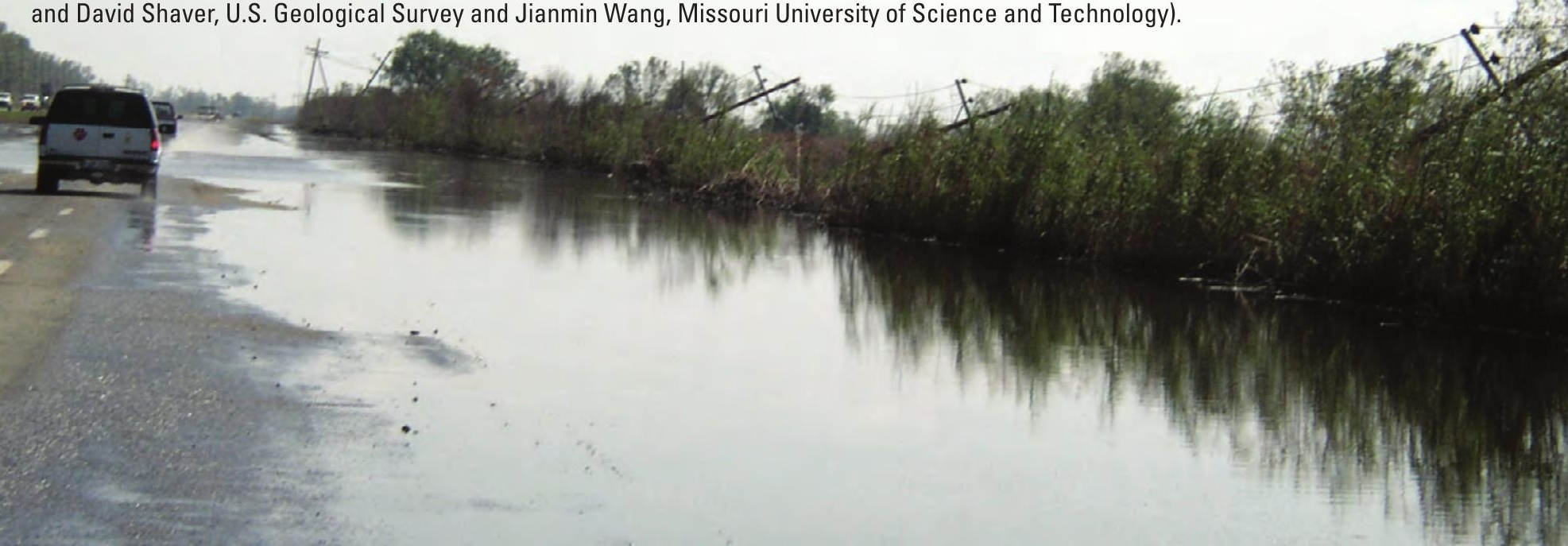


tion present $(3,510 \mu \mathrm{g} / \mathrm{kg})$ per day. Further, this maximum concentration of methoxychlor is orders of magnitude below the high-priority screening levels of $3,100,000 \mu \mathrm{g} / \mathrm{kg}$ cited by the USEPA for residential soil (U.S. Environmental Protection Agency, 2006b). Thus, the levels observed in the samples analyzed from New Orleans and the Louisiana Delta appear to be well within the acceptable limits.

Herbicide compounds, particularily the triazine class compounds, have been studied extensively in the Mississippi River and along Gulf Coast because of their potential effects on the Delta's productivity. Clark and Goolsby (2000) measured 271 water samples during the 1990's to determine the seasonal and annual discharge of trazines to the Gulf of Mexico via the Mississippi River. Their study primarily considers the mobile or dissolved phase of these compounds, but demonstrates large quantities of pesticides are being transported from the rich farm country of the northern Mississippi Valley. The Clark and Goolsby (2000) study specifically studies the relation of the increased loading of atrazine with increasing discharge during the growing season of May through August with more than 640 metric tons being transported annually. McMillin and Means (1996) measured the quantity of triazine pesticides in dissolved, colloidal, particulate phases, and sediment. Their results indicate that more frequent detections were observed in the dissolved and colloidal phases, with atrazine being the dominant compound and having the largest concentration. Studies involving the adsorption of atrazine have indicated that this compound has a favorable adsorption coefficient that allows it to be associated with clay minerals, sediment, and soil with large concentrations of amorphous iron and aluminum oxides and organic matter (Huang and others, 1984; Godskensen and others, 2005; Chefetz and others, 2004; Weber and others, 2004). Schwab and others (2006) indicate that surface sediment and soil are the more preferential adsorption sites for atrazine; however, adsorption accounts only for a small part of the total atrazine moving through the subsurface. These studies seem to confirm the findings of the post- Hurricane Katrina and Rita samples where few samples actually contained measurable concentrations of atrazine and simazine. This indicates that the large annual discharge of trazine compounds has a small total effect on the concentrations of these compounds in the Gulf Coast sediment. The fact that any of these compounds were observed in post-hurricane samples may indicate the possibility of local introduction of these compounds resulting from the Hurricanes' impact on the regional infrastructure. The Hurricanes' impacts would have been responsible for scattering local stores of these chemicals or the redistribution of sediment from local agricultural operations that use these herbicides.

\section{Polychlorinated Biphenyl in Sediment}

Polychlorinated biphenyls (PCB) were measured using the GC-ECD method only. Insufficient amounts of sample remained to use the GC-MS method which, in hindsight, may have been the more appropriate method of analysis for PCBs. There were no detectable concentrations of Aroclor 1016, 1221, 1232, 1242, 1248,1254 , and 1260 above the MDLs for any environmental sample (table 21, at the back of this report). Because of the high background of the sample, 39 of 157 samples were not analyzed; these samples are reported as non-detects (ND).

PCBs have been detected in small concentrations in sediments of the Gulf of Mexico and in sediments to the east of the Mississippi River (Sericano and others, 1989). Whereas the post-hurricane PCB study is inconclusive, it may be an important consideration for future studies where adequate sample is acquired under more rigorous field quality assurance procedures.

\section{Summary and Conclusion}

The results of this study represent the chemical characteristics of perishable soil and sediment samples obtained from New Orleans and the Louisiana Delta following the destruction of the 2005 storm season. Gathering the samples within one month after Hurricanes Katrina and Rita, the team was given the opportunity to catalog the effects the storms had on the landscape before the debris and deposited sediments were removed from the affected area. A maximum of 157 of the remaining samples were analyzed for single extraction trace elements and iron, sequential extraction of trace elements and iron, pesticides, and PCB Aroclor congeners. Some of the original 238 samples were field duplicates, samples of oil stained vegetation, and samples that would otherwise not contribute to the hurricane deposited sediment discussion; therefore, these samples were not analyzed for nor discussed in this report.

Extensive quality assurance procedures were used during laboratory analysis to provide the highest quality database possible. In some cases, alternative analytical techniques were used to confirm or refine the results of earlier analyses. Such was the case with the environmental samples analyzed for pesticides. Nearly 35 percent of the analytical effort was dedicated to analysis of blanks, duplicates, and matrix spikes.

Chemical concentrations were measured for $\mathrm{Cu}, \mathrm{Pb}, \mathrm{As}$, $\mathrm{Cd}, \mathrm{Hg}, \mathrm{Cr}, \mathrm{V}$, and $\mathrm{Fe}$ using a single extraction procedure defined by U.S. Environmental Protection Agency (USEPA) methods. In decreasing order, the largest range in constituent concentration variability was observed for $\mathrm{Pb}, \mathrm{V}, \mathrm{Cr}, \mathrm{Cu}$, $\mathrm{As}, \mathrm{Cd}$, and $\mathrm{Hg}$. Lead, arsenic, and mercury were elements of interest in this study because of the potential for toxic effects on repopulating residents and debris removal crews. The large lead concentrations that were observed in samples are consistent with pre-hurricane studies of New Orleans soils. This indicates that lead concentrations may not be the result of hurricane debris mixing with sediments, but may be from redistribution of existing lead-contaminated sediment. Nevertheless, lead is expected to be at hazardous levels for repopulating residents, debris removal crews, and to children who come into contact with New Orleans soils. Arsenic concentration exceeded the USEPA Region 6 HHMSSL cancer level of 
$0.39 \mathrm{mg} / \mathrm{kg}$ in all samples. Additionally, 7 samples contained arsenic concentrations above the larger non-cancer screening level. Mercury data for these post-hurricane samples was compared with the USGS NGS regional data, and determined to have significantly larger concentrations; however, all of the concentrations were significantly below HHMSSL. Vanadium, chromium and cadmium pose little danger to New Orleans and Louisiana Delta residents at concentration levels observed in this study. Elemental concentrations of iron in post hurricane samples are large and consistent with results of earlier research. Iron showed a strong relationship with arsenic, chromium, and vanadium, but did not correlate well with the other trace elements.

To further investigate the nature of the trace elements and iron in environmental soil and sediment samples, 51 of 157 samples were selected for a sequential extraction procedure to understand the form in which each element exists. Mercury was not included in this procedure because of low levels detected in the single-extraction method and the potential for contamination in any one of the extraction steps. Because of low levels in the samples, cadmium concentrations were inconclusive in this analysis and caution should be exercised whenever these results are used. The residual component of the determination, or that which represents the concentration of an element that is associated with the immobile crystalline structure of the sample matrix, was the dominant form in which vanadium, copper, chromium, and iron were detected in these post-hurricane samples. Arsenic and lead predominantly were contained in the iron-manganese oxides of samples. Lead was the only element to have a substantial percentage of its total concentration in the highly mobile exchangeable and carbonate fractions. Based on these sequential extraction results, and in consideration of the previous research done on this element in soils of New Orleans, lead could be considered the most problematic trace element measured in the study, and poses the greatest threat to the clean up and repopulation of New Orleans.

Pesticides in soil and sediment samples generally were small with some exceptions. Methoxychlor was the largest concentration measured and was detected in 22 of 157 samples measured for organic compounds. The presence of methoxychlor in these samples does not pose a health threat at any level measured in this study. Smaller concentrations of atrazine, prometon, simazine, and heptachlor also were observed in samples from New Orleans and the Louisiana Delta. The presence of these compounds in the reported concentrations is not a primary concern to repopulating residents.

Polychlorinated biphenyl Arochlor congeners were measured but not observed above the method detection limits for any of the analyzed samples. There were several samples that had large background matrix interference problems. These samples are reported as non-detects in the dataset. Although the overall results are not conclusive, the PCB dataset indicates that they are not compounds of concern in sediments and soils of post-hurricane Louisiana.

Deploying to an area recently ravaged by a natural disaster always creates a large degree of uncertainty for an investi- gative team. Working under these demanding circumstances forced the team to be adaptive in planning and executing new data-collection methods. Given the complexity of responding to any natural disaster, the collection of perishable data may not always conform to rigorous statistical sampling schemes or even established sample collection procedures that have been proven to ensure representativeness and quality during normal study conditions. The conditions surrounding data collection in this study were complex, and unforgiving; however, every effort was made to enlist the best talent, highest-quality equipment, and most rigorous procedures given the challenges of sampling among the post-hurricane chaos. Every scientific investigation that was performed following these devastating hurricanes provides the scientific community with a unique opportunity to document lessons learned. In an effort to aid recovery and response efforts in the future, these should be used to compile a standardized methods manual. The research and analytical efforts employed by the USGS and Missouri S\&T team provides an essential contribution to that cause. Additionally, the research results herein provide vital information to resource managers, debris removal personnel, and the repopulating residents of southern Louisiana. Finally, no one could have predicted the vast destruction left after nature wrecked havoc on New Orleans and the Louisiana Delta; though no one can erase the past, the chemical status of posthurricane sediments described in this report can help ensure a safer tomorrow for all of Louisiana's residents.

\section{Acknowledgments}

This work was sponsored by hurricane supplemental funds allocated to the U.S. Geological Survey, Mid-Continent Geographic Science Center, through the Geographic Analysis and Monitoring Program, to facilitate the collection of perishable engineering and environmental data in cooperation with the Missouri University of Science and Technology Natural Hazard Mitigation Institute following Hurricanes Katrina and Rita. Analyses and additional support was provided by the Environmental Research Center for Emerging Contaminants at the Missouri University of Science and Technology. Special thanks to the OCSNER Medical Group of New Orleans for allowing the team to use its administrative facility as a base of operations for this effort. Also, special thanks to Calvin O'Neal and the U.S. Geological Survey, National Wetland Science Center, Lafayette, Louisiana, for providing temporary housing for the deployed team. Furthermore, this effort could not have been conducted without field-level data collection, laboratory, and GIS support from Adam Sevi, Connor Watkins, David Summers, Neil Anderson, Ronaldo Luna, David Shaver, Youssef Filali-Meknassi, Tingzhi Su, David Kaufman, Michael Starbuck, David Rogers, Shi Shu, and Jie Ding. 


\section{References}

Adams, C., Witt, E.C., III, Wang, J., Shaver, D., Summers, D., Filali-Meknassi, Y., Shi, H., Luna, R., Anderson, N., 2007, Chemical quality of depositional sediments and associated soils in New Orleans and the Louisiana Peninsula following Hurricane Katrina: Environmental Science and Technology, 41, p. $3,437-3,443$.

Agency for Toxic Substance and Disease Registry, (ATSDR), 1995, Toxicological profile for methoxychlor: Atlanta, Ga., U.S. Department of Health and Human Service, 2 p.

Barceloux, D.G., 1999, Vanadium: Journal of ToxicologyClinical Toxicology, v. 37, issue 2, p. 265-278.

Basta, N.T., Ryan, J.A., and Chaney, R.L., 2005, Trace element chemistry in residual-treated soil: Key concepts and metal bioavailability: Journal of Environmental Quality v. 34 , p. 49-63.

Carnelos, S., McCorquodale, A., and Barbé, D., 2002, Environmental issues-water quality, in S. Penland S., Beall A. and Kindinger J., eds., Environmental atlas of the Lake Pontchartrain Basin-Lake Pontchartrain Basin Foundation, New Orleans, Louisiana: U.S. Geological Survey Open-File Report 02-206, accessed May 22, 2007, at URL http://pubs. usgs.gov/of/2002/ofo2-206/index.htm

Chefetz, B., Bilkis, Y.I., and Polubesova, T., 2004, Sorptiondesorption behavior of triazine and phenylurea herbicides in Kishon river sediments: Water Research, v. 38, p. 4,383-4,394.

Chen, G., Witt, E.C., Hoffman, D., Luna, R., and Sevi, A., 2006, Analysis of the Interstate-10 Twin Bridges collapse during Hurricane Katrina, in Farris, G.S., Smith, G.J., Crane, M.P., Demas, C.R., Robbins, L.L., and Lavoie, D.L., eds., Science and the storms - the USGS response to the hurricanes of 2005: U.S. Geological Survey Circular 1306, p. $35-42$.

Choi, S.C., Wai, Onyx W.H., Choi, Thomas W.H., Li, X.D., and Tsang, C.W., 2006, Distribution of cadmium, chromium, copper, lead and zinc in marine sediments in Hong Kong waters: Environmental Geology, v. 51, p. 455-461.

Clark, G.M., and Goolsby, D.A., 2000, Occurrence and load of selected herbicides and metabolites in the lower Mississippi River: The Science of the Total Environment, v. 248, p. 101-113.

Cobb, G.P., Abel, M.T., Rainwater, T. R., Austin, G.P., Cox, S.B., Kendall, R.J., Marsland, E.J., Andersoin, T.A., Leftwich, B.D., Zak, J.C., and Presley, S.M., 2006, Metal distributions in New Orleans following Hurricanes Katrina and Rita-a continuation study: Environmental Science and Technology, v. 40, no. 15 , p. 4,571-4,577.
Godskesen, B., Holm, P.E., Jacobsen, O.S., and Jacobsen, C.S., 2005, Aging of triazine amine in soils demonstrated through sorption, desorption, and bioavailability measurements: Environmental Toxicology and Chemistry, v. 24, p. $510-516$.

Huang, P.M., Grover, R., and McKercher, R.B., 1984, Components and particle size fraction involved in atrazine adsorption by soils: Soil Science, v. 138, p. 20-24.

Knabb, R.D., and Brown, D.P., 2006, Tropical cyclone report Tropical Storm Zeta 30 December-6 January, 2006: National Oceanic and Atmospheric Administration, National Hurricane Center, p. 10.

Knabb, R.D., Rhome, J.R., and Brown, D.P., 2006a, Tropical cyclone report Hurricane Katrina 23-30 August 2005: National Oceanic and Atmospheric Administration, National Hurricane Center, p. 43.

Knabb, R.D., Brown, D.P., and Rhome, J.R., 2006b, Tropical cyclone report Hurricane Rita 18-26 September 2005: National Oceanic and Atmospheric Administration, National Hurricane Center, p. 33.

Kolb, C.R., and Saucier, R.T., 1982, Engineering geology of New Orleans: Geological Society of America, Reviews in Engineering Geology, v. 5, p. 75-93.

Kumpiene, J., Ore, S., Renella, G., Mench, M., Lagerkvist, A., and Maurice, C., 2006, Assessment of zerovalent iron for stabilization of chromium, copper, and arsenic in soil: Environmental Pollution, v. 144, p. 62-69.

Louisiana State University, 2007, The Louisiana Statewide GIS: LOSCO Environmental Baseline Inventory Dataset 'Land and Water Interface of the Louisiana Coastal Region, Geographic NAD83, LOSCO, 2000 Landwater shapefile retrieved June 18, 2007, from URL http://www.atlas.lsu. edu.

Luna, R., Summers, D., Hoffman, D., Rogers, D., Sevi, A., and Witt, E.C., III, 2006, Geotechnical reconnaissance of flood protection system post-Hurricane Katrina: in Farris, G.S., Smith, G.J., Crane, M.P., Demas, C.R., Robbins, L.L., and Lavoie, D.L., eds., Science and the storms-the USGS response to the hurricanes of 2005: U.S. Geological Survey Circular 1306, p. 27-34.

McGee, B.D., Goree, B.B., Tollett, R.W., Woodward, B.K., and Kress, W.H., 2006, Hurricane Rita surge data, southwestern Louisiana and southeastern Texas, September to November 2005: U.S. Geological Survey Data Series 220, accessed July 11, 2007, at URL http://pubs.water.usgs.gov ds220.

McLean, E.O. 1982, Soil pH and lime requirement: in Page, A.L. and others, eds., Methods of soil analysis, pt. 2, (2d 
ed.): Madison, Wis., American Society of Agronomy, Inc., Agronomy, v. 9, p. 199-224.

McMillin, D.J., and Means, J.C., 1996, Spatial and temporal trends of pesticide residues in water and particulates in the Mississippi River plume and the northwestern Gulf of Mexico: Journal of Chromatography A, v. 754, p. 169-185.

Mielke, H.W., Dugas, D., Mielke, P.W., Smith, K.S., Smith, S.L., and Gonzales, C.R., 1997, Associations between soil lead and childhood blood lead in urban New Orleans and rural Lafourche Parish of Louisiana: Environmental Health Perspectives, v. 105, no. 9, p. 950-954.

Mielke, H.W., Gonzales, C.R., Smith, M.K., and Mielke, P.W., 1999, The urban environment and children's health: Solis as an integrator of lead, zinc, and cadmium in New Orleans, Louisiana, U.S.A.: Environmental Research, v. 81, no. 2, p. 117-129.

Mielke, H.W., Gonzales, C.R., Smith, M.K., and Mielke, P.W., 2000, Quantities and associations of lead, zinc, cadmium, manganese, chromium, nickel, vanadium, and copper in fresh Mississippi delta alluvium and New Orleans alluvial soils: Science of the Total Environment, v. 246, no. 2-3, p. 249-259.

Mielke, H.W., Powell, E.T., Shah, A., Gonzales, C.R., and Mielke, P.W., 2001, Multiple metal contamination from house paints: consequences of power sanding and paint scraping in New Orleans: Environmental Health Perspectives, v. 109, no. 9, p. 973-978.

Mielke, H.W., Powell, E.T., Gonsales, C.R., and Mielke, P.W., Ottesen, R.T., Langedal, M., 2006, New Orleans soil lead $\mathrm{Pb})$ cleanup using Mississippi River alluvium-Need, feasibility, and cost: Environmental Science and Technology, v. 40 , no. 8 , p. $2,784-2,789$.

Mielke, H.W., Powell, E.T., Gonsales, C.R., and Mielke, P.W., 2007, Potential lead on play surfaces-Evaluation of the "PLOPS" sampler as a new tool for primary lead prevention: Environmental Research, v. 103, issue 2, p. 154-159.

Moore, N.R., 1972, Improvement of the Lower Mississippi River and tributaries 1931-1972: Vicksburg, Miss., U.S. Army Corps of Engineers, Mississippi River Commission.

Neuendorf, K.K.E., Mehl, J.P., and Jackson, J.A., eds., 2005, Glossary of geology (5th ed.): Alexandria, Va., American Geological Institute, p. 584.

Omernik, J.M., 1995, Ecoregions-A spatial framework for environmental management: in Davis, W.S. and Simon, T.P., eds., Biological assessments and criteria-Tools for water resources planning and decision making: Boca Raton, Fla., Lewis Publishers, p. 49-62.

Osgood, D.T., Santos, M.C.V., and Zieman, J.C., 1995, Sediment physico-chemistry associated with natural marsh development on a storm-deposited sand flat: Marine Ecology Progress Series 120, p. 271-283.

Osgood, D.T., and Zieman, J.C., 1993, Spatial and temporal patterns of substrate physicochemical parameters in different-aged barrier island marshes: Estuarine Coastal Shelf Science 37, p. 421-436.

Pardo, R., Barrado E., Perez L., and Vega, M., 1990, Determination and speciation of heavy metals in sediments of the Posuerga River: Water Resources, v. 24, p. 373-379.

Sastre, J., Hernandez, E., Rodroguez, R., Alcobe, X., Vidal, M., and Rauret, G., 2004, Use of sorption and extraction tests to predict the dynamics of the interaction of trace elements in agricultural soils contaminated by a mine tailing accident: Science of the Total Environment, v. 329, p. 261-281.

Saucier, R.T., 1963, Recent geomorphic history of the Pontchartrain Basin—Louisiana: Baton Rouge, La., Louisiana State University Press, Coastal Studies Series No. 9, p. 114.

Schwab, A.P., Splichal, P.A., and Banks, M.K., 2006, Adsorption of atrazine and alachlor to aquifer material and soil: Water, Air, and Soil Pollution, v. 177, p. 119-134.

Sericano, J.L., Atlas, E.L., Wade, T.L., Brooks, J.M., 1989, NOAA's status and trends mussel watch program-chlorinated pesticides and PCBs in oysters (Crassostrea virginica) and sediments from the Gulf of Mexico, 1986-1987: Marine Environmental Research, v. 29, p. 161-203.

Sjoberg, S.G., 1950, Vanadium pentoxide dust-A clinical and experimental investigation on its effects after inhalation: Acta Medical Scandinavia, v. 138, supplemental 238, p. 1-188.

Sposito, Garrison, 1989, The chemistry of soils: New York, Oxford University Press, p. 6.

Stumm, W., and Morgan, J.J., 1981, Aquatic chemistry—an introduction emphasizing chemical equilibria in natural waters ( $2 \mathrm{~d}$ ed.): New York, Wiley, 780 p.

Taylor, J.K., 1987, Quality assurance of chemical measurements: Boca Raton, Fla., CRC Press LLC, 328 p.

Tessier, A., Campbell, P.G.C., and Bisson, M., 1979, Sequential extraction procedure for the speciation of particulate trace elements: Analytical Chemistry, v. 51, no. 7, p. $844-851$.

Tiessen H., and Moir, J.O.. 1993, Total and organic carbon: in Carter, M.E., ed., Soil sampling and methods of analysis: Ann Arbor, Mich., Lewis Publishers, p. 187-211.

U.S. Environmental Protection Agency, 1992, Method 7000A-Atomic absorption methods: EPA-SW-846-On- 
line, (3d ed.): accessed on July 11, 2007, at URL http:// www.epa.gov/epaoswer/hazwaste/test/pdfs/7000a.pd].

U.S. Environmental Protection Agency, 1994, Method 200.8, Determination of trace elements in waters and wastes by inductively coupled plasma-mass spectrometry, (revision 5.4), Creed, J.T., Brockhoff, C.A., and Martin, T.D. eds.: Cincinnati, Ohio, U.S. Environmental Protection Agency, Environmental Monitoring Systems Laboratory, Office of Research and Development, p. 1-57.

U.S. Environmental Protection Agency, 1995, Method 508, Determination of chlorinated pesticides in water by gas chromatography with an electron capture detector, (revision 3.1), Munch, J. W. ed.: Cincinnati, Ohio, U.S. Environmental Protection Agency, National Exposure Research Laboratory, Office of Research and Development, p. 1-30.

U.S. Environmental Protection Agency, 1996, Method 8082, Polychlorinated biphenyls (PCB) by gas chromatography, (revision O): Washington, D.C., U.S. Environmental Protection Agency, p. 1-41.

U.S. Environmental Protection Agency, 1998, Method 3051A, Microwave assisted acid digestion of sediments, sludges, soils, and oils: Washington, D.C., U.S. Environmental Protection Agency, p 25.

U.S. Environmental Protection Agency, 2000, Method 3550C, Ultrasonic extraction, (revision 3), SW-846: Washington, D.C., U.S. Environmental Protection Agency, p. 1-16.

U.S. Environmental Protection Agency, 2001, Lead-Identification of dangerous levels of lead, Final Rule, Part III: Federal Register, 40 CFR Part 745, p. 1,211.

U.S. Environmental Protection Agency, 2002a, Method 1631, Mercury in water by oxidation, purge and trap, and cold vapor atomic fluorescence spectrometry, (revision E): Office of Water 4303, EPA-821-R-02-019, p. 1-38.

U.S. Environmental Protection Agency, 2002b, Methods for the determination of total organic carbon in soil and sediments, Schumacher, B.A., ed., Ecological Risk Assessment Support Center, Office of Research and Development, NCEA-C-1282 EMASC-001 p. 258.

U.S. Environmental Protection Agency, 2006a, EPA Region 6, Human health medium-specific screening levels: Dallas, Tex., U.S. Environmental Protection Agency, p. 36, accessed on July 11, 2007, at URL http://www.epa. gov/earth1r6/6pd/rcra_c/pd-n/screen.htm.

U.S. Environmental Protection Agency, 2006b, Technology transfer network air toxics website-Methoxychlor: accessed on July 11, 2007, at URL http://www.epa.gov/ttn atw/hlthef/methoxyc.htm.

U.S. Environmental Protection Agency, 2007, Method 7000B, Flame atomic absorption spectrophotometry (revision 2):
EPA-SW-846-Online, accessed on July 23, 2008, at URL http://www.epa.gov/sw-846/pdfs/7000b.pdf.

U.S. Geological Survey, 2004, The National Geochemical Survey_database and documentation: U.S. Geological Survey Open-File Report 2004-1001, accessed January 16, 2006, at URL http://tin.er.usgs.gov/geochem.

U.S. Geological Survey, 2007, National Water Information System USGS Real-Time Data for the Nation: accessed March 14, 2007, at URL http://waterdata. usgs.gov/nwis.

National Oceanic and Atmospheric Administration, [n.d.], NOAA Technical Memorandum NMFS-NE-167, Assessment and characterization of salt marshes in the Arthur Kill (New York and New Jersey) replanted after a severe oil spill: accessed June 13, 2007, at URL http://www.nefsc.noaa.gov/nefsc/publications/tm/tm1671 tm167p4.htm.

National Oceanic and Atmospheric Administration, National Weather Service, National Hurricane Center, [n.d.], 2005 Atlantic Hurricane Season: accessed February 1, 2007, at URL http://www.nhc.noaa.gov/2005atlan.shtm

National Oceanic and Atmospheric Administration, National Weather Center, [n.d.], Hurricane Katrina Advisory Archive: accessed February 1, 2007, at URL http://www. nhc.noaa.gov/archive/2005/KATRINA.shtm.

Weber, J.B., Wilkerson, G.G., and Reinhardt, C.F., 2004, Calculating pesticide sorption coefficients $(\mathrm{Kd})$ using selected soil properties: Chemosphere, v. 55, p. 157-166.

World Health Organization, 1996, Methoxychlor in drinkingwater-Background document for development of WHO guidelines for drinking-water quality, ( $2 \mathrm{~d}$ ed.), Health criteria and other supporting information: Geneva, World Health Organization, v. 2, p. 15.

Witt, E.C., Adams, C., Wang, J., Shaver, D.K., and Filali-Meknassi, Y., 2006, Selected chemical composition of deposited dediments in the flooded areas of New Orleans, Louisiana, following Hurricane Katrina: in Farris, G.S., Smith, G.J., Crane, M. P., Demas, C.R., Robbins, L.L., and Lavoie, D.L., eds., Science and the storms - the USGS response to the hurricanes of 2005: U.S. Geological Survey Circular 1306, p. 201-206.

Witt, E.C., Adams, C., Wang, J., Shaver, D.K., and FilaliMeknasi, Y., 2006, Soil and sediment chemistry in the Mississippi Delta following Hurricane Katrina: in Farris, G.S., Smith, G.J., Crane, M. P., Demas, C.R., Robbins, L.L., and Lavoie, D.L., eds., Science and the storms: the USGS response to the hurricanes of 2005: U.S. Geological Survey Circular 1306, p. 207-212. 


\section{Tables}

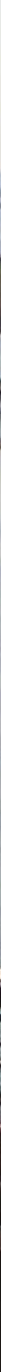




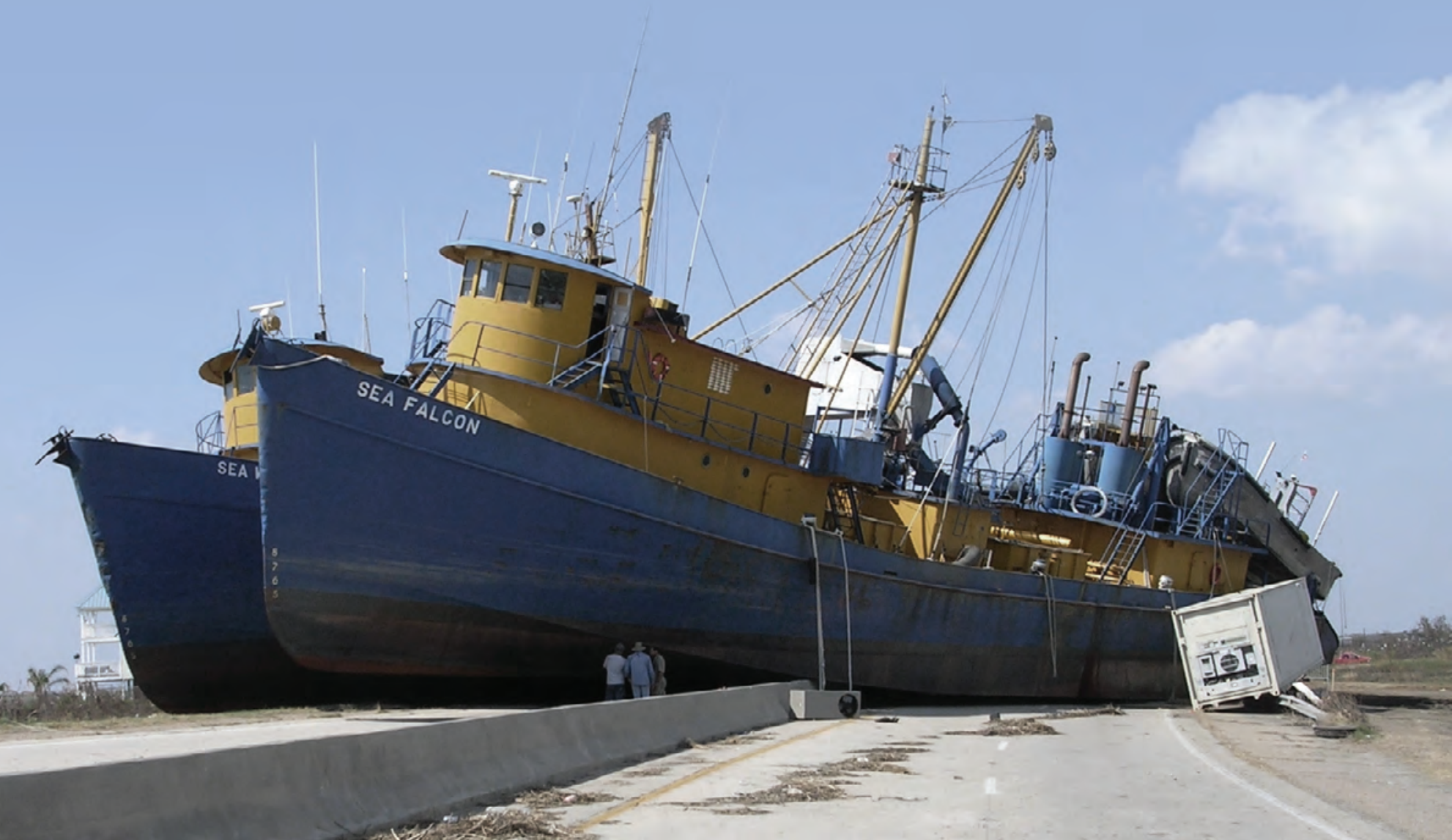




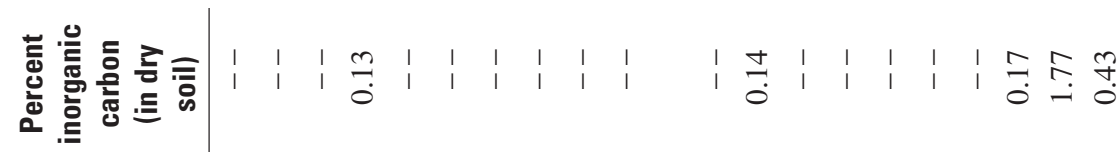

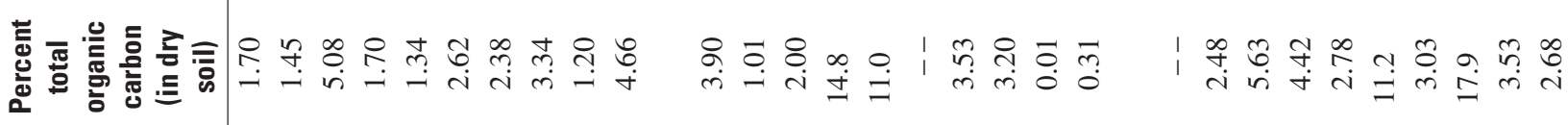

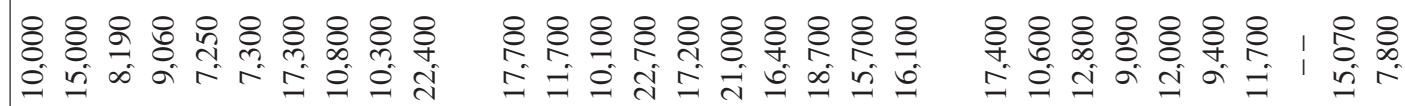

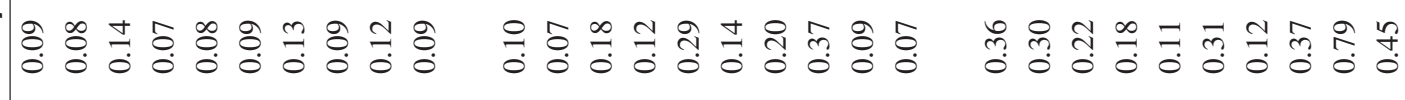

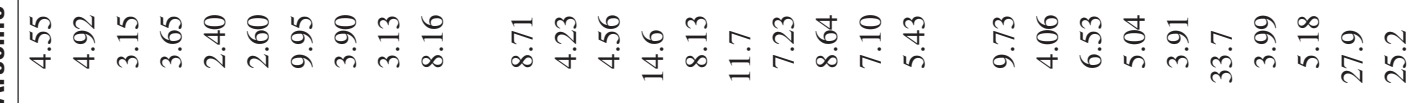

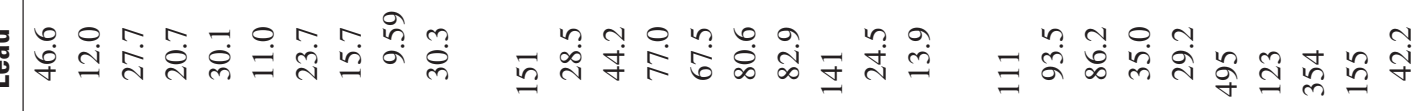

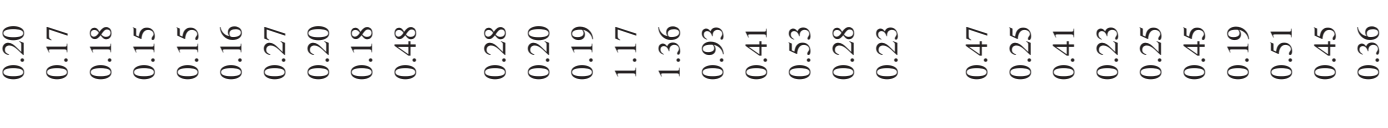

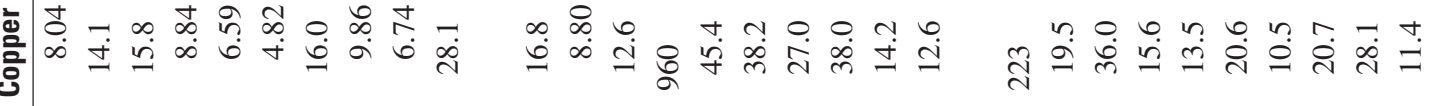

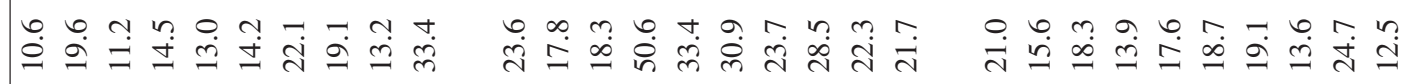

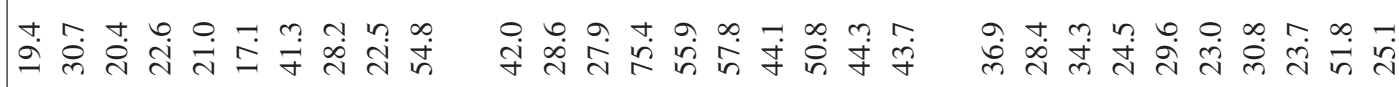

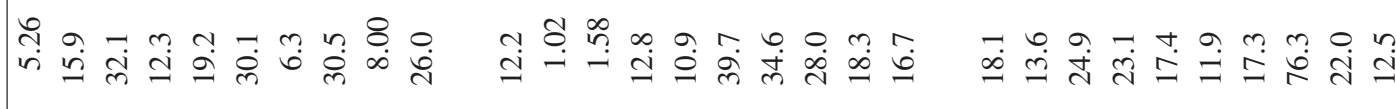

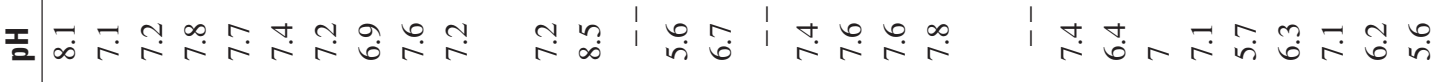

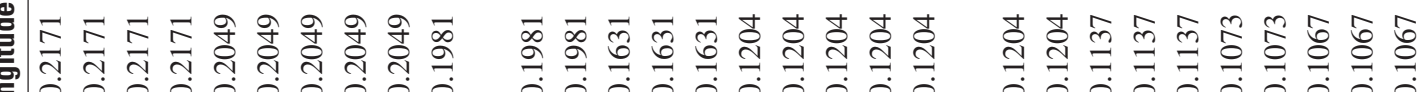

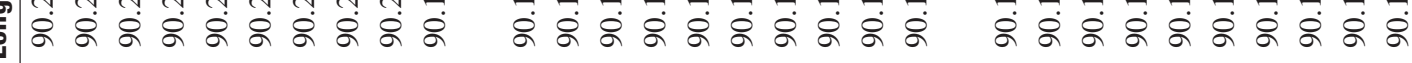

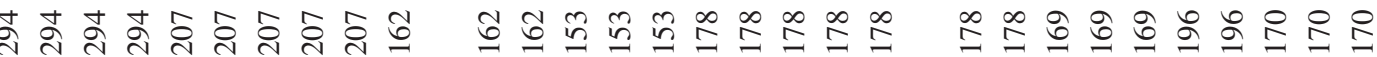

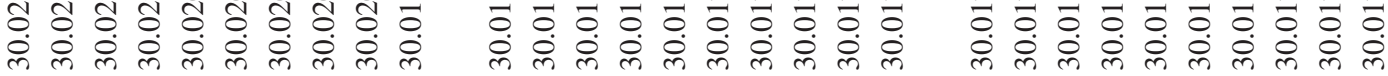

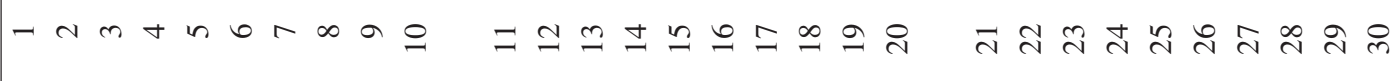




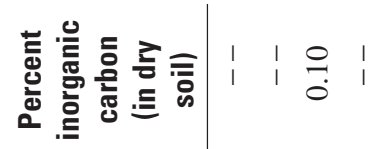

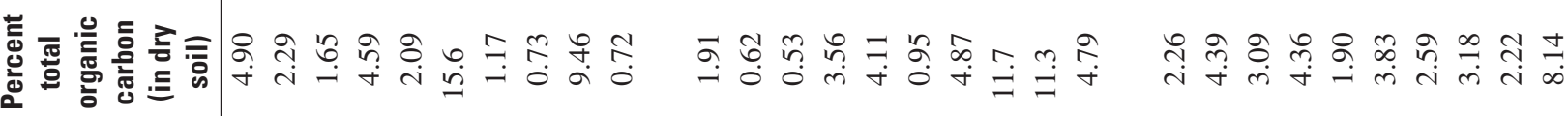

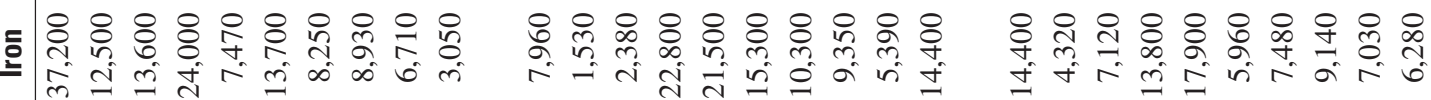

馬

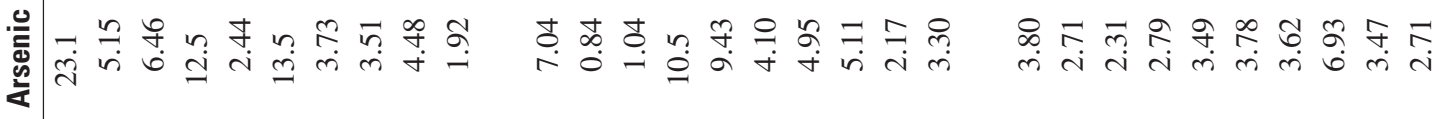

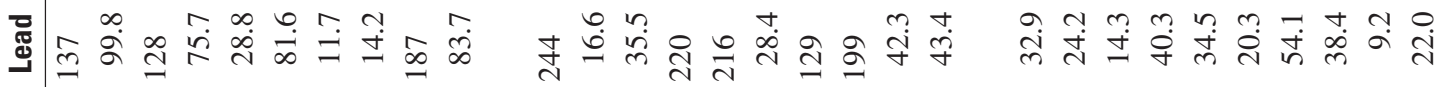

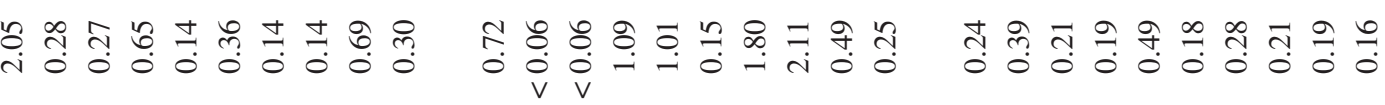

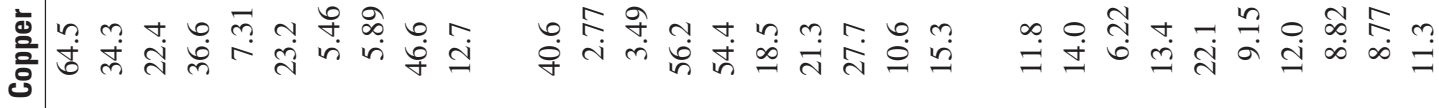

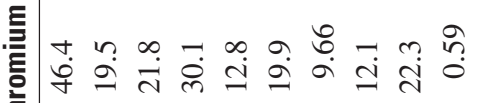

तु

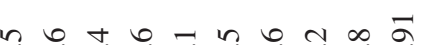

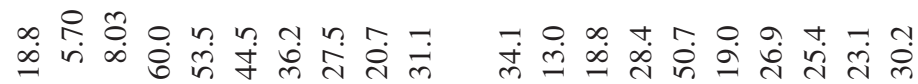

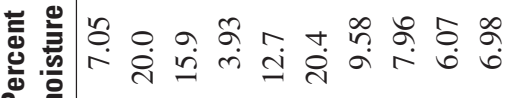

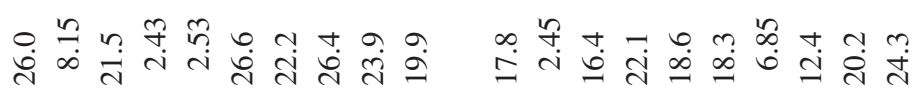

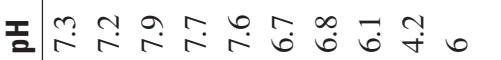

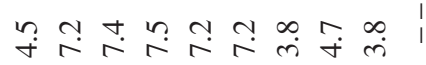

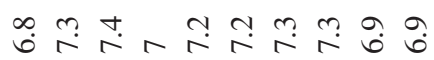

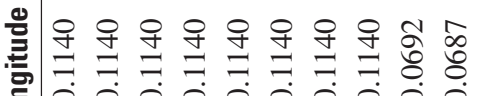

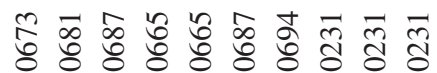

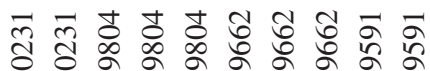

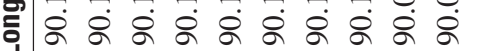

ஃ

वें के के के के के के

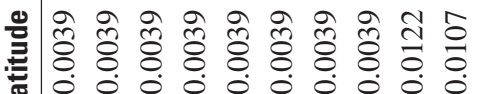

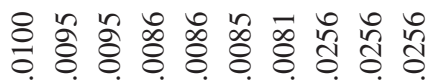

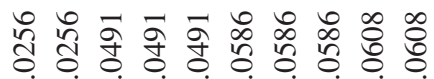

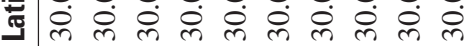

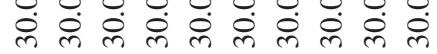

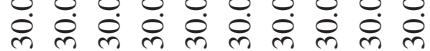

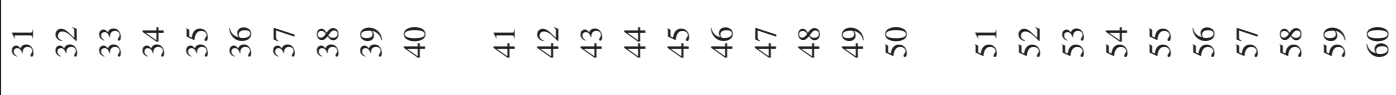




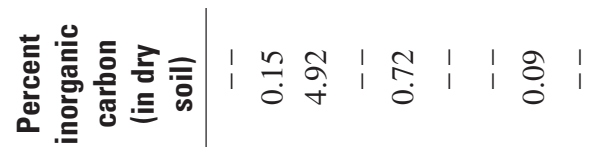

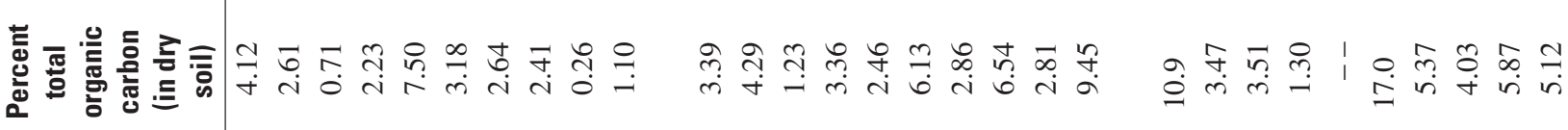

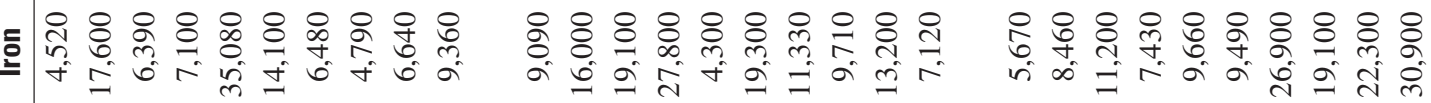

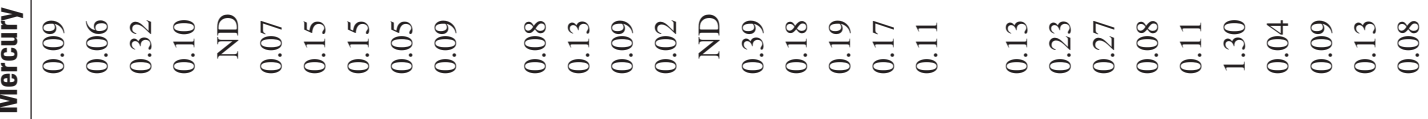

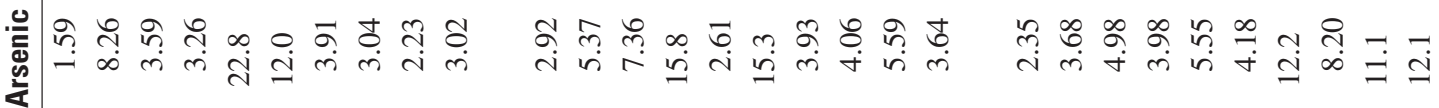

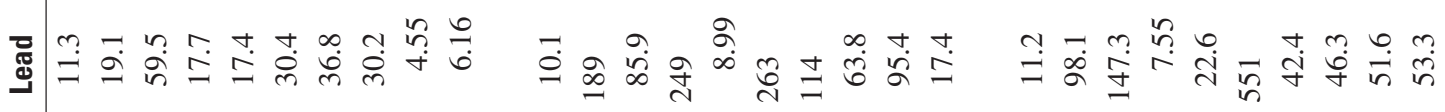

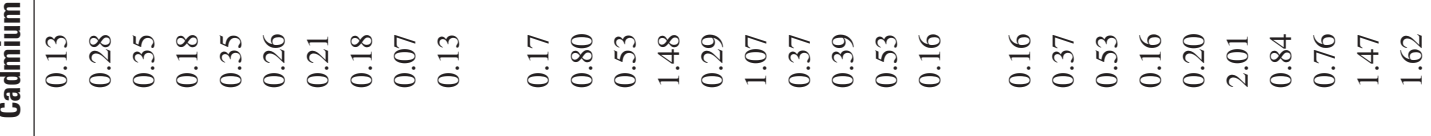

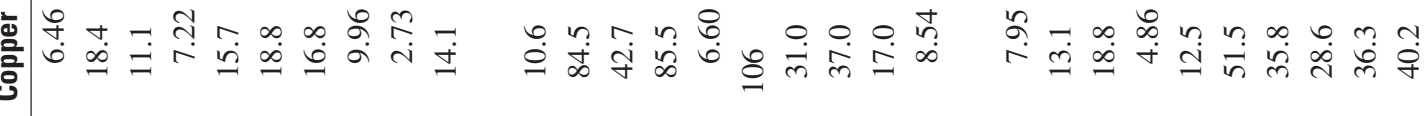

苛

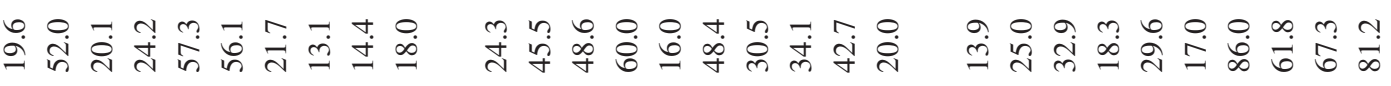

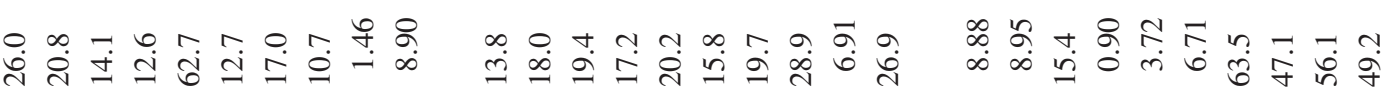

존

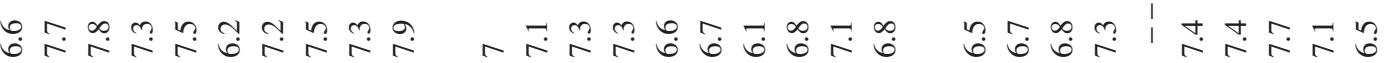

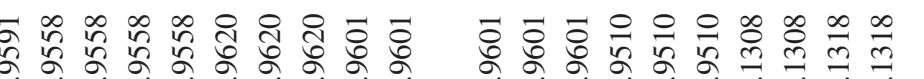

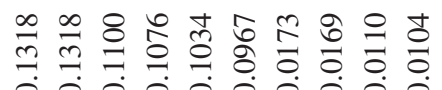

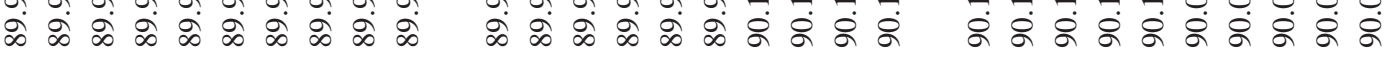

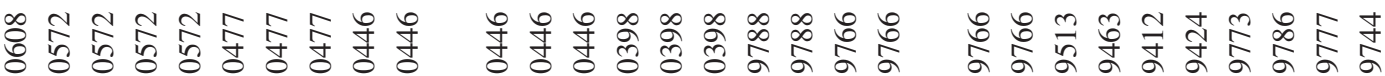

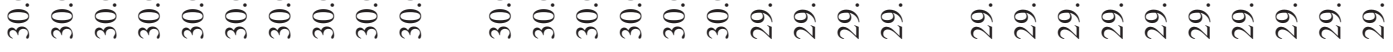

எ 


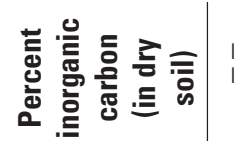

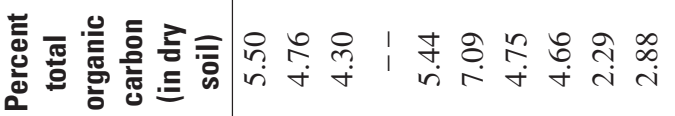

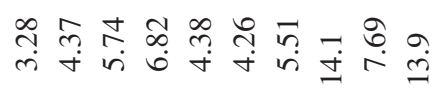

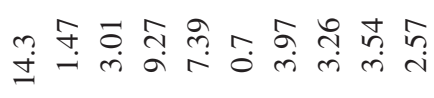

흐

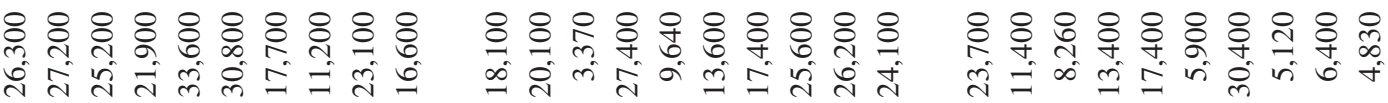

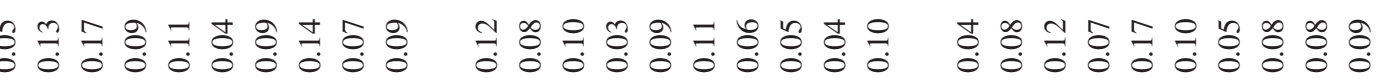

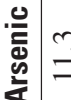

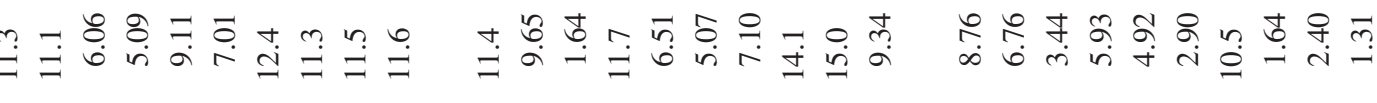

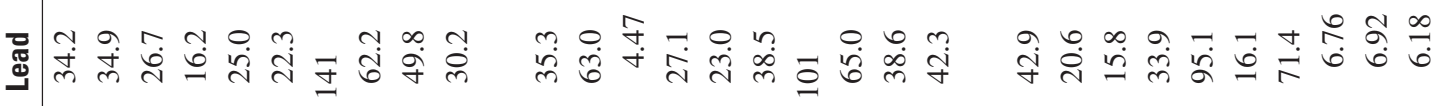

車

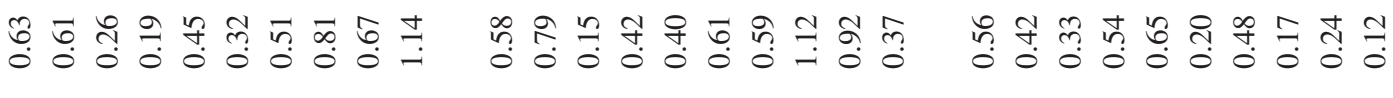

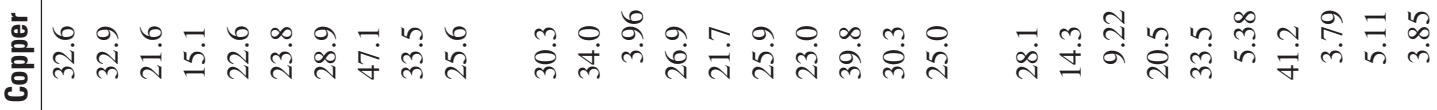

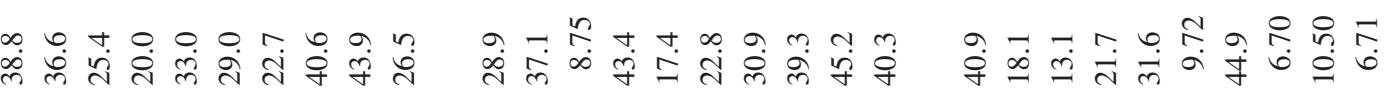

幽

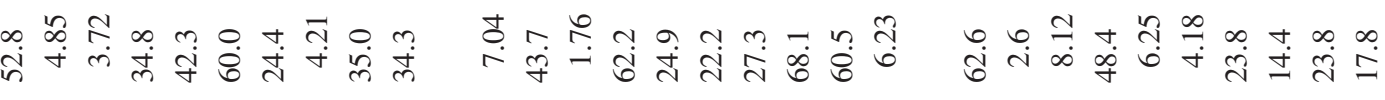

工至

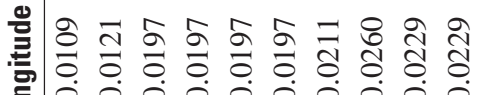

సิ હิ

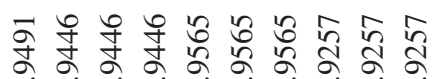

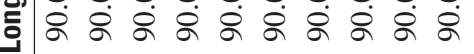

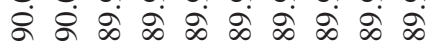

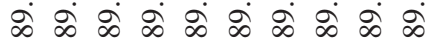

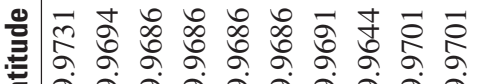

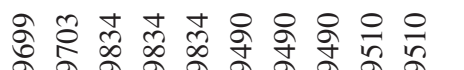

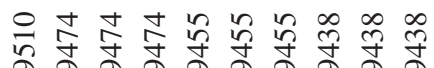

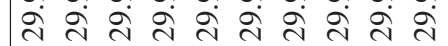

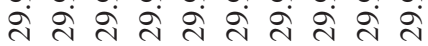

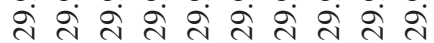

悹竞

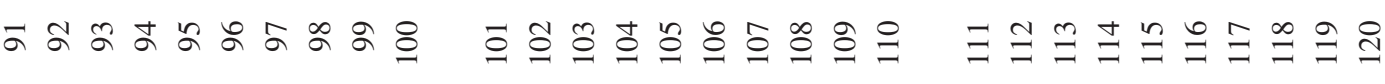




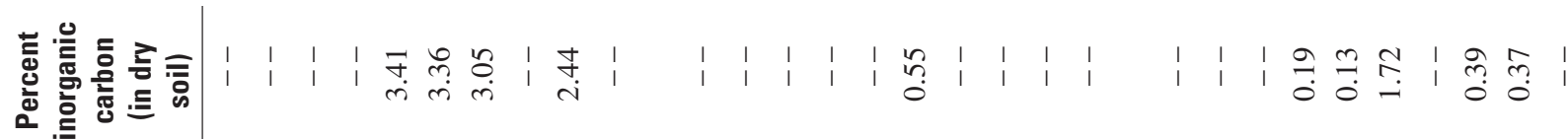

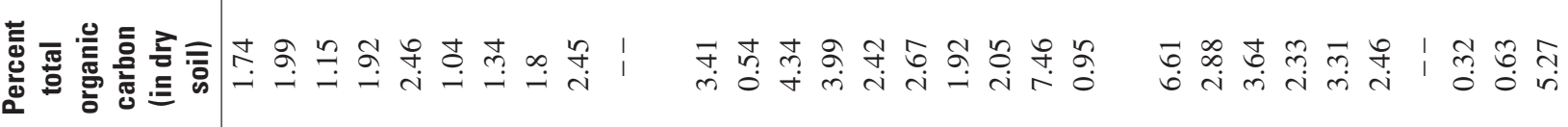

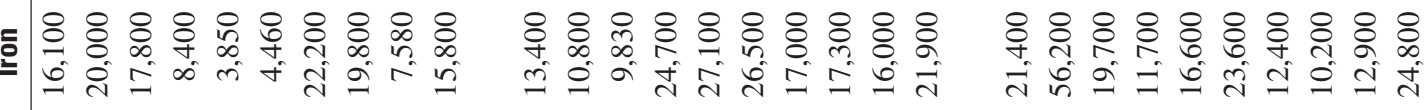

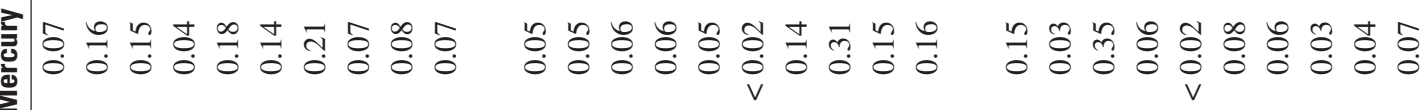

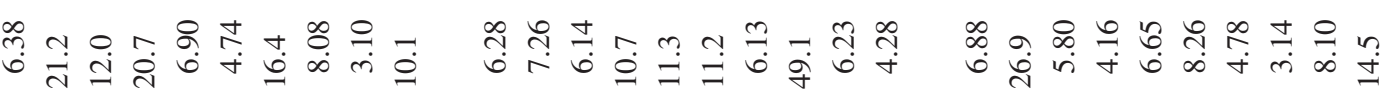

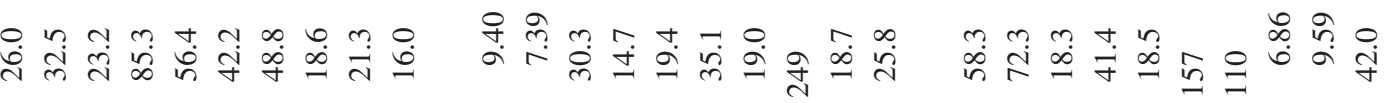
茯 产豙过 กูำ ำ

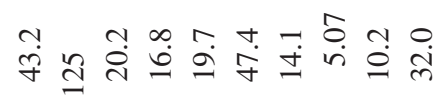

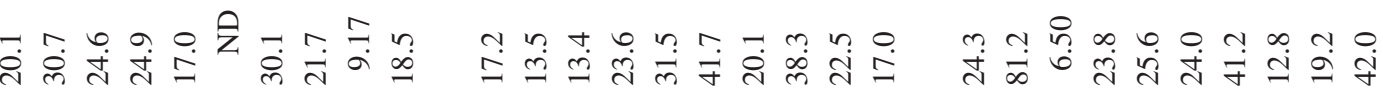

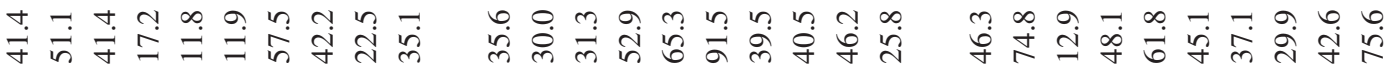
ঢ엄

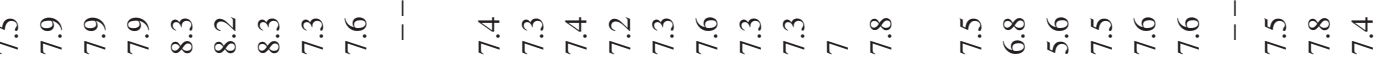

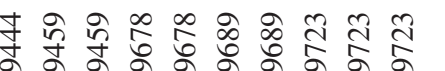

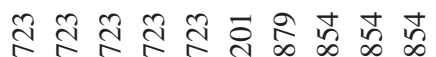

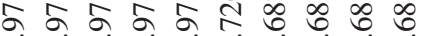

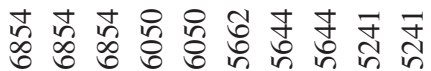

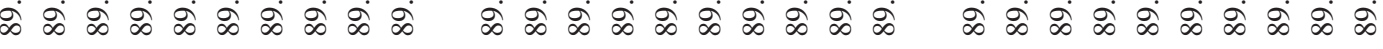



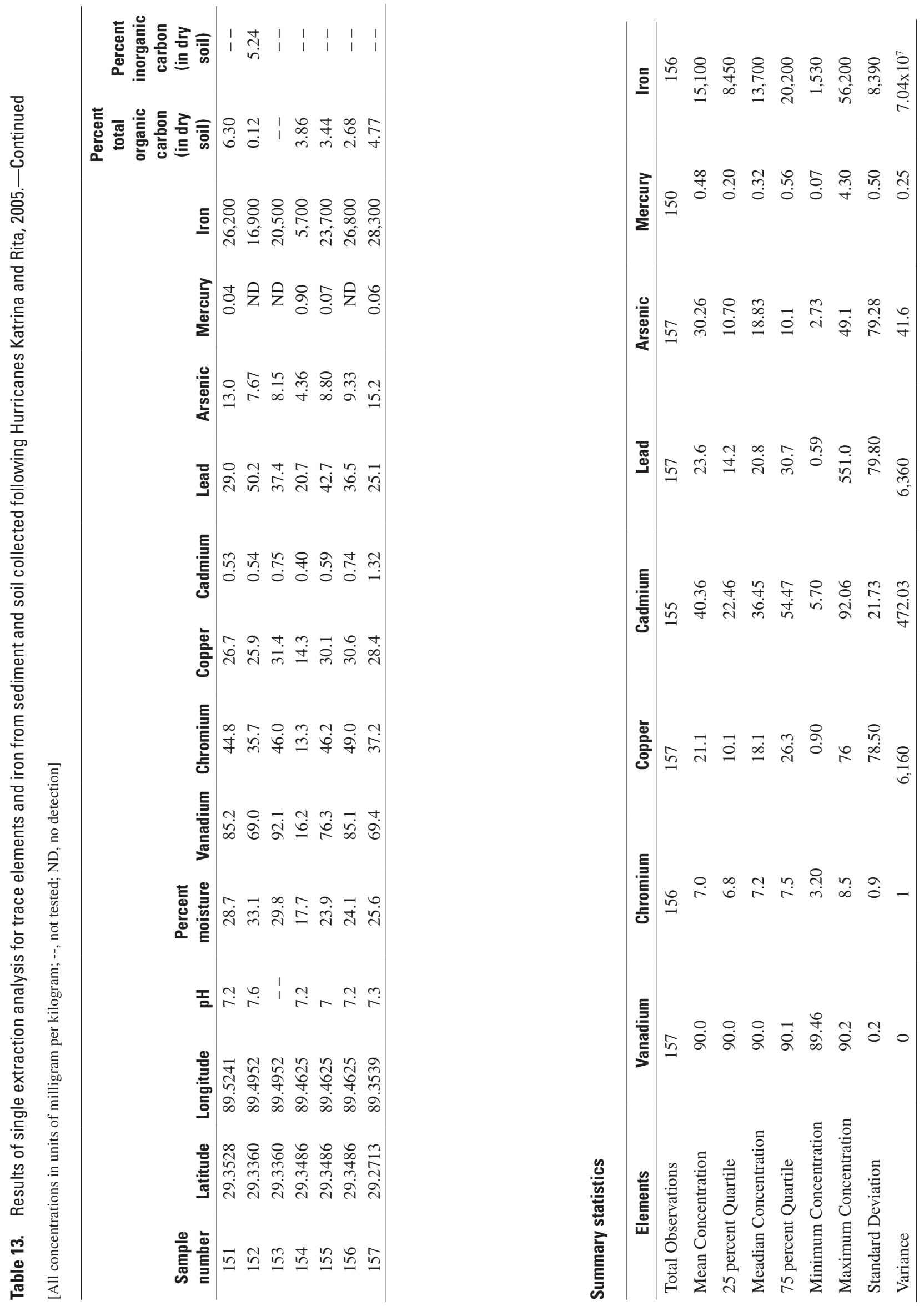
Table 14. Results of sequential extraction analysis for lead from sediment and soil collected following Hurricanes Katrina and Rita.

[mg/kg, milligram per kilogram; F1, exchangeable fraction; F2, bound to carbonate fraction; F3, iron and manganese oxides fraction; F4, organic matter fraction; F5, residual; <, less than]

\begin{tabular}{|c|c|c|c|c|c|c|c|c|c|}
\hline \multirow{2}{*}{$\begin{array}{l}\text { Sample } \\
\text { number }\end{array}$} & \multicolumn{2}{|c|}{ Location } & \multicolumn{6}{|c|}{ Sequential Extraction fraction (mg/kg dry soil) } & \multirow{2}{*}{$\begin{array}{l}\text { Single extraction } \\
\text { (mg/kg dry soil) }\end{array}$} \\
\hline & Latitude & Longitude & F1 & F2 & F3 & F4 & F5 & Sum (F) & \\
\hline 10 & 30.0162 & 90.1981 & $<0.10$ & 2.09 & 14.3 & 7.62 & 11.8 & 35.8 & 30.3 \\
\hline 15 & 30.0153 & 90.1631 & 0.22 & 6.88 & 18.0 & 18.13 & 14.5 & 57.7 & 67.5 \\
\hline 16 & 30.0178 & 90.1204 & $<0.10$ & 10.8 & 42.7 & 8.22 & 17.1 & 78.7 & 80.6 \\
\hline 26 & 30.0196 & 90.1073 & 88.4 & 108 & 175.3 & 169 & 53.7 & 595 & 495 \\
\hline 31 & 30.0039 & 90.1140 & 0.21 & 14.61 & 41.8 & 17.2 & 36.4 & 110.18 & 137 \\
\hline 34 & 30.0039 & 90.1140 & 0.30 & 5.82 & 25.3 & 17.7 & 24.0 & 73.1 & 75.7 \\
\hline 36 & 30.0039 & 90.1140 & 3.60 & 6.23 & 36.17 & 29.3 & 17.6 & 92.9 & 81.6 \\
\hline 44 & 30.0086 & 90.0665 & 2.51 & 41.2 & 94.4 & 21.6 & 60.0 & 220 & 220 \\
\hline 65 & 30.0572 & 89.9558 & $<0.10$ & 1.10 & 4.83 & 0.97 & 8.34 & 15.2 & 17.4 \\
\hline 88 & 29.9786 & 90.0169 & $<0.10$ & 7.96 & 26.2 & 5.99 & 12.3 & 52.5 & 46.3 \\
\hline 89 & 29.9777 & 90.0110 & $<0.10$ & 2.76 & 32.4 & 7.11 & 13.3 & 55.6 & 51.6 \\
\hline 90 & 29.9744 & 90.0104 & 0.12 & 3.24 & 28.2 & 6.61 & 16.2 & 54.4 & 53.3 \\
\hline 91 & 29.9731 & 90.0109 & 0.14 & 4.38 & 13.8 & 3.34 & 12.0 & 33.7 & 34.2 \\
\hline 92 & 29.9694 & 90.0121 & $<0.10$ & 7.57 & 20.0 & 4.61 & 14.3 & 46.5 & 49.8 \\
\hline 95 & 29.9686 & 90.0197 & 0.10 & 1.51 & 15.5 & 4.89 & 11.5 & 33.5 & 25.0 \\
\hline 96 & 29.9686 & 90.0197 & 0.14 & 2.59 & 14.11 & 4.11 & 9.14 & 30.1 & 22.3 \\
\hline 97 & 29.9691 & 90.0211 & 0.81 & 18.5 & 58.0 & 46.4 & 37.7 & 161 & 141 \\
\hline 98 & 29.9644 & 90.0260 & 0.16 & 4.26 & 24.6 & 13.9 & 36.3 & 79.2 & 62.2 \\
\hline 99 & 29.9701 & 90.0229 & $<0.10$ & 1.75 & 10.01 & 5.25 & 18.3 & 35.3 & 34.9 \\
\hline 101 & 29.9699 & 90.0229 & $<0.10$ & 4.17 & 20.33 & 3.59 & 15.6 & 43.7 & 35.3 \\
\hline 102 & 29.9703 & 90.0230 & $<0.10$ & 4.63 & 31.16 & 5.39 & 13.6 & 54.8 & 63.0 \\
\hline 117 & 29.9455 & 89.9565 & 0.21 & 1.84 & 18.5 & 19.5 & 22.4 & 62.4 & 71.4 \\
\hline 122 & 29.9314 & 89.9459 & $<0.10$ & 1.32 & 20.4 & 3.83 & 12.2 & 37.8 & 32.5 \\
\hline 124 & 29.9336 & 89.9678 & $<0.10$ & 2.18 & 26.2 & 5.67 & 13.8 & 47.8 & 85.3 \\
\hline 127 & 29.9313 & 89.9689 & $<0.10$ & 6.02 & 32.4 & 3.91 & 6.94 & 49.2 & 48.8 \\
\hline 135 & 29.6703 & 89.9723 & $<0.10$ & $<0.10$ & 6.59 & 2.42 & 16.1 & 25.1 & 19.4 \\
\hline 136 & 29.5004 & 89.7201 & $<0.10$ & 0.64 & 12.2 & 2.41 & 15.7 & 30.9 & 35.1 \\
\hline 138 & 29.4722 & 89.6854 & 0.18 & 22.3 & 118 & 19.2 & 67.4 & 227 & 249 \\
\hline 142 & 29.4722 & 89.6854 & $<0.10$ & 2.96 & 16.63 & 1.09 & 66.1 & 86.8 & 72.3 \\
\hline 145 & 29.3883 & 89.6050 & $<0.10$ & 1.07 & 3.91 & 0.99 & 10.7 & 16.7 & 18.5 \\
\hline 150 & 29.3528 & 89.5241 & 0.32 & 0.86 & 16.0 & 4.22 & 6.36 & 27.8 & 42.1 \\
\hline 151 & 29.3528 & 89.5241 & 0.49 & 1.39 & 13.1 & 4.63 & 10.2 & 29.9 & 29.0 \\
\hline 152 & 29.3360 & 89.4952 & $<0.10$ & 4.42 & 14.4 & 5.02 & 9.92 & 33.7 & 50.2 \\
\hline 153 & 29.3360 & 89.4952 & $<0.10$ & 2.27 & 10.1 & 2.9 & 13.5 & 28.7 & 37.4 \\
\hline 155 & 29.3486 & 89.4625 & $<0.10$ & 0.92 & 8.36 & 5.88 & 13.6 & 28.8 & 42.7 \\
\hline 156 & 29.3486 & 89.4625 & 0.63 & $<0.10$ & 7.43 & 6.13 & 17.3 & 31.5 & 36.5 \\
\hline 157 & 29.2713 & 89.3539 & $<0.10$ & 2.33 & 15.9 & 3.6 & 14.1 & 35.9 & 25.1 \\
\hline
\end{tabular}


Table 15. Results of sequential extraction analysis for vanadium from sediment and soil collected following Hurricanes Katrina and Rita.

[mg/kg, milligram per kilogram; F1, exchangeable fraction; F2, bound to carbonate fraction; F3, iron and manganese oxides fraction; F4, organic matter fraction; F5, residual; <, less than; --, not tested]

\begin{tabular}{|c|c|c|c|c|c|c|c|c|c|}
\hline \multirow{2}{*}{$\begin{array}{l}\text { Sample } \\
\text { number }\end{array}$} & \multicolumn{2}{|c|}{ Location } & \multicolumn{6}{|c|}{ Sequential extraction fraction (mg/kg dry soil) } & \multirow{2}{*}{$\begin{array}{l}\text { Single extraction } \\
\text { (mg/kg dry soil) }\end{array}$} \\
\hline & Latitude & Longitude & F1 & F2 & F3 & F4 & F5 & Sum (F) & \\
\hline 10 & 30.0162 & 90.1981 & $<1.00$ & $<1.00$ & 7.80 & 2.83 & 50.8 & 61.4 & 54.8 \\
\hline 15 & 30.0153 & 90.1631 & $<1.00$ & $<1.00$ & 5.62 & 8.21 & 30.3 & 44.2 & 55.9 \\
\hline 16 & 30.0178 & 90.1204 & $<1.00$ & $<1.00$ & 9.67 & 3.02 & 44.6 & 57.3 & 57.8 \\
\hline 26 & 30.0196 & 90.1073 & $<1.00$ & $<1.00$ & 8.52 & 2.23 & 57.8 & 68.5 & 60.0 \\
\hline 31 & 30.0039 & 90.1140 & $<1.00$ & $<1.00$ & 5.09 & 15.2 & 48.8 & 69.1 & 81.5 \\
\hline 34 & 30.0039 & 90.1140 & $<1.00$ & $<1.00$ & 9.55 & 11.5 & 55.9 & 77.0 & 83.5 \\
\hline 36 & 30.0039 & 90.1140 & $<1.00$ & $<1.00$ & 8.78 & 1.21 & 68.1 & 78.0 & 82.5 \\
\hline 44 & 30.0086 & 90.0665 & $<1.00$ & $<1.00$ & 7.55 & 2.99 & 56.2 & 66.7 & 52.6 \\
\hline 65 & 30.0572 & 89.9558 & $<1.00$ & $<1.00$ & 5.95 & 7.35 & 27.1 & 40.4 & 36.5 \\
\hline 66 & 30.0477 & 89.9620 & $<1.00$ & $<1.00$ & 17.8 & 2.07 & 59.6 & 79.5 & 82.0 \\
\hline 88 & 29.9786 & 90.0169 & $<1.00$ & $<1.00$ & 17.2 & 4.41 & 45.0 & 66.6 & 63.5 \\
\hline 89 & 29.9777 & 90.0110 & $<1.00$ & $<1.00$ & 12.8 & 4.38 & 69.2 & 86.4 & 81.2 \\
\hline 90 & 29.9744 & 90.0104 & $<1.00$ & $<1.00$ & 12.8 & 2.62 & 52.8 & 68.2 & 67.3 \\
\hline 91 & 29.9731 & 90.0109 & $<1.00$ & $<1.00$ & 18.3 & 2.84 & 61.5 & 82.7 & 59.3 \\
\hline 92 & 29.9694 & 90.0121 & $<1.00$ & $<1.00$ & 14.4 & 3.07 & 44.6 & 62.1 & 64.2 \\
\hline 95 & 29.9686 & 90.0197 & $<1.00$ & $<1.00$ & 10.1 & 2.30 & 25.2 & 37.7 & 61.8 \\
\hline 96 & 29.9686 & 90.0197 & $<1.00$ & $<1.00$ & 11.2 & 4.39 & 110 & 125.97 & 71.3 \\
\hline 97 & 29.9691 & 90.0211 & $<1.00$ & $<1.00$ & 2.92 & 5.66 & 16.9 & 25.5 & 23.0 \\
\hline 98 & 29.9644 & 90.0260 & $<1.00$ & $<1.00$ & 14.5 & 2.59 & 60.6 & 77.7 & 86.0 \\
\hline 99 & 29.9701 & 90.0229 & $<1.00$ & $<1.00$ & 12.4 & 2.75 & 63.6 & 78.7 & 76.3 \\
\hline 101 & 29.9699 & 90.0229 & $<1.00$ & $<1.00$ & 5.48 & 5.61 & 31.1 & 42.1 & 51.8 \\
\hline 102 & 29.9703 & 90.0230 & $<1.00$ & $<1.00$ & 3.94 & 2.21 & 12.2 & 18.4 & 25.1 \\
\hline 117 & 29.9455 & 89.9565 & $<1.00$ & $<1.00$ & 9.99 & 3.43 & 39.25 & 52.7 & 40.5 \\
\hline 122 & 29.9314 & 89.9459 & $<1.00$ & $<1.00$ & 17.5 & 2.65 & 32.7 & 52.9 & 74.8 \\
\hline 124 & 29.9336 & 89.9678 & $<1.00$ & $<1.00$ & 12.5 & 3.39 & 61.3 & 77.2 & 69.4 \\
\hline 127 & 29.9313 & 89.9689 & $<1.00$ & $<1.00$ & 13.1 & 4.54 & 21.3 & 39.0 & 75.6 \\
\hline 135 & 29.6703 & 89.9723 & $<1.00$ & $<1.00$ & 10.7 & 6.80 & 48.8 & 66.3 & 85.2 \\
\hline 136 & 29.5004 & 89.7201 & $<1.00$ & $<1.00$ & 10.1 & 3.19 & 51.6 & 64.9 & 76.3 \\
\hline 138 & 29.4722 & 89.6854 & $<1.00$ & $<1.00$ & 9.10 & 1.95 & 78.4 & 89.4 & 85.1 \\
\hline 142 & 29.4722 & 89.6854 & $<1.00$ & $<1.00$ & 5.56 & 9.16 & 45.2 & 59.9 & 58.5 \\
\hline 145 & 29.3883 & 89.6050 & $<1.00$ & $<1.00$ & 22.2 & 3.28 & 27.9 & 53.4 & 57.3 \\
\hline 150 & 29.3528 & 89.5241 & $<1.00$ & $<1.00$ & 13.8 & 5.21 & 57.1 & 76.1 & 88.2 \\
\hline 151 & 29.3528 & 89.5241 & $<1.00$ & 2.38 & 10.9 & 4.14 & 41.8 & 59.2 & 69.0 \\
\hline 152 & 29.3360 & 89.4952 & $<1.00$ & $<1.00$ & 17.0 & 6.05 & 63.7 & 86.8 & 92.1 \\
\hline 153 & 29.3360 & 89.4952 & $<1.00$ & $<1.00$ & 8.02 & 2.80 & 29.2 & 40.0 & 60.0 \\
\hline 155 & 29.3486 & 89.4625 & $<1.00$ & $<1.00$ & 13.1 & 2.43 & 79.8 & 95.3 & 89.7 \\
\hline 156 & 29.3486 & 89.4625 & $<1.00$ & $<1.00$ & -- & 8.14 & 34.2 & -- & 58.7 \\
\hline 157 & 29.2713 & 89.3539 & $<1.00$ & $<1.00$ & 14.1 & 11.1 & 82.7 & 108 & 85.6 \\
\hline
\end{tabular}


Table 16. Results of sequential extraction analysis for chromium from sediment and soil collected following Hurricanes Katrina and Rita.

[mg/kg, milligram per kilogram; F1, exchangeable fraction; F2, bound to carbonate fraction; F3, iron and manganese oxides fraction; F4, organic matter fraction; F5, residual; <, less than]

\begin{tabular}{|c|c|c|c|c|c|c|c|c|c|}
\hline \multirow{2}{*}{$\begin{array}{l}\text { Sample } \\
\text { number }\end{array}$} & \multicolumn{2}{|c|}{ Location } & \multicolumn{6}{|c|}{ Sequential extraction fraction (mg/kg dry soil) } & \multirow{2}{*}{$\begin{array}{l}\text { Single extractior } \\
\text { (mg/kg dry soil) }\end{array}$} \\
\hline & Latitude & Longitude & F1 & F2 & F3 & F4 & F5 & Sum (F) & \\
\hline 10 & 30.0162 & 90.1981 & $<1.00$ & $<1.00$ & 3.20 & 7.85 & 23.8 & 34.8 & 33.4 \\
\hline 15 & 30.0153 & 90.1631 & $<1.00$ & $<1.00$ & 3.51 & 8.41 & 14.4 & 26.3 & 33.4 \\
\hline 16 & 30.0178 & 90.1204 & $<1.00$ & $<1.00$ & 3.99 & 6.76 & 22.4 & 33.2 & 30.9 \\
\hline 26 & 30.0196 & 90.1073 & $<1.00$ & $<1.00$ & 7.98 & 12.8 & 31.4 & 52.2 & 44.9 \\
\hline 31 & 30.0039 & 90.1140 & $<1.00$ & $<1.00$ & 0.80 & 9.32 & 23.8 & 33.9 & 40.3 \\
\hline 34 & 30.0039 & 90.1140 & $<1.00$ & $<1.00$ & 1.52 & 9.78 & 23.6 & 34.9 & 40.9 \\
\hline 36 & 30.0039 & 90.1140 & $<1.00$ & $<1.00$ & 3.96 & 7.57 & 32.2 & 43.7 & 46.4 \\
\hline 44 & 30.0086 & 90.0665 & $<1.00$ & $<1.00$ & 2.55 & 7.49 & 26.8 & 36.8 & 30.1 \\
\hline 65 & 30.0572 & 89.9558 & $<1.00$ & $<1.00$ & 1.43 & 6.91 & 14.1 & 22.4 & 19.9 \\
\hline 66 & 30.0477 & 89.9620 & $<1.00$ & $<1.00$ & 2.49 & 7.57 & 38.8 & 48.9 & 36.6 \\
\hline 88 & 29.9786 & 90.0169 & $<1.00$ & $<1.00$ & 3.17 & 8.84 & 19.7 & 31.7 & 29.0 \\
\hline 89 & 29.9777 & 90.0110 & $<1.00$ & $<1.00$ & 6.09 & 8.05 & 34.2 & 48.3 & 45.3 \\
\hline 90 & 29.9744 & 90.0104 & $<1.00$ & $<1.00$ & 9.79 & 9.25 & 26.0 & 45.1 & 37.9 \\
\hline 91 & 29.9731 & 90.0109 & $<1.00$ & $<1.00$ & 3.49 & 5.58 & 30.2 & 39.2 & 28.9 \\
\hline 92 & 29.9694 & 90.0121 & $<1.00$ & $<1.00$ & 9.01 & 9.61 & 22.2 & 40.8 & 37.1 \\
\hline 95 & 29.9686 & 90.0197 & $<1.00$ & $<1.00$ & 5.41 & 7.31 & 16.2 & 28.9 & 35.8 \\
\hline 96 & 29.9686 & 90.0197 & $<1.00$ & $<1.00$ & 3.73 & 8.64 & 54.7 & 67.0 & 40.6 \\
\hline 97 & 29.9691 & 90.0211 & $<1.00$ & $<1.00$ & 1.37 & 7.96 & 11.4 & 20.7 & 18.7 \\
\hline 98 & 29.9644 & 90.0260 & $<1.00$ & $<1.00$ & 7.95 & 7.73 & 31.8 & 47.5 & 45.9 \\
\hline 99 & 29.9701 & 90.0229 & $<1.00$ & $<1.00$ & 3.55 & 7.49 & 29.6 & 40.7 & 38.8 \\
\hline 101 & 29.9699 & 90.0229 & $<1.00$ & $<1.00$ & 1.60 & 5.12 & 15.7 & 22.4 & 24.7 \\
\hline 102 & 29.9703 & 90.0230 & $<1.00$ & $<1.00$ & 0.95 & 2.51 & 7.49 & 10.9 & 12.5 \\
\hline 117 & 29.9455 & 89.9565 & $<1.00$ & $<1.00$ & 6.75 & 5.76 & 22.9 & 35.4 & 38.3 \\
\hline 122 & 29.9314 & 89.9459 & $<1.00$ & $<1.00$ & 52.4 & 30.6 & 32.9 & 116 & 81.2 \\
\hline 124 & 29.9336 & 89.9678 & $<1.00$ & $<1.00$ & 5.12 & 6.80 & 31.7 & 43.6 & 37.2 \\
\hline 127 & 29.9313 & 89.9689 & $<1.00$ & $<1.00$ & 3.12 & 4.49 & 10.6 & 18.2 & 42.0 \\
\hline 135 & 29.6703 & 89.9723 & $<1.00$ & $<1.00$ & 2.04 & 4.91 & 25.0 & 31.9 & 44.8 \\
\hline 136 & 29.5004 & 89.7201 & $<1.00$ & $<1.00$ & 1.82 & 4.62 & 25.7 & 32.1 & 46.2 \\
\hline 138 & 29.4722 & 89.6854 & $<1.00$ & $<1.00$ & 1.88 & 4.1 & 37.8 & 43.7 & 49.1 \\
\hline 142 & 29.4722 & 89.6854 & $<1.00$ & $<1.00$ & 1.15 & 6.99 & 23.0 & 31.1 & 31.7 \\
\hline 145 & 29.3883 & 89.6050 & $<1.00$ & $<1.00$ & 2.39 & 4.96 & 11.7 & 19.1 & 20.9 \\
\hline 150 & 29.3528 & 89.5241 & $<1.00$ & $<1.00$ & 2.65 & 8.43 & 26.4 & 37.5 & 43.4 \\
\hline 151 & 29.3528 & 89.5241 & $<1.00$ & $<1.00$ & 2.18 & 4.85 & 20.1 & 27.1 & 35.7 \\
\hline 152 & 29.3360 & 89.4952 & $<1.00$ & $<1.00$ & 2.97 & 4.25 & 32.7 & 40.0 & 46.0 \\
\hline 153 & 29.3360 & 89.4952 & $<1.00$ & $<1.00$ & 3.42 & 7.7 & 18.9 & 30.0 & 31.0 \\
\hline 155 & 29.3486 & 89.4625 & $<1.00$ & $<1.00$ & 3.05 & 5.29 & 37.3 & 45.6 & 44.9 \\
\hline 156 & 29.3486 & 89.4625 & $<1.00$ & $<1.00$ & 1.60 & 5.88 & 18.1 & 25.5 & 30.9 \\
\hline 157 & 29.2713 & 89.3539 & $<1.00$ & $<1.00$ & 1.73 & 11.2 & 35.6 & 48.6 & 39.3 \\
\hline
\end{tabular}


Table 17. Results of sequential extraction analysis for copper from sediment and soil collected following Hurricanes Katrina and Rita.

[mg/kg, milligram per kilogram; F1, exchangeable fraction; F2, bound to carbonate fraction; F3, iron and manganese oxides fraction; F4, organic matter fraction; F5, residual; <, less than]

\begin{tabular}{|c|c|c|c|c|c|c|c|c|c|}
\hline \multirow{2}{*}{$\begin{array}{l}\text { Sample } \\
\text { number }\end{array}$} & \multicolumn{2}{|c|}{ Location } & \multicolumn{6}{|c|}{ Sequential extraction fraction (mg/kg dry soil) } & \multirow{2}{*}{$\begin{array}{l}\text { Single extraction } \\
\text { (mg/kg dry soil) }\end{array}$} \\
\hline & Latitude & Longitude & F1 & F2 & F3 & F4 & F5 & Sum (F) & \\
\hline 10 & 30.0162 & 90.1981 & $<0.40$ & 0.99 & 1.68 & 11.8 & 17.7 & 32.2 & 28.1 \\
\hline 15 & 30.0153 & 90.1631 & $<0.40$ & 1.42 & 1.25 & 17 & 19.1 & 38.8 & 45.4 \\
\hline 16 & 30.0178 & 90.1204 & $<0.40$ & 1.94 & 5.90 & 28.4 & 20.1 & 56.3 & 38.2 \\
\hline 26 & 30.0196 & 90.1073 & $<0.40$ & 1.57 & 5.54 & 33.5 & 19.8 & 60.5 & 56.2 \\
\hline 31 & 30.0039 & 90.1140 & $<0.40$ & $<0.40$ & 0.10 & 5.93 & 20.2 & 26.2 & 25.0 \\
\hline 34 & 30.0039 & 90.1140 & $<0.40$ & $<0.40$ & 0.20 & 6.58 & 21.4 & 28.2 & 28.1 \\
\hline 36 & 30.0039 & 90.1140 & $<0.40$ & 1.66 & 3.03 & 26.6 & 26.3 & 57.6 & 64.5 \\
\hline 44 & 30.0086 & 90.0665 & $<0.40$ & 0.81 & 1.75 & 19.7 & 21.4 & 43.7 & 36.6 \\
\hline 65 & 30.0572 & 89.9558 & $<0.40$ & 0.67 & 0.97 & 8.66 & 16.8 & 27.1 & 23.2 \\
\hline 66 & 30.0477 & 89.9620 & $<0.40$ & $<0.40$ & 1.24 & 11.5 & 23.0 & 35.8 & 32.9 \\
\hline 88 & 29.9786 & 90.0169 & $<0.40$ & 0.76 & 1.72 & 7.38 & 15.0 & 24.8 & 23.8 \\
\hline 89 & 29.9777 & 90.0110 & $<0.40$ & 1.13 & 3.16 & 14.2 & 26.2 & 44.7 & 40.2 \\
\hline 90 & 29.9744 & 90.0104 & $<0.40$ & $<0.40$ & 1.83 & 17.3 & 18.3 & 37.5 & 36.3 \\
\hline 91 & 29.9731 & 90.0109 & $<0.40$ & 1.79 & 3.41 & 12.3 & 20.0 & 37.5 & 30.3 \\
\hline 92 & 29.9694 & 90.0121 & $<0.40$ & $<0.40$ & 5.22 & 9.91 & 16.9 & 32.1 & 34.0 \\
\hline 95 & 29.9686 & 90.0197 & $<0.40$ & $<0.40$ & 2.23 & 11.3 & 15.6 & 29.1 & 28.6 \\
\hline 96 & 29.9686 & 90.0197 & $<0.40$ & 0.92 & 2.51 & 25.2 & 33.7 & 62.3 & 47.1 \\
\hline 97 & 29.9691 & 90.0211 & $<0.40$ & $<0.40$ & 0.88 & 7.56 & 13.1 & 21.5 & 20.6 \\
\hline 98 & 29.9644 & 90.0260 & $<0.40$ & $<0.40$ & 2.99 & 13.4 & 20.0 & 36.4 & 35.8 \\
\hline 99 & 29.9701 & 90.0229 & $<0.40$ & 0.48 & 1.41 & 11.1 & 20.1 & 33.1 & 32.6 \\
\hline 101 & 29.9699 & 90.0229 & $<0.40$ & 0.54 & 2.33 & 6.89 & 16.9 & 26.7 & 28.1 \\
\hline 102 & 29.9703 & 90.0230 & $<0.40$ & $<0.40$ & 1.00 & 1.02 & 6.48 & 8.50 & 11.4 \\
\hline 117 & 29.9455 & 89.9565 & $<0.40$ & 3.66 & 19.0 & 18.4 & 22.4 & 63.5 & 53.2 \\
\hline 122 & 29.9314 & 89.9459 & $<0.40$ & 11.7 & 17.2 & 75.1 & 35.0 & 139 & 125 \\
\hline 124 & 29.9336 & 89.9678 & $<0.40$ & 1.17 & 1.14 & 14.1 & 21.1 & 37.5 & 28.4 \\
\hline 127 & 29.9313 & 89.9689 & $<0.40$ & 0.64 & 4.11 & 6.23 & 9.42 & 20.4 & 32.0 \\
\hline 135 & 29.6703 & 89.9723 & $<0.40$ & 0.42 & 1.91 & 4.46 & 17.8 & 24.5 & 26.7 \\
\hline 136 & 29.5004 & 89.7201 & $<0.40$ & $<0.40$ & 1.51 & 4.1 & 14.2 & 19.8 & 30.1 \\
\hline 138 & 29.4722 & 89.6854 & $<0.40$ & $<0.40$ & 2.29 & 6.13 & 19.0 & 27.4 & 30.6 \\
\hline 142 & 29.4722 & 89.6854 & $<0.40$ & 0.47 & 0.98 & 3.23 & 26.2 & 30.9 & 33.5 \\
\hline 145 & 29.3883 & 89.6050 & $<0.40$ & 0.66 & 1.46 & 3.96 & 7.32 & 13.4 & 15.7 \\
\hline 150 & 29.3528 & 89.5241 & $<0.40$ & 0.69 & 1.42 & 7.06 & 18.1 & 27.3 & 26.9 \\
\hline 151 & 29.3528 & 89.5241 & $<0.40$ & $<0.40$ & 1.74 & 9.13 & 18.2 & 29.1 & 25.9 \\
\hline 152 & 29.3360 & 89.4952 & $<0.40$ & 0.55 & 1.71 & 3.19 & 20.7 & 26.1 & 31.4 \\
\hline 153 & 29.3360 & 89.4952 & $<0.40$ & 1.42 & 13.0 & 43.9 & 36.4 & 94.7 & 85.5 \\
\hline 155 & 29.3486 & 89.4625 & $<0.40$ & 0.95 & 4.98 & 10.0 & 30.0 & 46 & 41.2 \\
\hline 156 & 29.3486 & 89.4625 & $<0.40$ & $<0.40$ & 1.3 & 4.31 & 13.7 & 19.3 & 23.0 \\
\hline 157 & 29.2713 & 89.3539 & $<0.40$ & $<0.40$ & 0.66 & 7.91 & 29.7 & 38.2 & 39.8 \\
\hline
\end{tabular}


Table 18. Results of sequential extraction analysis for arsenic from sediment and soil collected following Hurricanes Katrina and Rita.

[mg/kg, miligram per kilogram; F1, exchangeable fraction; F2, bound to carbonate fraction; F3, iron and manganese oxides fraction; F4, organic matter fraction; F5, residual; <MDL, less than method detection limit; <, less than]

\begin{tabular}{|c|c|c|c|c|c|c|c|c|c|}
\hline \multirow{2}{*}{$\begin{array}{l}\text { Sample } \\
\text { number }\end{array}$} & \multicolumn{2}{|c|}{ Location } & \multicolumn{6}{|c|}{ Sequential extraction fraction (mg/kg dry soil) } & \multirow{2}{*}{$\begin{array}{l}\text { Single extraction } \\
\text { (mg/kg dry soil) }\end{array}$} \\
\hline & Latitude & Longitude & F1 & F2 & F3 & F4 & F5 & Sum (F) & \\
\hline 10 & 30.0162 & 90.1981 & $<0.10$ & 0.23 & 6.73 & 0.51 & 5.40 & 12.9 & 8.16 \\
\hline 15 & 30.0153 & 90.1631 & $<0.10$ & 0.40 & 3.54 & 1.62 & 2.33 & 7.88 & 8.13 \\
\hline 16 & 30.0178 & 90.1204 & $<0.10$ & 0.42 & 13.3 & 0.59 & 5.40 & 19.7 & 11.7 \\
\hline 26 & 30.0196 & 90.1073 & $<0.10$ & 0.27 & 4.69 & 0.66 & 7.52 & 13.1 & 10.5 \\
\hline 31 & 30.0039 & 90.1140 & $<0.10$ & 0.33 & 5.95 & 4.11 & 3.00 & 13.4 & 9.34 \\
\hline 34 & 30.0039 & 90.1140 & $<0.10$ & 0.25 & 9.71 & 2.90 & 2.86 & 15.7 & 8.76 \\
\hline 36 & 30.0039 & 90.1140 & $<0.10$ & 0.49 & 14.5 & 0.79 & 11.9 & 27.7 & 23.1 \\
\hline 44 & 30.0086 & 90.0665 & $<0.10$ & 0.27 & 7.15 & 0.92 & 8.30 & 16.6 & 12.5 \\
\hline 65 & 30.0572 & 89.9558 & $<0.10$ & 0.83 & 17.6 & 2.56 & 6.41 & 27.4 & 13.5 \\
\hline 66 & 30.0477 & 89.9620 & $<0.10$ & 0.54 & 9.59 & 0.34 & 7.95 & 18.4 & 11.5 \\
\hline 88 & 29.9786 & 90.0169 & $<0.10$ & 0.46 & 10.2 & 1.12 & 3.14 & 14.9 & 7.01 \\
\hline 89 & 29.9777 & 90.0110 & $<0.10$ & 0.15 & 14.4 & 0.91 & 5.62 & 21.1 & 12.1 \\
\hline 90 & 29.9744 & 90.0104 & $<0.10$ & 0.42 & 13.0 & 1.05 & 3.88 & 18.4 & 11.1 \\
\hline 91 & 29.9731 & 90.0109 & $<0.10$ & 0.21 & 5.64 & 0.36 & 8.65 & 14.9 & 11.4 \\
\hline 92 & 29.9694 & 90.0121 & $<0.10$ & 0.75 & 8.35 & $<0.10$ & 3.93 & 13.0 & 9.65 \\
\hline 95 & 29.9686 & 90.0197 & $<0.10$ & 0.52 & 7.81 & 0.52 & 3.41 & 12.3 & 8.20 \\
\hline 96 & 29.9686 & 90.0197 & $<0.10$ & 0.23 & 5.69 & 1.17 & 10.5 & 17.6 & 11.3 \\
\hline 97 & 29.9691 & 90.0211 & $<0.10$ & 1.63 & 26.8 & 10.2 & 13.5 & 52.2 & 33.8 \\
\hline 98 & 29.9644 & 90.0260 & $<0.10$ & 1.15 & 12.18 & 1.09 & 4.49 & 18.9 & 12.2 \\
\hline 99 & 29.9701 & 90.0229 & $<0.10$ & 0.37 & 9.19 & 0.96 & 5.36 & 15.9 & 11.3 \\
\hline 101 & 29.9699 & 90.0229 & $<0.10$ & 0.93 & 28.0 & 2.79 & 15.4 & 47.1 & 27.9 \\
\hline 102 & 29.9703 & 90.0230 & $<0.10$ & 1.06 & 28.3 & 3.9 & 5.84 & 39.1 & 25.2 \\
\hline 117 & 29.9455 & 89.9565 & $<0.10$ & 2.35 & 39.7 & 1.15 & 30.3 & 73.5 & 49.1 \\
\hline 122 & 29.9314 & 89.9459 & $<0.10$ & 0.42 & 16.9 & 0.54 & 22.2 & 40.1 & 27.0 \\
\hline 124 & 29.9336 & 89.9678 & $<0.10$ & 0.62 & 19.2 & 1.03 & 8.01 & 28.9 & 15.3 \\
\hline 127 & 29.9313 & 89.9689 & $<0.10$ & $<0.10$ & 7.75 & 0.37 & 3.48 & 11.6 & 14.5 \\
\hline 135 & 29.6703 & 89.9723 & $<0.10$ & 0.13 & 3.54 & 0.79 & 3.71 & 8.17 & 13.0 \\
\hline 136 & 29.5004 & 89.7201 & $<0.10$ & 0.13 & 2.61 & 0.17 & 5.95 & 8.86 & 8.8 \\
\hline 138 & 29.4722 & 89.6854 & $<0.10$ & $<0.10$ & 2.05 & $<0.10$ & 6.63 & 8.67 & 9.33 \\
\hline 142 & 29.4722 & 89.6854 & $<0.10$ & 0.17 & 2.78 & 0.99 & 2.91 & 6.85 & 4.92 \\
\hline 145 & 29.3883 & 89.6050 & $<0.10$ & 0.41 & 11.8 & 0.5 & 15.1 & 27.8 & 22.8 \\
\hline 150 & 29.3528 & 89.5241 & $<0.10$ & 0.31 & 7.41 & 1.65 & 4.67 & 14.0 & 11.7 \\
\hline 151 & 29.3528 & 89.5241 & $<0.10$ & 0.37 & 4.59 & 0.21 & 1.87 & 7.04 & 7.67 \\
\hline 152 & 29.3360 & 89.4952 & $<0.10$ & 0.17 & 3.49 & $<0.10$ & 4.73 & 8.38 & 8.15 \\
\hline 153 & 29.3360 & 89.4952 & $<0.10$ & 0.21 & 4.39 & 0.1 & 8.76 & 13.5 & 15.8 \\
\hline 155 & 29.3486 & 89.4625 & $<0.10$ & $<0.10$ & 6.15 & 0.34 & 8.48 & 15.0 & 10.5 \\
\hline 156 & 29.3486 & 89.4625 & $<0.10$ & 0.16 & 2.17 & 0.77 & 3.28 & 6.38 & 7.1 \\
\hline 157 & 29.2713 & 89.3539 & $<0.10$ & $<0.10$ & 9.31 & 3.29 & 3.21 & 15.8 & 14.1 \\
\hline
\end{tabular}


Table 19. Results of sequential extraction analysis for cadmium from sediment and soil following Hurricanes Katrina and Rita.

[mg/kg, miligram per kilogram; F1, exchangeable fraction; F2, bound to carbonate fraction; F3, iron and manganese oxides fraction; F4, organic matter fraction; F5, residual; <MDL, less than method detection limit; <, less than; --, not tested]

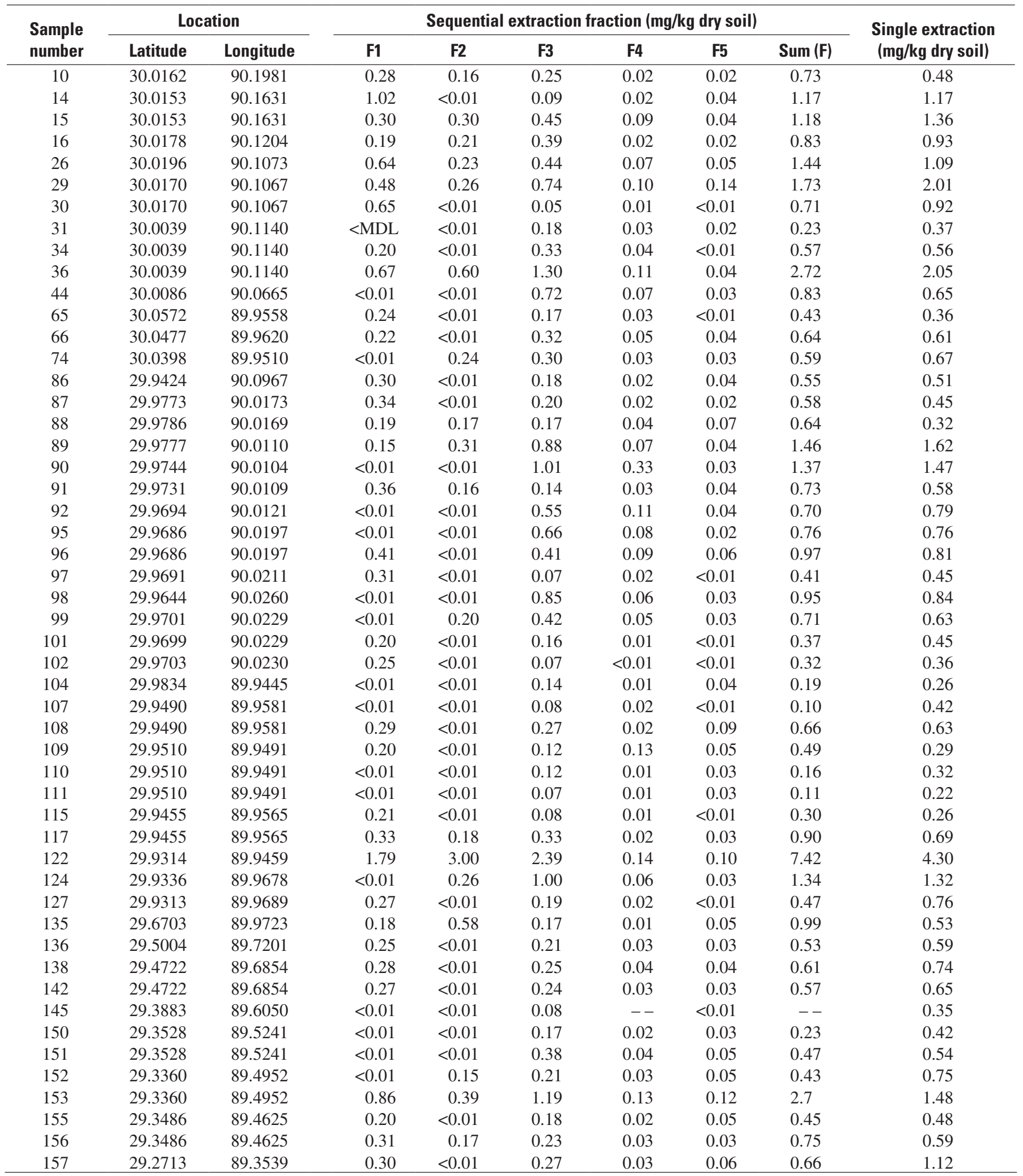


Table 20. Results of sequential extraction analysis for iron from sediment and soil collected following Hurricanes Katrina and Rita.

[mg/kg, milligram per kilogram; F1, exchangeable fraction; F2, bound to carbonate fraction; F3, iron and manganese oxides fraction; F4, organic matter fraction; F5, residual; <, less than]

\begin{tabular}{|c|c|c|c|c|c|c|c|c|c|}
\hline \multirow{2}{*}{$\begin{array}{l}\text { Sample } \\
\text { number }\end{array}$} & \multicolumn{2}{|c|}{ Location } & \multicolumn{5}{|c|}{ Sequential extraction fraction (mg/kg dry soil) } & \multirow[b]{2}{*}{ Sum (F) } & \multirow{2}{*}{$\begin{array}{l}\text { Single extraction } \\
\text { (mg/kg dry soil) }\end{array}$} \\
\hline & Latitude & Longitude & F1 & F2 & F3 & F4 & F5 & & \\
\hline 10 & 30.0162 & 90.1981 & $<15.0$ & 74.0 & 6,560 & 3,260 & 17,300 & 27,200 & 22,400 \\
\hline 14 & 30.0153 & 90.1631 & $<15.0$ & 17.0 & 2,340 & 2,700 & 18,600 & 23,600 & 22,700 \\
\hline 15 & 30.0153 & 90.1631 & $<15.0$ & $<15.0$ & 1,670 & 2,020 & 11,500 & 15,200 & 17,200 \\
\hline 16 & 30.0178 & 90.1204 & $<15.0$ & 241 & 7,810 & 2,060 & 16,100 & 261,200 & 21,000 \\
\hline 26 & 30.0196 & 90.1073 & $<15.0$ & 33.0 & 2,370 & 4,570 & 15,200 & 22,200 & 22,800 \\
\hline 29 & 30.0170 & 90.1067 & $<15.0$ & $<15.0$ & 282 & 607 & 7,650 & 8,540 & 9,490 \\
\hline 30 & 30.0170 & 90.1067 & $<15.0$ & 897 & 6,080 & 4,880 & 15,800 & 27,600 & 26,200 \\
\hline 31 & 30.0039 & 90.1140 & $<15.0$ & $<15.0$ & 2,590 & 8,860 & 12,300 & 23,700 & 24,100 \\
\hline 34 & 30.0039 & 90.1140 & $<15.0$ & 121 & 4,100 & 7,600 & 13,200 & 25,000 & 23,700 \\
\hline 36 & 30.0039 & 90.1140 & $<15.0$ & 106 & 5,590 & 4,340 & 19,100 & 29,200 & 37,200 \\
\hline 44 & 30.0086 & 90.0665 & $<15.0$ & 36.0 & 4,480 & 4,750 & 19,800 & 29,000 & 24,000 \\
\hline 65 & 30.0572 & 89.9558 & $<15.0$ & $<15.0$ & 3,150 & 1,870 & 9,570 & 14,600 & 13,700 \\
\hline 66 & 30.0477 & 89.9620 & $<15.0$ & 228 & 7,160 & 1,120 & 17,800 & 26,300 & 22,400 \\
\hline 74 & 30.0398 & 89.9510 & $<15.0$ & 77.0 & 4,870 & 5,910 & 24,100 & 34,900 & 27,200 \\
\hline 86 & 29.9424 & 90.0967 & $<15.0$ & 42.0 & 3,050 & 1,540 & 14,100 & 18,700 & 17,700 \\
\hline 87 & 29.9773 & 90.0173 & $<15.0$ & 242 & 8,690 & 4,660 & 22,300 & 35,900 & 33,600 \\
\hline 88 & 29.9786 & 90.0169 & $<15.0$ & 432 & 9,890 & 4,050 & 19,500 & 33,900 & 30,800 \\
\hline 89 & 29.9777 & 90.0110 & $<15.0$ & 192 & 10,800 & 2,470 & 18,000 & 31,500 & 30,900 \\
\hline 90 & 29.9744 & 90.0104 & $<15.0$ & 1,440 & 6,920 & 3,420 & 14,600 & 26,400 & 22,300 \\
\hline 91 & 29.9731 & 90.0109 & $<15.0$ & 68.0 & 4,680 & 1,880 & 18,100 & 24,800 & 18,100 \\
\hline 92 & 29.9694 & 90.0121 & $<15.0$ & 1,750 & 5,100 & 952 & 16,300 & 24,100 & 20,000 \\
\hline 95 & 29.9686 & 90.0197 & $<15.0$ & 691 & 5,590 & 2,090 & 12,400 & 20,800 & 19,100 \\
\hline 96 & 29.9686 & 90.0197 & $<15.0$ & 59.0 & 6,820 & 5,860 & 31,500 & 44,300 & 11,200 \\
\hline 97 & 29.9691 & 90.0211 & $<15.0$ & 28.0 & 1,470 & 1,490 & 5,490 & 8,470 & 9,400 \\
\hline 98 & 29.9644 & 90.0260 & $<15.0$ & 1,090 & 12,100 & 3,920 & 17,900 & 35,000 & 26,900 \\
\hline 99 & 29.9701 & 90.0229 & $<15.0$ & 251 & 8,320 & 4,840 & 16,900 & 30,300 & 26,300 \\
\hline 101 & 29.9699 & 90.0229 & $<15.0$ & 111 & 3,320 & 837 & 10,600 & 14,900 & 15,100 \\
\hline 102 & 29.9703 & 90.0230 & $<15.0$ & 127 & 2,520 & 462 & 4,130 & 7,240 & 7,800 \\
\hline 104 & 29.9834 & 89.9445 & $<15.0$ & $<15.0$ & 3,780 & 233 & 18,000 & 22,100 & 8,400 \\
\hline 107 & 29.9490 & 89.9581 & $<15.0$ & $<15.0$ & 2,140 & 197 & 5,650 & 7,990 & 22,200 \\
\hline 108 & 29.9490 & 89.9581 & $<15.0$ & $<15.0$ & 4,300 & 220 & 15,700 & 20,200 & 20,000 \\
\hline 109 & 29.9510 & 89.9491 & $<15.0$ & $<15.0$ & 8,100 & 1,850 & 31,400 & 41,300 & 27,100 \\
\hline 110 & 29.9510 & 89.9491 & $<15.0$ & 24.0 & 4,190 & 993 & 19,800 & 25,000 & 26,500 \\
\hline 111 & 29.9510 & 89.9491 & $<15.0$ & 72.0 & 4,050 & 1,200 & 14,500 & 19,800 & 16,600 \\
\hline 115 & 29.9455 & 89.9565 & $<15.0$ & $<15.0$ & 4,000 & 1,220 & 12,200 & 17,400 & 13,900 \\
\hline 117 & 29.9455 & 89.9565 & $<15.0$ & $<15.0$ & 23,780 & 200 & 12,800 & 15,400 & 17,300 \\
\hline 122 & 29.9314 & 89.9459 & $<15.0$ & 295 & 20,600 & 1,520 & 31,900 & 54,300 & 56,200 \\
\hline 124 & 29.9336 & 89.9678 & $<15.0$ & 95.0 & 6,160 & 2,630 & 16,800 & 25,700 & 28,300 \\
\hline 127 & 29.9313 & 89.9689 & $<15.0$ & $<15.0$ & 5,090 & 859 & 18,300 & 24,300 & 24,800 \\
\hline 135 & 29.6703 & 89.9723 & $<15.0$ & $<15.0$ & 4,000 & 5,480 & 14,200 & 23,700 & 26,200 \\
\hline 136 & 29.5004 & 89.7201 & $<15.0$ & 22.0 & 3,370 & 1,880 & 24,500 & 29,800 & 23,700 \\
\hline 138 & 29.4722 & 89.6854 & $<15.0$ & $<15.0$ & 4,460 & 1,310 & 23,400 & 29,200 & 27,000 \\
\hline 142 & 29.4722 & 89.6854 & $<15.0$ & $<15.0$ & 2,750 & 1,730 & 13,800 & 18,300 & 17,400 \\
\hline 145 & 29.3883 & 89.6050 & $<15.0$ & 1,136 & 15,000 & 3,180 & 15,800 & 35,100 & 35,100 \\
\hline 150 & 29.3528 & 89.5241 & $<15.0$ & 134 & 6,250 & 4,660 & 14,700 & 25,700 & 27,400 \\
\hline 151 & 29.3528 & 89.5241 & $<15.0$ & 1,140 & 3,920 & 967 & 15,300 & 21,300 & 16,900 \\
\hline 152 & 29.3360 & 89.4952 & $<15.0$ & 68.0 & 4,750 & 615 & 18,900 & 24,400 & 20,500 \\
\hline 153 & 29.3360 & 89.4952 & $<15.0$ & $<15.0$ & 5,360 & 1,330 & 24,500 & 31,200 & 27,800 \\
\hline 155 & 29.3486 & 89.4625 & $<15.0$ & $<15.0$ & 4,940 & 1,180 & 24,900 & 31,000 & 30,400 \\
\hline 156 & 29.3486 & 89.4625 & $<15.0$ & $<15.0$ & 2,190 & 962 & 16,900 & 20,100 & 17,400 \\
\hline 157 & 29.2713 & 89.3539 & $<15.0$ & 177 & 6,110 & 6,550 & 15,600 & 28,500 & 25,600 \\
\hline
\end{tabular}




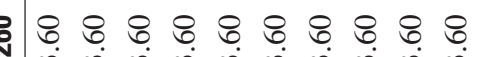

$\dot{v} \dot{v} \dot{v} \dot{v} \dot{v} \tilde{v} \dot{v} \dot{v} \dot{v} \dot{v}$

\& \& \& \& \& \& \& \& \& \&

$\frac{8}{\dot{v}} \frac{8}{v}$

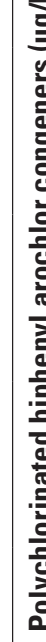

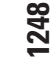

\& \& \& \& \& \&

v

มี \& \& \& \& \& \& \& \& \& \&

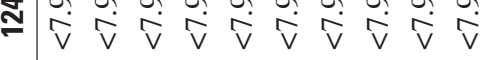

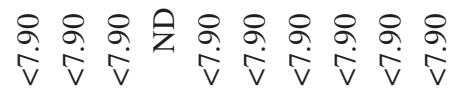

\& \&

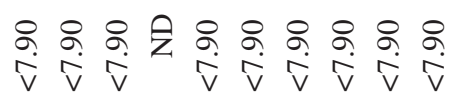

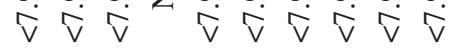

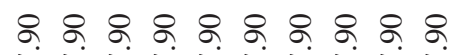

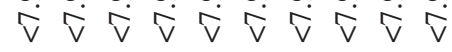

กับ \& \& \& \& \& \& \& \& \&

\& \& \& \& \& \& \& \& \&

\& \& \& \& \& \& \& \& \& \&

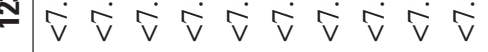

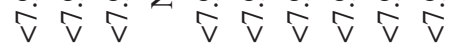

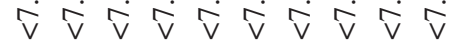

$\overline{\text { ล }}$

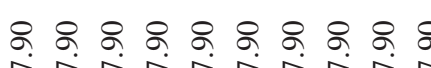

음

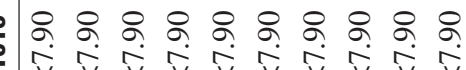

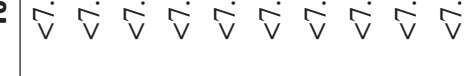

연

문

\& \& \& \& \& \& \& \& \& \&

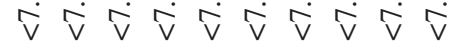

夜

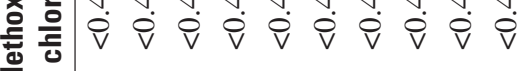

픔

흘 흘

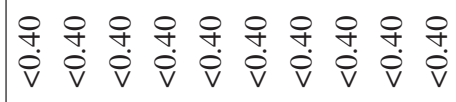

홓

ธ

|

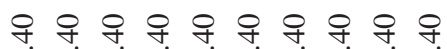

$\dot{\vec{v}} \vec{v} \dot{v} \vec{v} \dot{v} \dot{v} \dot{v} \vec{v} \dot{v} \dot{v}$

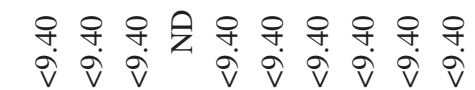

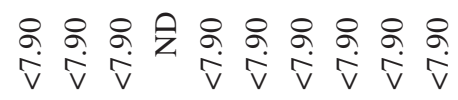

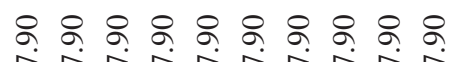

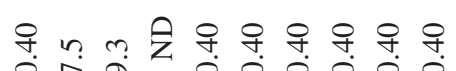

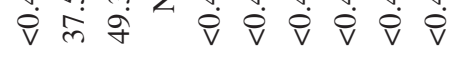

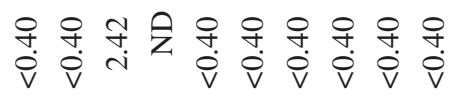

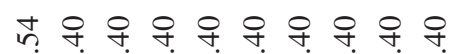

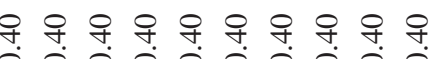

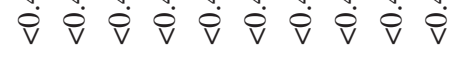

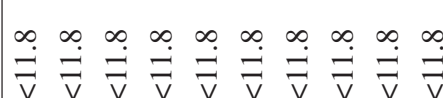

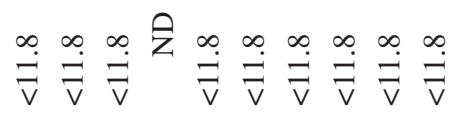

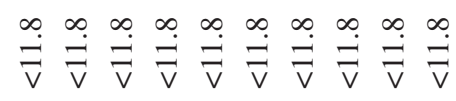

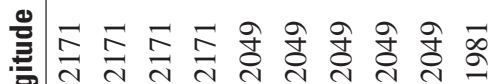

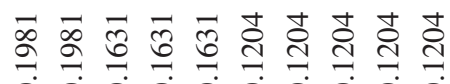

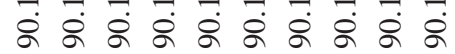

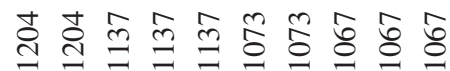

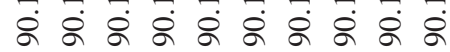

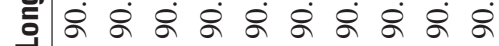

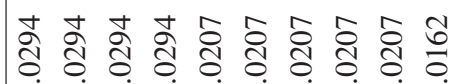

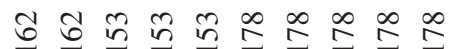

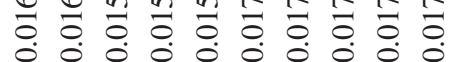

용ㅇㅇ유유

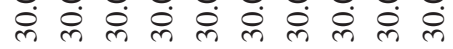

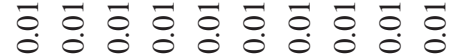

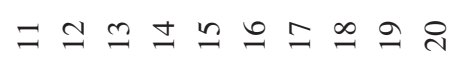

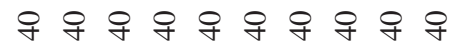
$\vec{v} \dot{v} \vec{v} \vec{v} \vec{v} \vec{v} \dot{v} \vec{v} \vec{v} \vec{v}$ 


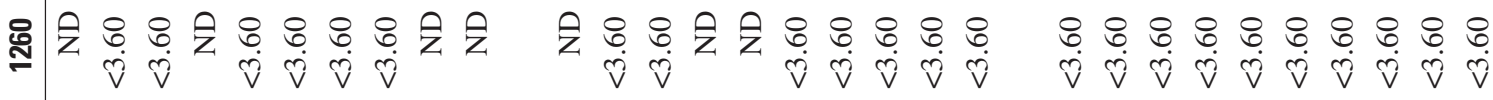

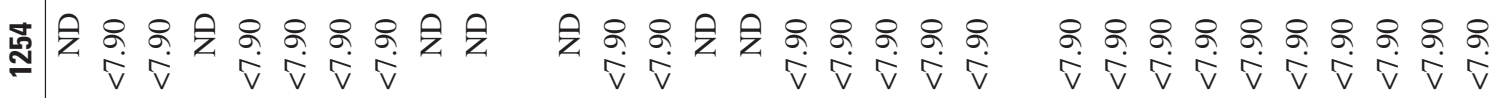

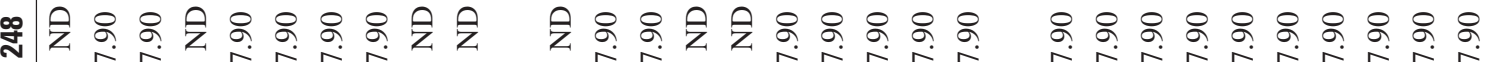

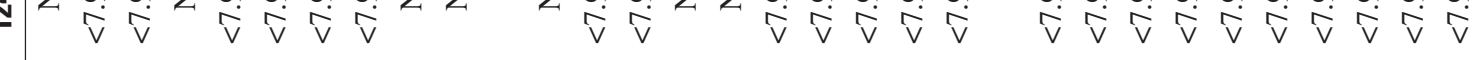

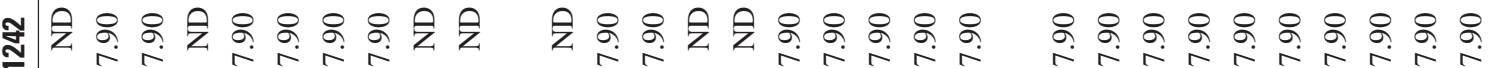

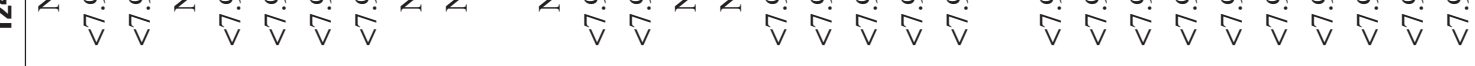

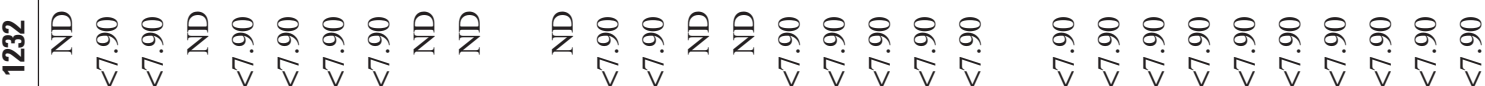

ธ三人

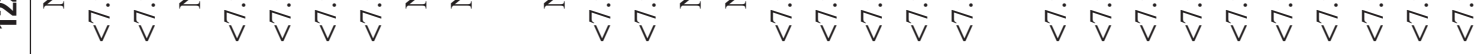

늑요

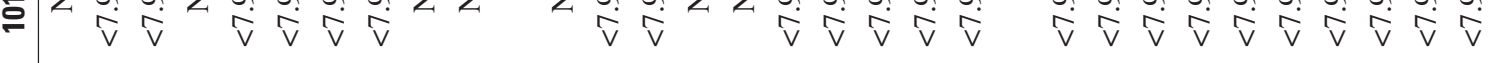

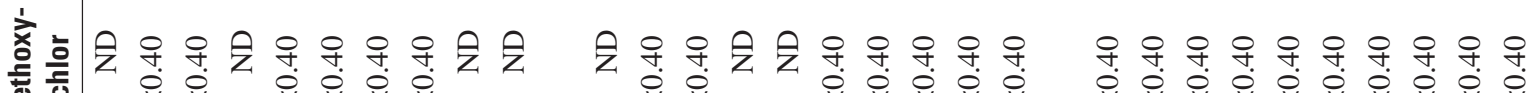
틈

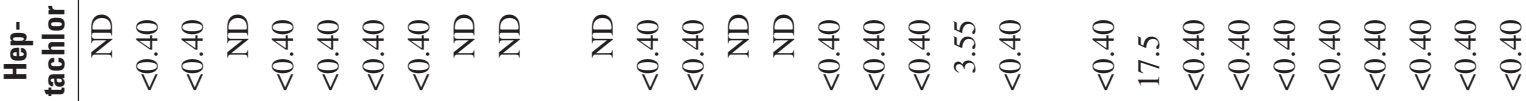

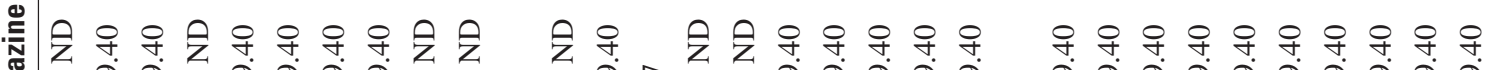

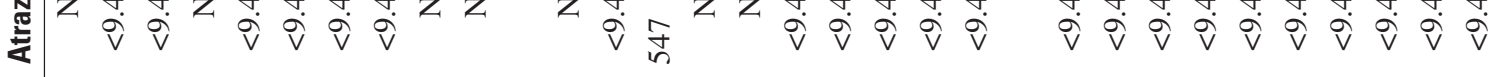

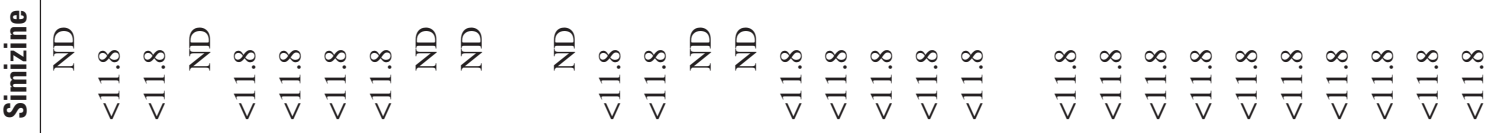

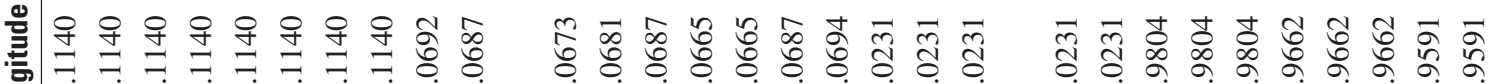

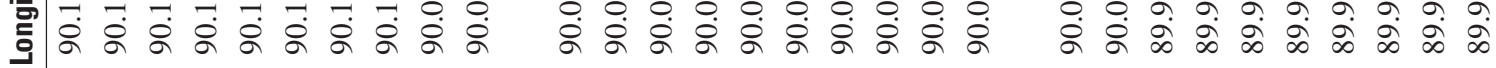




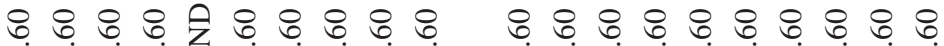
$\dot{v} \dot{v} \tilde{v} \tilde{v} \dot{v} \tilde{v} \dot{v} \tilde{v} \dot{v} \tilde{v}$

范

\& \& \& \& \& \&

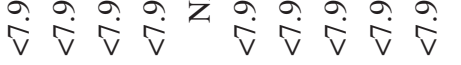

$\stackrel{\text { ปิ }}{\mathfrak{N}}$

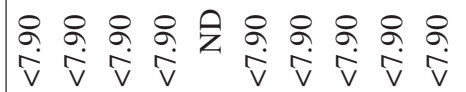

בั

ด \& \& \&

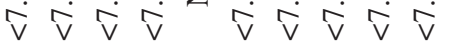

జ్

\& \&

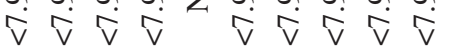

ลุ

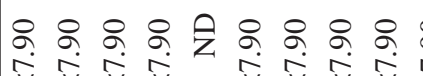

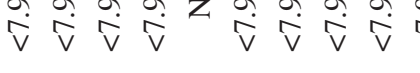

○人

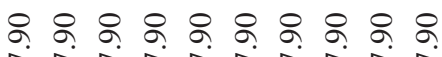

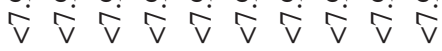

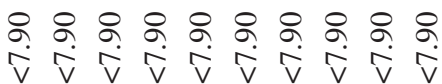

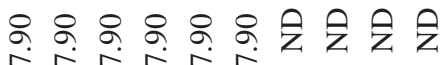

ஃ \& \& \& \& \& \& \& \& \&

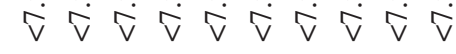

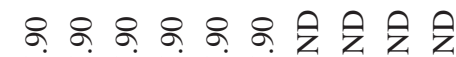

$\vec{v} \vec{v} \widetilde{v} \vec{v} \widetilde{v} \vec{v}$

\& \&\&\&\&合合令

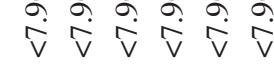

$\vec{v} \bar{v} \bar{v} \vec{v} \bar{v} \vec{v}$

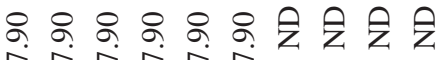

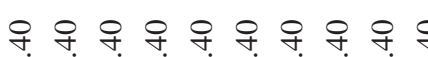

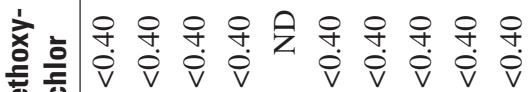
$\dot{v} \dot{v} \dot{v} \dot{v} \dot{v} \dot{v} \dot{v} \dot{v} \dot{v} \vec{v}$

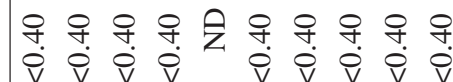

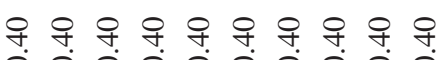

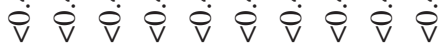

원원원원원

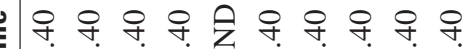

$\vec{v} \dot{v} \vec{v} \vec{v} \quad \vec{v} \vec{v} \vec{v} \vec{v} \vec{v}$

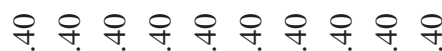

$\vec{v} \vec{v} \vec{v} \dot{v} \vec{v} \dot{v} \vec{v} \dot{v} \vec{v} \vec{v}$

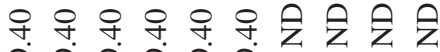

$\vec{v} \dot{v} \vec{v} \dot{v} \vec{v} \dot{v}$

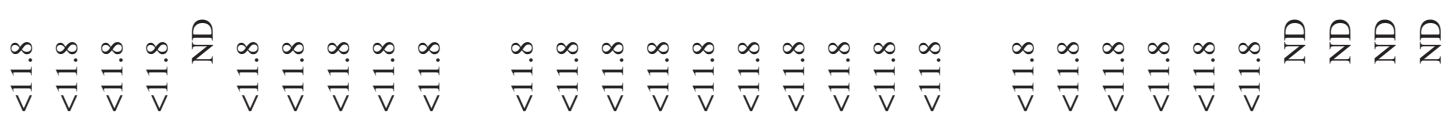

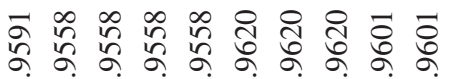

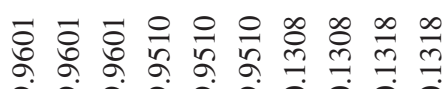

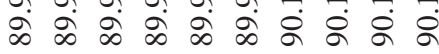

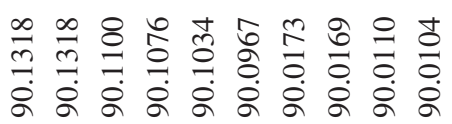

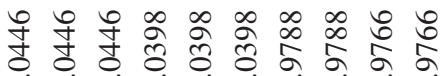

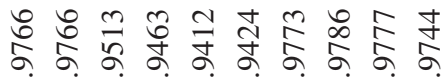

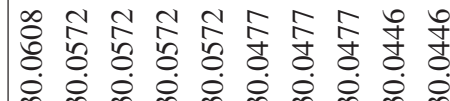

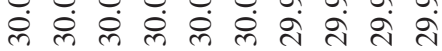

ते बें बें बें बें बें

எ

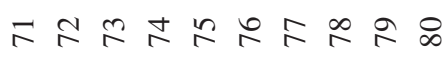

우우워워워 $\dot{\vec{v}} \dot{\vec{V}} \dot{\vec{V}} \dot{\vec{v}} \dot{\vec{v}} \dot{\mathrm{v}}$ 


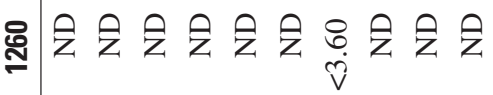

会会会完导会导导

合

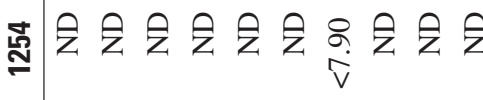

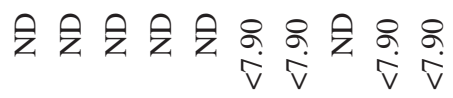

ᄀ

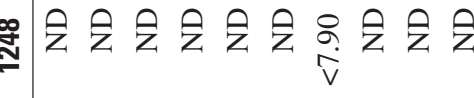

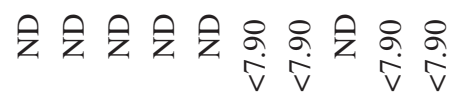

之ค ㅇำ

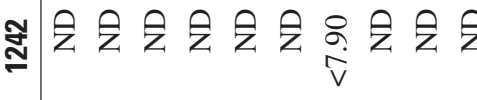

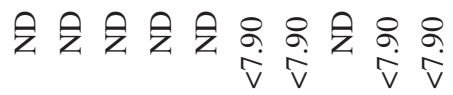

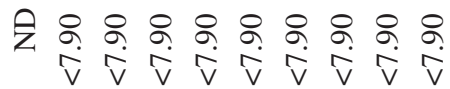

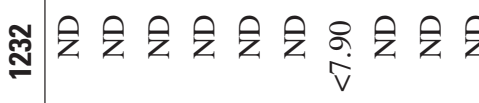

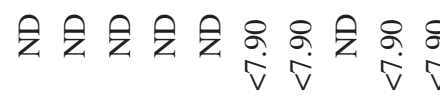

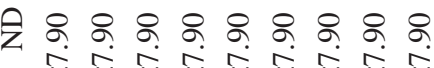

吾云会会会会完会会会

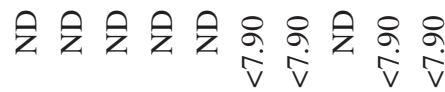

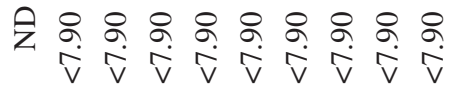

을 会会会会完会会令

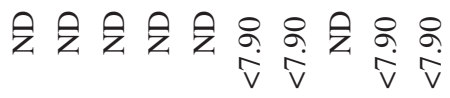

之

$\dot{\vec{v}} \vec{v} \dot{\vec{v}} \dot{\vec{v}} \dot{\vec{v}} \overrightarrow{\vec{v}} \dot{\vec{v}} \vec{v} \dot{v}$

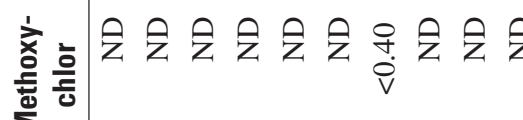

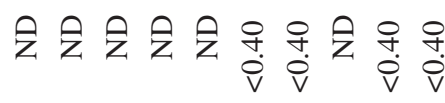

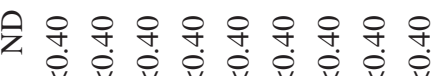

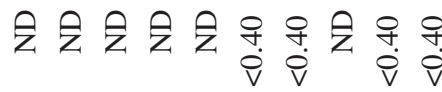

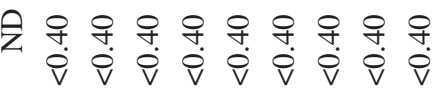

$\dot{v} \hat{v} \dot{v} \vec{v} \dot{v} \vec{v} \dot{v} \vec{v} \dot{v}$

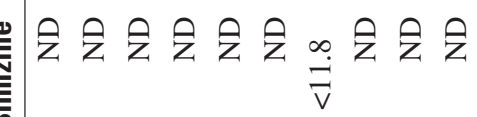

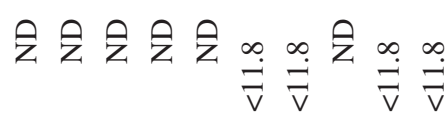

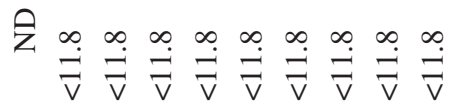

흘

造

尊

눙

害

要

$\dot{\bar{\alpha}}$

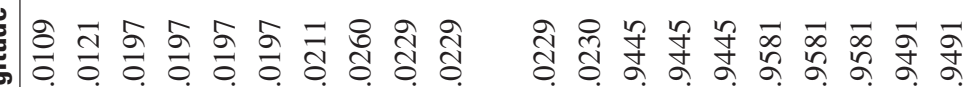

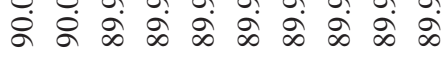

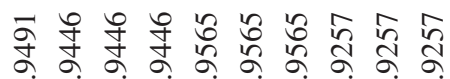

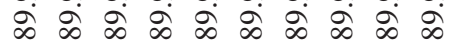

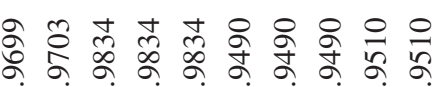

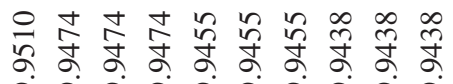

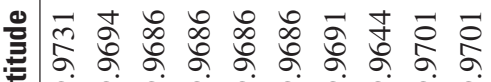
ते ते ते ते ते ते ते ते ते

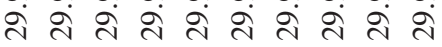




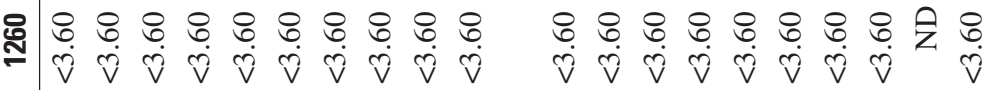

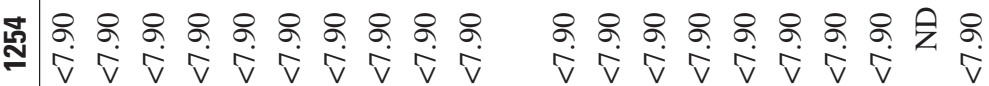

\% \& \& \& \& \& \& \& \& \& \&

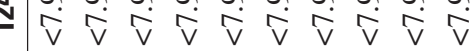

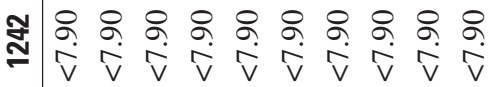

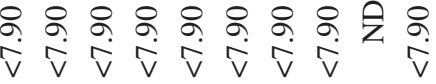

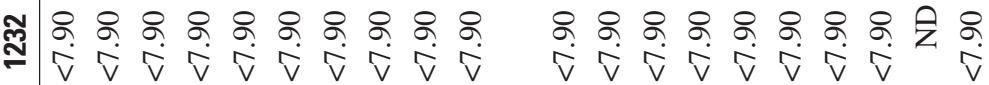

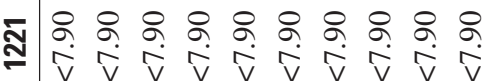

ㅇ \& \& \& \& \& \& \& \&

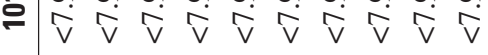

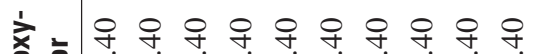

$\vec{v} \dot{v} \vec{v} \dot{v} \vec{v} \dot{v} \vec{v} \dot{v} \vec{v} \dot{v}$

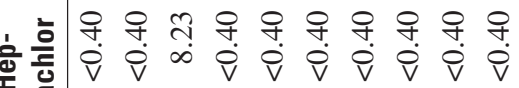

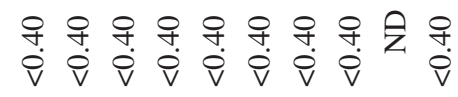

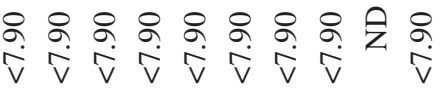

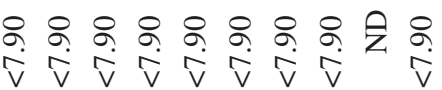

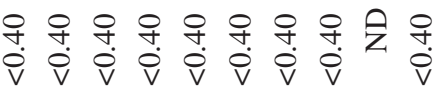

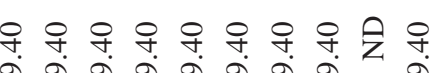

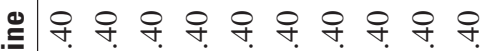

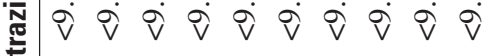

$\vec{v} \vec{v} \vec{v} \vec{v} \vec{v} \vec{v} \dot{v} \vec{v} \quad \vec{v}$

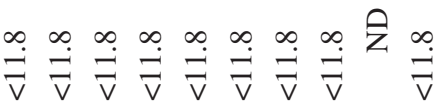

会会实

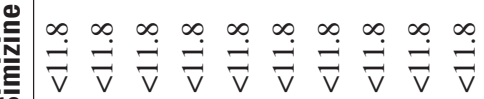

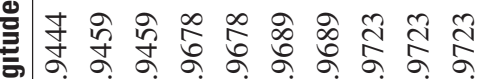

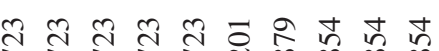

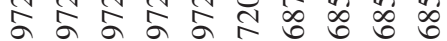

$\dot{\infty} \dot{\infty} \dot{\infty} \dot{\infty} \dot{\infty} \dot{\infty} \dot{\infty} \dot{\infty} \dot{\infty} \dot{\infty}$

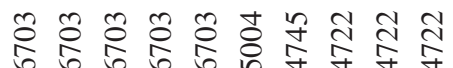
वें

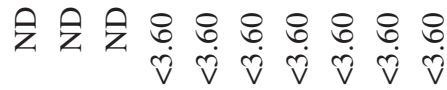

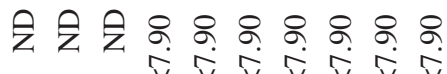

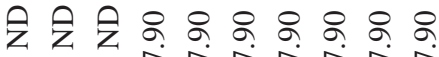

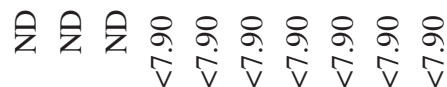

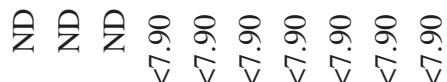

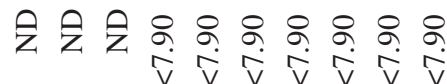

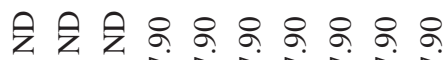

$\dot{\vec{v}} \vec{v} \dot{\vec{v}} \vec{v} \vec{v} \vec{v} \dot{v}$

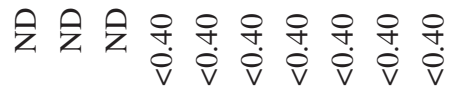

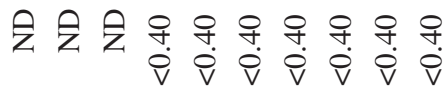

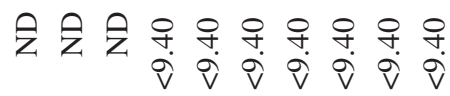

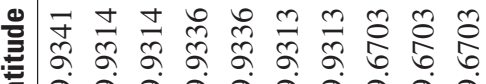

च ते वे ते बें बें बें

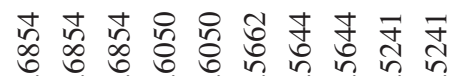
ते ते ते ते ते ते ते ते ते

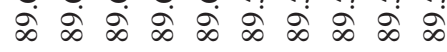

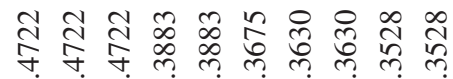




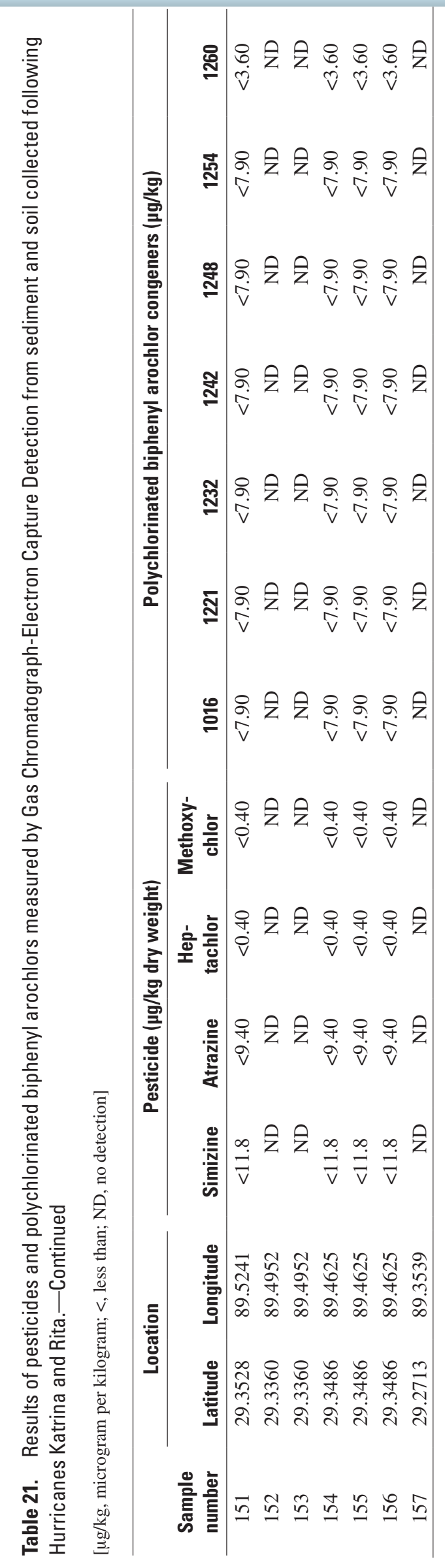


Table 22. Results of pesticide compounds measured by Gas Chromatograph-Mass Spectrometry from sediment and soil collected following Hurricanes Katrina and Rita.

$[\mu \mathrm{g} / \mathrm{kg}$, microgram per kilogram]

\begin{tabular}{|c|c|c|c|c|c|c|c|}
\hline \multirow{2}{*}{$\begin{array}{l}\text { Sample } \\
\text { number }\end{array}$} & \multicolumn{2}{|c|}{ Location } & \multicolumn{5}{|c|}{ Concentration ( $\mu \mathrm{g} / \mathrm{kg}$ dry soil) } \\
\hline & Latitude & Longitude & Prometon & Simazine & Atrazine & Heptachlor & Methoxychlor \\
\hline 12 & 30.0162 & 90.1981 & 0.67 & 0.44 & 4.76 & 0.44 & 36.2 \\
\hline 14 & 30.0153 & 90.1631 & 7.37 & 0.44 & 49.7 & 0.44 & 2,040 \\
\hline 21 & 30.0178 & 90.1204 & 106 & 0.44 & 0.27 & 0.44 & 3.47 \\
\hline 39 & 30.0122 & 90.0692 & 0.67 & 0.44 & 10.1 & 0.44 & 3.47 \\
\hline 40 & 30.0107 & 90.0687 & 11.8 & 10.5 & 0.27 & 0.44 & 3.47 \\
\hline 41 & 30.0100 & 90.0673 & 36.2 & 0.44 & 9.53 & 0.44 & 3.47 \\
\hline 43 & 30.0095 & 90.0687 & 5.71 & 0.44 & 4.45 & 0.44 & 3.47 \\
\hline 44 & 30.0086 & 90.0665 & 44.3 & 0.44 & 8.00 & 0.44 & 3.47 \\
\hline 65 & 30.0572 & 89.9558 & 0.67 & 0.44 & 25.1 & 0.44 & 3.47 \\
\hline 85 & 29.9412 & 90.1034 & 0.67 & 0.44 & 5.41 & 0.44 & 190 \\
\hline 87 & 29.9773 & 90.0173 & 10.5 & 0.44 & 0.27 & 0.44 & 143 \\
\hline 88 & 29.9786 & 90.0169 & 9.03 & 0.44 & 0.27 & 22.2 & 330 \\
\hline 89 & 29.9777 & 90.0110 & 14.2 & 0.44 & 0.27 & 0.44 & 3.47 \\
\hline 90 & 29.9744 & 90.0104 & 35.7 & 82.4 & 0.27 & 0.44 & 3.47 \\
\hline 91 & 29.9731 & 90.0109 & 21.0 & 45.3 & 25.0 & 0.44 & 3.47 \\
\hline 92 & 29.9694 & 90.0121 & 4.60 & 0.44 & 0.27 & 0.44 & 3.55 \\
\hline 93 & 29.9686 & 90.0197 & 6.66 & 0.44 & 0.27 & 0.44 & 3.47 \\
\hline 104 & 29.9834 & 89.9445 & 193 & 0.44 & 187 & 0.44 & 3.47 \\
\hline 105 & 29.9834 & 89.9445 & 7.44 & 0.44 & 7.14 & 0.44 & 35.7 \\
\hline 108 & 29.9490 & 89.9581 & 0.34 & 0.44 & 10.5 & 0.44 & 3.47 \\
\hline 111 & 29.9510 & 89.9491 & 15.7 & 0.44 & 0.27 & 0.44 & 35.7 \\
\hline 123 & 29.9314 & 89.9459 & 2.37 & 0.44 & 8.88 & 6.31 & 3.47 \\
\hline 139 & 29.4722 & 89.6854 & 9.10 & 6.95 & 0.27 & 12.4 & 3,510 \\
\hline 141 & 29.4722 & 89.6854 & 0.34 & 4.79 & 0.27 & 3.70 & 357 \\
\hline 142 & 29.4722 & 89.6854 & 26.3 & 21.4 & 8.74 & 4.96 & 332 \\
\hline 143 & 29.4722 & 89.6854 & 27.2 & 27.7 & 0.27 & 0.44 & 3.47 \\
\hline 152 & 29.3360 & 89.4952 & 10.2 & 0.44 & 11.1 & 0.44 & 3.47 \\
\hline 153 & 29.3360 & 89.4952 & 0.67 & 0.44 & 6.66 & 0.44 & 57.6 \\
\hline 157 & 29.2713 & 89.3539 & 0.67 & 0.44 & 21.9 & 0.44 & 3.47 \\
\hline
\end{tabular}




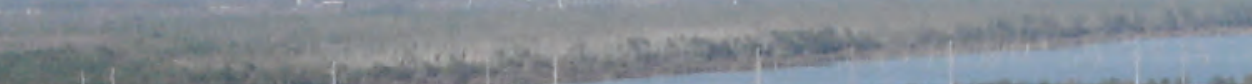

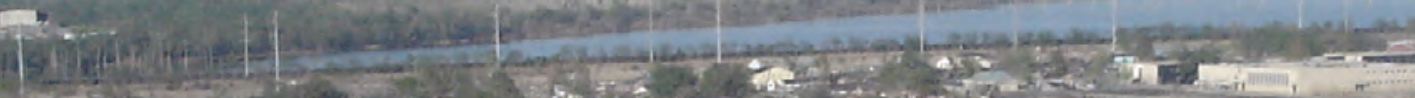
4h

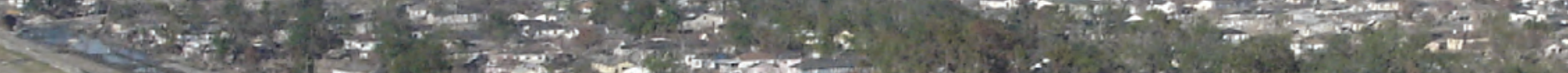
$2+5$ at

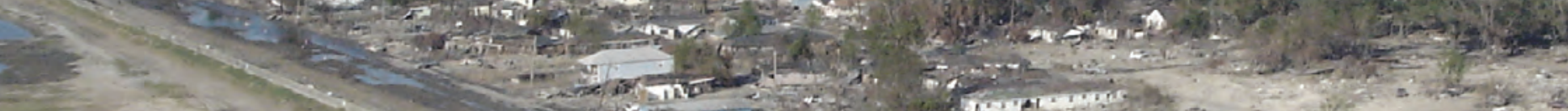

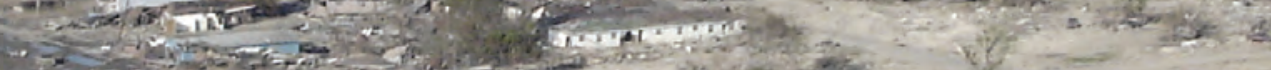

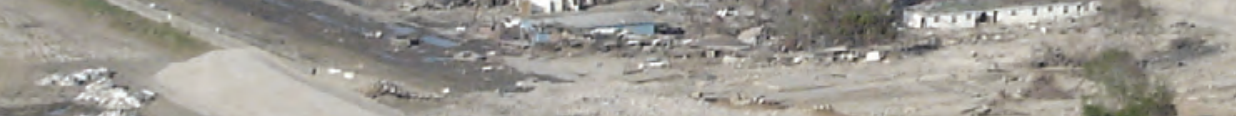

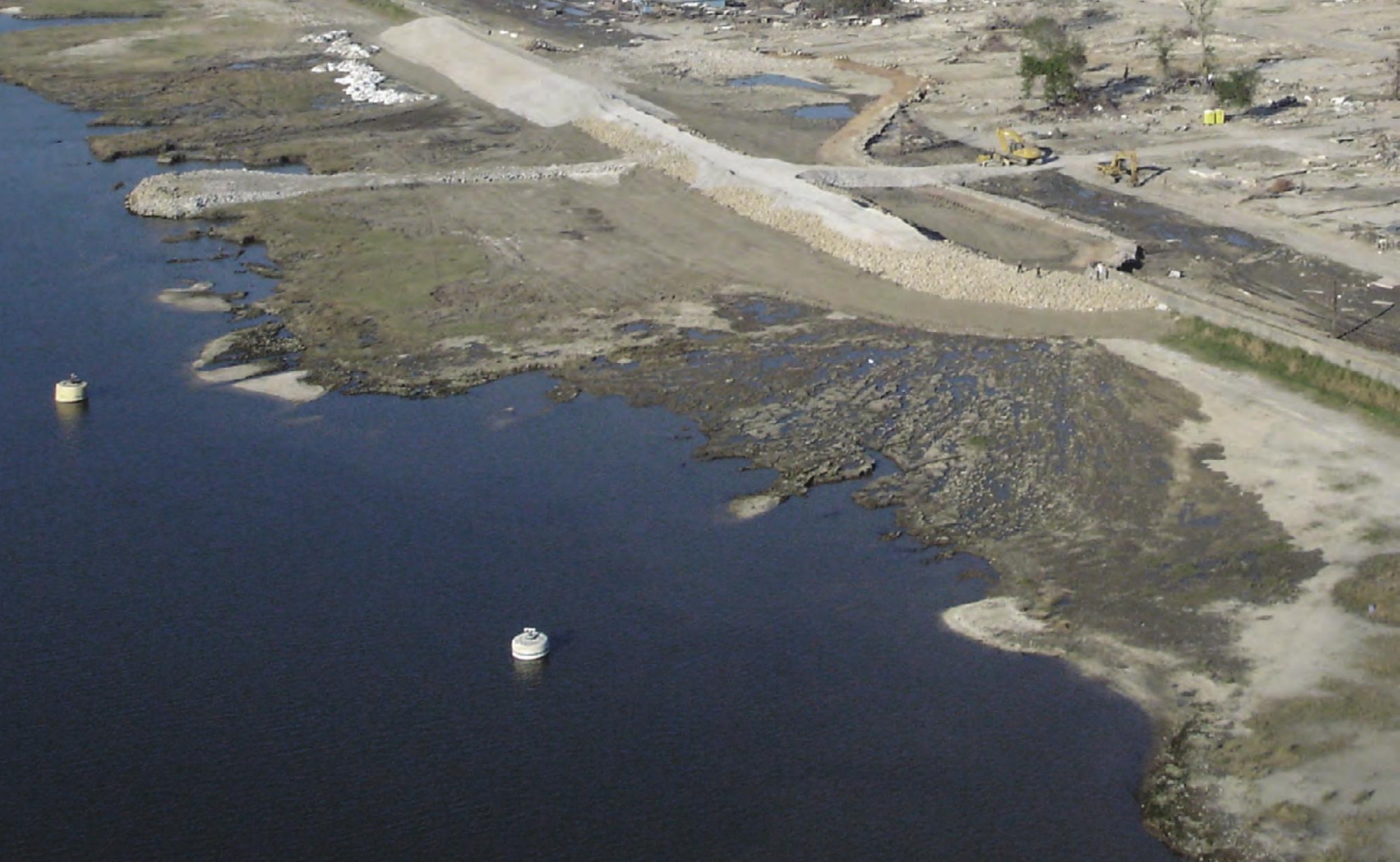




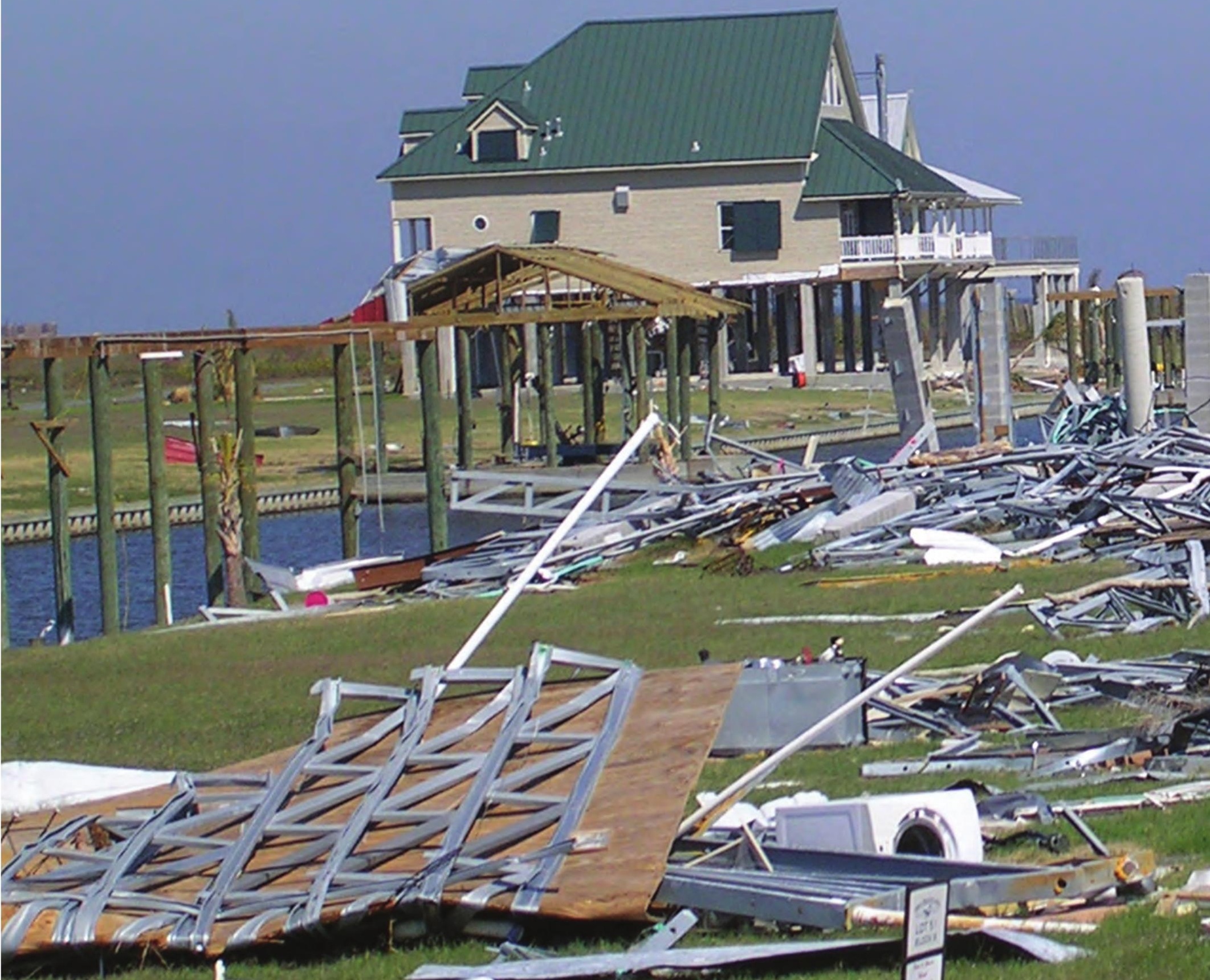



Publishing support provided by:

Rolla Publishing Service Center

For more information concerning this publication, contact:

Director, USGS Mid-Continent Geographic Science Center

1400 Independence Road

Rolla, M0 65401

(573) 308-3550

Or visit the Mid-Continent Geographic Science Center Web site at: http://mcgsc.usgs.gov

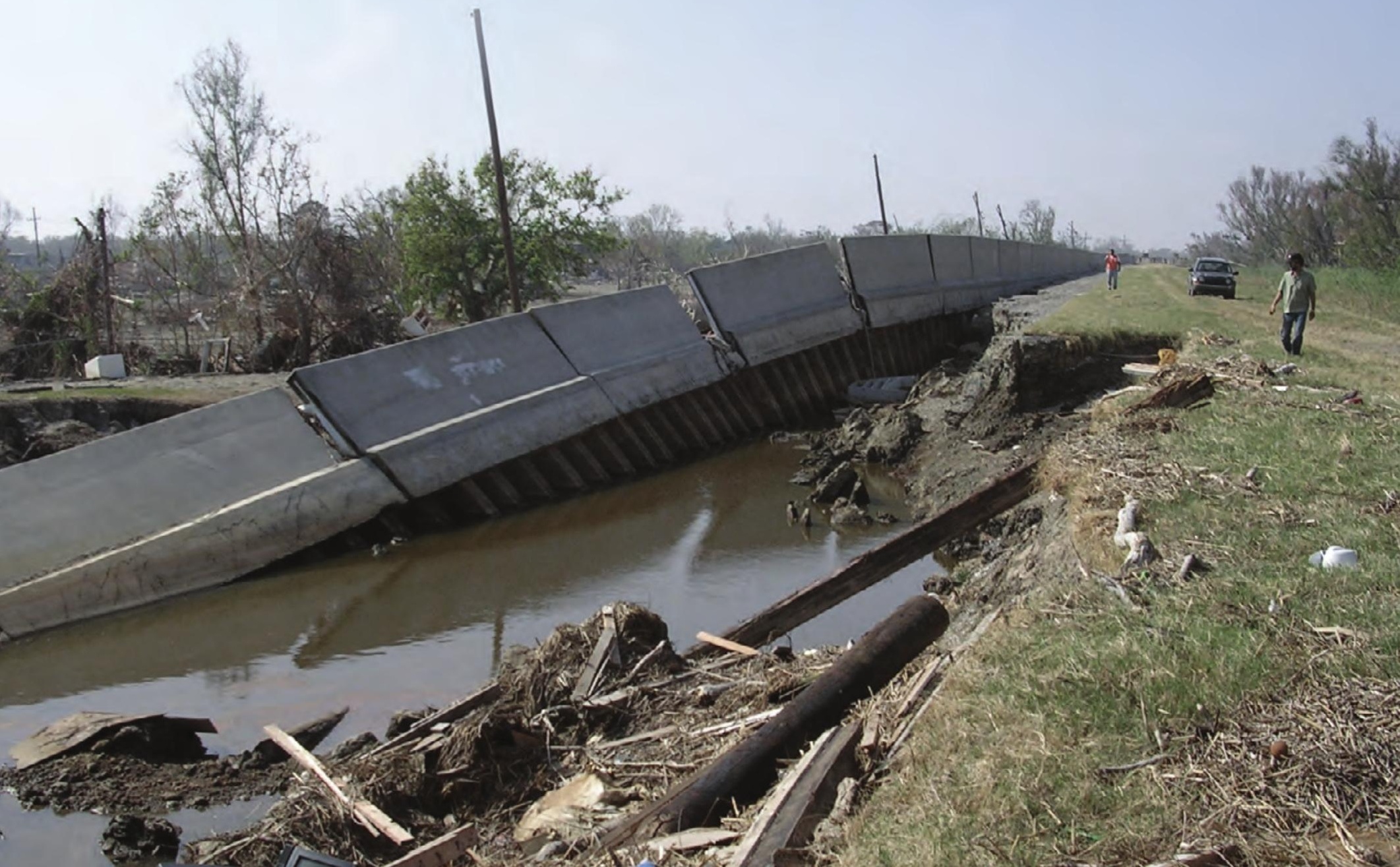



